\title{
The Multifaceted Roles of Proline in Cell Behavior
}

\author{
Eduardo J. Patriarca, Federica Cermola, Cristina D’Aniello, Annalisa Fico, \\ Ombretta Guardiola, Dario De Cesare and Gabriella Minchiotti*
}

Stem Cell Fate Laboratory, Institute of Genetics and Biophysics "A. Buzzati Traverso", Consiglio Nazionale delle Ricerche, Naples, Italy

Herein, we review the multifaceted roles of proline in cell biology. This peculiar cyclic imino acid is: (i) A main precursor of extracellular collagens (the most abundant human proteins), antimicrobial peptides (involved in innate immunity), salivary proteins (astringency, teeth health) and cornifins (skin permeability); (ii) an energy source for pathogenic bacteria, protozoan parasites, and metastatic cancer cells, which engage in extracellular-protein degradation to invade their host; (iii) an antistress molecule (an osmolyte and chemical chaperone) helpful against various potential harms (UV radiation, drought/salinity, heavy metals, reactive oxygen species); (iv) a neural metabotoxin associated with schizophrenia; (v) a modulator of cell signaling pathways such as the

\section{OPEN ACCESS}

Edited by:

Andrei Surguchov,

University of Kansas Medical Center,

United States

Reviewed by:

Irina G. Sourgoutcheva, University of Kansas Medical Center,

United States

Dwijendra K. Gupta, Jai Prakash Vishwavidyalaya, India

*Correspondence:

Gabriella Minchiott gabriella.minchiotti@igb.cnr.it

Specialty section:

This article was submitted to

Cellular Biochemistry,

a section of the journal

Frontiers in Cell and Developmental

Biology

Received: 21 June 2021

Accepted: 23 July 2021

Published: 12 August 2021

Citation:

Patriarca EJ, Cermola F, D'Aniello C, Fico A, Guardiola O, De Cesare D and Minchiotti G (2021) The Multifaceted Roles of Proline in Cell Behavior.

Front. Cell Dev. Biol. 9:728576. doi: 10.3389/fcell.2021.728576 amino acid stress response and extracellular signal-related kinase pathway; (vi) an epigenetic modifier able to promote DNA and histone hypermethylation; (vii) an inducer of proliferation of stem and tumor cells; and (viii) a modulator of cell morphology and migration/invasiveness. We highlight how proline metabolism impacts beneficial tissue regeneration, but also contributes to the progression of devastating pathologies such as fibrosis and metastatic cancer.

Keywords: proline metabolism, cell plasticity, extracellular proteins, energy source, antistress activity, neural toxicity, signaling modulators, metabolism

Abbreviations: AAR, amino acid starvation response; Acetyl-CoA, acetyl coenzyme A; ADCL3, autosomal dominant cutis laxa 3; $\alpha$-KG, $\alpha$-ketoglutarate; ALDH18A1, P5C synthase; AMPs, antimicrobial peptides; ARCLII, autosomal recessive cutis laxa type IIB; VitC, ascorbic acid, vitamin C; ATF4, activating transcription factor 4; BDNF, brain-derived neurotrophic factor; BJAB, human lymphoma cell line; CTs, connective tissues; C/EBP, CCAAT/enhancer-binding protein; ChIP-Seq, chromatin immunoprecipitation sequencing; CYR61, cysteine-rich angiogenic inducer 61; DIRICORE, differential ribosome codon reading; DMR, differentially methylated regions; 2-DG, 2-deoxy-D-glucose; ECM, extracellular matrix; ECSLC, embryonal carcinoma stem-like cells; EGF, epidermal growth factor; EIF2A, eukaryotic translation initiation factor 2; EIF5A, eukaryotic translation initiation factor 5A; EMT, epithelial-to-mesenchymal transition; ER, endoplasmic reticulum; ERK, extracellular signal-regulated kinase; FAP, fibroblast activation protein; FGF5, fibroblast growth factor 5; FGF8, fibroblast growth factor 8; FGF13, fibroblast growth factor 13; FBS, fetal bovine serum; GABA, $\gamma$-aminobutyric acid; GAD, L-glutamate decarboxylase; GCN2, general control non-derepressible 2; GDH, L-glutamate dehydrogenase; GPR142, G-protein-coupled receptor protein 142; HEK293, human embryonic kidney cell line; HeLa, human cervical cancer cell line; HEPG2, human liver cancer cell line; HIF-1 $\alpha$, hypoxia inducible factor alpha-subunit; HPI and HPII, hyperprolinemia type I and II; IGF-1, insulin-like growth factor 1; ICM, inner cell mass; JMJ, jumonji dioxygenases; Jurkat, human T lymphocyte cell line; mESCs, mouse embryonic stem cells; mTOR, mammalian target of rapamycin; 5mC, 5-methyl cytosine; 5hmC, 5hydroxymethyl cytosine; MSCs, mesenchymal stem cells; NEAA, non-essential amino acid; NGF, nerve growth factor; NMDA, N-methyl-D-aspartate; NMR, nuclear magnetic resonance; OCD, ornithine cyclodeaminase; PDAC, pancreatic ductal adenocarcinoma; PKDCC, protein kinase domain containing; PHD1-3, HIF prolyl hydroxylases 1-3; P4HA, prolylhydroxylase; P5C, $\Delta$ 1-pyrroline-5-carboxylate; P5CDH, P5C dehydrogenase; p53, tumor suppressor protein 53; L-Pro, L-proline; PRODH, L-proline dehydrogenase; L-Pro-OH, trans-4-hydroxy-L-proline; PRS, prolyl-tRNA synthetase; PYCR, P5C reductase; PREP, prolyl endopeptidase; ROS, reactive oxygen species; SAM, S-adenosyl-methionine; SDF-1, stromal cellderived factor-1; SLC38A2, solute carrier family 38 member 2; SPRR, small proline-rich region protein; TCA, tricarboxylic acid; TET, ten-eleven translocation dioxygenase; TGF $\beta$, transforming growth factor beta; UV, ultraviolet; VSMCs, vascular smooth muscle cells; WNT, wingless and/NT-1. 


\section{INTRODUCTION}

In 1900, Richard M. Willstätter reported the synthesis of $(S)$ pyrrolidine-2-carboxylic acid, better known as L-Pro. Town (1928) reported the purification of L-Pro from gliadin proteins, and Levine (1959) reported that nitrous acid destroys all amino acids apart from L-Pro in hydrolyzed gelatins, and highlighted its unusual structure. L-Pro is a small $(115.13 \mathrm{~g} / \mathrm{mol})$, cyclic, non-polar, non-toxic, odorless, sweet-tasting imino acid, with unique physicochemical proprieties and numerous biotechnological applications (Figure 1). For instance, acting as an enantioselective organocatalyst, L-Pro makes possible the synthesis of therapeutically active enantiopure drugs (Table 1). Moreover, acting as a chemical chaperone, L-Pro can prevent protein aggregation/fibrillation, and is therefore used to stabilize monoclonal antibodies, to generate protein crystals (Table 1), and for the cryopreservation of biological specimens, including stem cells and oocytes (Table 1). Due to its peculiar cyclic structure, its metabolism relies on specific enzymes. For instance, in mammalian cells L-Pro is synthesized from Lglutamate in a two-step intramitochondrial process catalyzed by aldehyde dehydrogenase 18 family member A1 (ALDH18A1) and pyrroline-5-carboxylate reductase 1 (PYCR1) enzymes (Figure 1), whereas it is oxidized to L-glutamate in a two-step intramitochondrial process catalyzed by proline dehydrogenase (PRODH) and pyrroline-5-carboxylate dehydrogenase (P5CDH) enzymes (Figure 1).

\section{PROLINE IN EXTRACELLULAR MATRIX PRODUCTION}

L-Proline residues constitute nearly $6 \%$ of the human proteome, mainly concentrated in L-Pro-rich proteins, with up to $1 \times 10^{4} \mathrm{~L}$ Pro-rich motifs/stretches occurring in $1.8 \times 10^{4}$ human proteins (Morgan and Rubenstein, 2013; Mandal et al., 2014). In addition to a high L-Pro content (up to 50\% of total residues), L-Pro-rich peptides/proteins share extracellular localization (secreted proteins), a dedicated translation factor (EIF5A), and a requirement for timely L-Pro-tRNA loading (Doerfel et al., 2013; Gutierrez et al., 2013; Wu et al., 2020; Faundes et al., 2021). Free LPro is derived from dietary sources (animal collagens or vegetable extensins) or from de novo biosynthesis (Figure 1), which relies on mitochondrial generation of reduced nicotinamide adenine dinucleotide phosphate (NADPH) (Tran et al., 2021; Zhu et al., 2021). Why so many extracellular proteins are rich in L-Pro is a fascinating question; L-Pro residues destabilize $\alpha$-helices and $\beta$-sheets protein secondary structures, enables turns and poly-Pro helices, and are major 'disorder-promoting' residues in intrinsically disordered proteins (Theillet et al., 2013; Alderson et al., 2018; Mateos et al., 2020).

\section{Matrix Collagens}

Collagens constitute $\sim 30 \%$ of total human proteins (Smith and Rennie, 2007), and are secreted by cells of CTs such as bone, cartilage, tendon, ligament, and interconnected fluid-filled CTs (Benias et al., 2018) that support and connects all other tissues (epithelial, muscular, etc.). Collagen synthesis is highly dependent on L-Pro availability ( $\sim 170 \mu \mathrm{M}$ in plasma) (Psychogios et al., 2011), and inherited mutations in ALDH18A1 or PYCR1 (de novo L-Pro biosynthesis) are a cause of abnormal CT development (Table 2). Extrinsic (dietary) L-Pro is essential during adult life to preserve bone density in a mice model of osteoporosis (Nam et al., 2016), collagen deposition in rats, pigs, chickens and fish (Li and $\mathrm{Wu}, 2018$; He et al., 2021), and L-Pro homeostasis in humans (Jaksic et al., 1990; Bertolo and Burrin, 2008).

\section{Antimicrobial Peptides}

L-Proline-rich antimicrobial peptides (PrAMPs), involved in innate immunity, are the first line of defense against infections (Graf and Wilson, 2019), and they contain up to 50\% L-Pro residues, and are secreted by insects, crustaceans and mammals (Table 3; Mishra et al., 2018). Mechanistically, PrAMPs are channeled by the peptide antibiotic transporter SbmA into the bacterial cytoplasm (Mattiuzzo et al., 2007; Runti et al., 2013), where they bind ribosomal proteins and inhibit protein synthesis (Figure 2 and Table 3; Graf et al., 2017; Graf and Wilson, 2019; Baliga et al., 2021).

\section{Salivary Proteins}

Unstructured L-Pro-rich salivary proteins (PRPs) contain up to $40 \%$ L-Pro residues and account for $\sim 70 \%$ of total proteins in human saliva (Messana et al., 2015; Lorenzo-Pouso et al., 2018). The acinar cells of parotid and submandibular salivary glands synthesize and secrete acidic (aPRP) and basic (bPRP) proteins (Figure 2). While aPRPs bind calcium and protect the tooth surface, bPRPs bind polyphenols/tannins inducing the astringency sensation that influences diet selection (Canon et al., 2021; Dufourc, 2021). Since tannins induce ER stress and ATF4 expression (Nagesh et al., 2018), and since ATF4 in turn induces the transcription of L-Pro biosynthesis genes (ALDH18A1 and PYCR1) (Han et al., 2013; D'Aniello et al., 2015; Gonen et al., 2019), it is tempting to hypothesize that a neutralizing response axis (ER stress $\rightarrow$ ATF4 $\rightarrow$ L-Pro biosynthesis $\rightarrow$ PRP synthesis/secretion) can be induced by tannins in salivary glands.

\section{Cornified Cell Envelope}

Skin is the largest organ of the human body, and it protects internal tissues/organs from water and heat loss, physicochemical insults (e.g., UV light), and microbial attack. Cornifins (or SPRRs) are cross-bridging L-Pro-rich proteins of the cell envelope (Marvin et al., 1992; Steinert et al., 1998a,b), a 5-15 nm thick layer of proteins deposited in epidermis corneocytes (Figure 2). Cornifins are markers of psoriasis syndrome (Luo et al., 2020) and are induced in some tumors (Deng et al., 2020; Sasahira et al., 2021).

\section{Cell Wall Proteins}

The extracellular space in plants and algae contains up to $10 \%$ dry weight of hydroxyproline (L-Pro-OH)-rich glycoproteins (HRGPs) such as extensins (Showalter, 1993; Lamport et al., 2011), in which L-Pro-OH constitutes up to $30 \%$ of total amino acids (Kieliszewski and Lamport, 1994). Besides being structural 


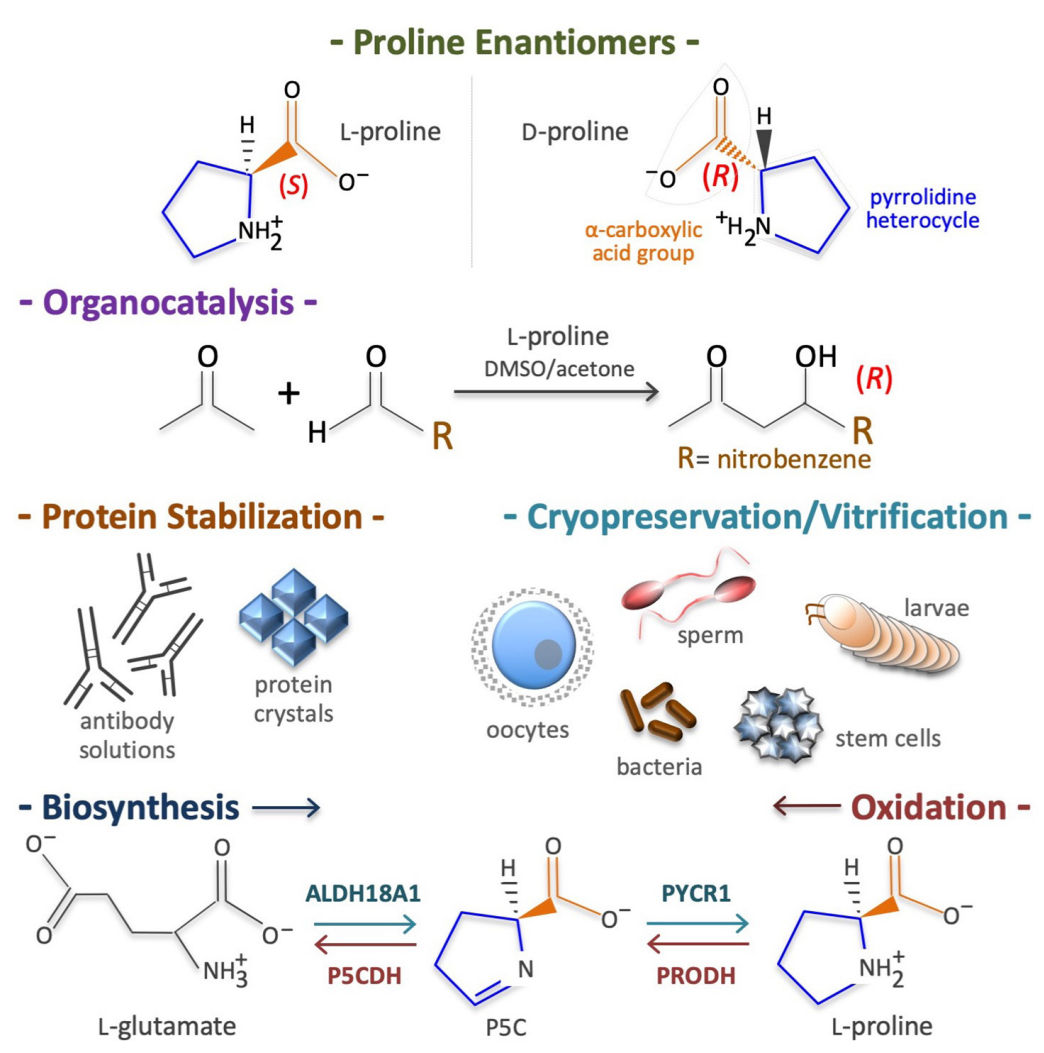

FIGURE 1 | Proline structure, uses, biosynthesis and degradation/oxidation. Chirality of pyrrolidine-2-carboxylic acid (top), known as proline (CAS: 147-85-3, EC: 205-702-2, CHEBI: 17203, HMDB0000162, MW = 115.13 g/mol). Of the two enantiomers ( $L$ and D) living cells metabolize predominantly the $L$-proline enantiomer (top). Proline is an organocatalyst used to synthesize enantiopure drugs (middle top). Proline is also a potent chemical chaperone able to stabilize proteins in their natural conformation and thus, it is used to cryopreserve living cells/organisms (middle bottom). Due to its pyrrolidine ring structure, the enzymes involved in de novo L-proline biosynthesis, namely aldehyde dehydrogenase 18 family member A1 (ALDH18A1) and pyrroline-5-carboxylate reductase 1 (PYCR1), as well as the enzymes involved in L-proline oxidation, namely proline dehydrogenase $(\mathrm{PRODH})$ and the pyrroline-5-carboxylate dehydrogenase (P5CDH), are highly specific (bottom)

pilasters, HRGPs are involved in (i) tissue/organ development (embryo, xylem, pod, root hairs, pollen) (Wu et al., 2001; Velasquez et al., 2011; Ogawa-Ohnishi et al., 2013), (ii) a defense mechanism against environmental stress (heat stress, mechanical wounding and bacterial infection) (Francisco and Tierney, 1990; Zhang et al., 2021b), and (iii) an oxygen barrier in the parenchyma of nitrogen-fixing legume root nodules (nodulins) (Scheres et al., 1990; Sherrier et al., 2005). HRGP synthesis requires free L-Pro, and plants respond to pathogen attack by inducing L-Pro accumulation and HRGP synthesis (Fabro et al., 2004).

\section{PROLINE IN ENERGY PROVISION}

Cells obtain energy/ATP through oxidation of glucose, fatty acids or L-glutamine. However, some cells obtain energy via oxidation of L-Pro in a three-step process (see Figure 3 ) that converts L-Pro into $\alpha-K G$, a Krebs cycle intermediate (Tanner et al., 2018). Up to 30 ATP equivalents per L-Pro molecule can sustain the growth of dissimilar cell types, from bacteria to insect muscle cells and human cancer cells (Servet et al., 2012; Nishida et al., 2016). Of note, human genetic defects in L-Pro oxidation are not associated with any developmental deficiency, suggesting that any normal cell type in the human body is strictly reliant on L-Pro energy.

\section{Cancer Cells}

Pancreatic and mammary tumor tissues are full of collagens, providing a large reservoir of free L-Pro (Linder et al., 2001; Barcus et al., 2017). Prolyl-specific peptidases are induced in cancer cells and can release L-Pro-rich peptides and free LPro in their microenvironment by degrading ECM collagens (Figure 3; Pure and Blomberg, 2018). For instance, free LPro is accumulated in esophageal carcinoma tissue, where it reaches significantly higher levels than in neighboring normal tissues (Sun et al., 2019). Free L-Pro is transported inside cancer cells, where it can be used for anabolic and catabolic purposes. Indeed, PDAC cancer cells (Olivares et al., 2017), colorectal cancer cells (Liu et al., 2012a), and transformed mammary epithelial cells (MCF10A H-Ras ${ }^{V 12}$ ) growing as 3D spheroids (Elia et al., 2017) use L-Pro to obtain energy/ATP (Figure 3). L-Pro is also used to produce new 
collagens (L-Pro recycling), and, eventually, to alter the ECM composition/stiffness (D’Aniello et al., 2020).

\section{Insect Vectors and Protozoan Parasites}

Protozoan parasites adapt their metabolism to the mutable environments encountered throughout their life cycle, including the hemolymph of their insect vectors (Bringaud et al., 2012). Trypanosoma brucei, the causative agent of sleeping sickness, is transmitted by tsetse flies (Glossina diptera), and both organisms can oxidize L-Pro to accomplish ATP biosynthesis (Figure 3; Michalkova et al., 2014; Mantilla et al., 2017; Smith et al., 2017; Dolezelova et al., 2020; Haindrich et al., 2021; Villafraz et al., 2021). L-Pro sustains Trypanosoma cruzi (the causative agent of Chagas disease) cell invasion and intracellular epimastigote-to-trypomastigote transition (Figure 3; Martins et al., 2009; Mantilla et al., 2015; Barison et al., 2017). Parasites also utilize L-Pro for anabolic purposes. For instance, halofuginone, a selective inhibitor of PRS, blocks the synthesis of L-Pro-rich proteins and the proliferation of Plasmodium falciparum (the causative agent of malaria) (Hewitt et al., 2017).

\section{Insect Flight Muscle}

Flight is one of the highest ATP/energy-requiring processes in animals, and the muscle cells involved can make use of different energy sources including carbohydrates (e.g., honeybee Apis mellifera) and fatty acids (e.g., butterflies) (Bursell, 1975; Candy et al., 1997). Some insects, such as Locusta migratoria, Bombus impatiens (bumblebee), Vespula vulgaris and Glossina diptera, oxidize L-Pro to power flight (Figure 3; Teulier et al., 2016). LPro supports flight muscle cells of Aedes aegypti mosquitoes that feed on blood and can obtain free L-Pro from the hydrolysis of blood proteins and/or from alanine in the fat body (Goldstrohm et al., 2003; Scaraffia and Wells, 2003; Mazzalupo et al., 2016). Indeed, free L-Pro is abundant in the hemolymph of adult female mosquitoes and other insects such as Diaphorina citri, the vector of Candidatus Liberibacter asiaticus (huanglongbing) (Killiny et al., 2017).

\section{Polyamine and Citrate Precursors}

Some cells use the carbon skeleton of L-Pro to synthesize Lornithine and L-arginine. For instance, in the gut of neonates, L-glutamate to pyrroline-5-carboxylate conversion is negligible,

TABLE 1 | Proline in drug synthesis, protein stabilization and cryopreservation.

\begin{tabular}{|c|c|c|}
\hline \multicolumn{3}{|c|}{ Enantioselective organocatalysis ${ }^{1}$} \\
\hline Compound synthesized & Type of chemical reaction & References \\
\hline Prostaglandin PGF2alpha & Corey's synthesis & Coulthard et al. (2012) \\
\hline Pyrans, and thiopyrans & Methylene ketones and $\alpha, \beta$-unsaturated nitriles & Elnagdi and Al-Hokbany (2012) \\
\hline (R)-4-(4-Methoxy-phenylamino)-6-methyl-heptan-2-one & Ketones, aldehydes and Meldrum's acid & List and Castello (2001) \\
\hline Oxazolidinones & Asymmetric aldol reaction & List et al. (2004) \\
\hline Delta(1)(2)-prostaglandin J(3) & - & Pelss et al. (2018) \\
\hline- & Hajos-Parrish-Eder-Sauer-Wiechert (HPESW) reaction & Rance and Khlobystov (2014) \\
\hline Erythromcin 1 & Stereospecific aldolization & Agami et al. (1987) \\
\hline- & Michael addition of malonate anions to enones and enals & Yamaguchi et al. (1996) \\
\hline \multicolumn{3}{|c|}{ Protein stabilization $^{2}$} \\
\hline Biological sample & Stabilizing medium & \\
\hline Insulin & L-Proline (0.05-0.25 M) & Choudhary et al. (2015) \\
\hline Insulin and lysozyme & L-Proline/sorbitol & Choudhary et al. (2016) \\
\hline Antibodies solutions (mAb) & L-Proline (up to $1.3 \mathrm{M}$ ) & Hung et al. (2018) \\
\hline Huntingtin (polyQ tracts) & L-Proline & Ignatova and Gierasch (2006) \\
\hline Lysozyme, xylose isomerase, P5CDH & L-Proline (2-3 M) and protein-crystallization solution & Pemberton et al. (2012) \\
\hline Lysozyme & L-Proline (1.5-4.0 M) & Samuel et al. (1997), Samuel et al. (2000) \\
\hline Lactate dehydrogenase & L-Proline (up to $4.0 \mathrm{M}$ ) & Wang and Bolen (1996) \\
\hline \multicolumn{3}{|c|}{ Cryopreservation/vitrification ${ }^{3}$} \\
\hline Specimen & Freezing medium & \\
\hline Human mesenchymal stem cells (hMSCs) & L-Proline, methylcellulose, ectoin & Freimark et al. (2011) \\
\hline Human endothelial cells & L-Proline & Sun et al. (2012) \\
\hline Ram sperm & L-Proline & Sanchez-Partida et al. (1998) \\
\hline Mammalian oocytes & L-Proline/ethylene glycol/DMSO & Zhang et al. (2016a,b) \\
\hline Donkey semen & L-Proline & Li et al. (2021) \\
\hline Mice oocytes & L-Proline oligomers (L-Pron) & Qin et al. (2020), Treleaven et al. (2021) \\
\hline Lactic acid bacteria & L-Proline/glycerol & Qiao et al. (2018) \\
\hline Vesicles of sarcoplasmic reticulum from lobster muscle & L-Proline (more effective than glycerol or DMSO) & Rudolph and Crowe (1985) \\
\hline
\end{tabular}

Applications in: ${ }^{1}$ pharmaceutical industry, ${ }^{2}$ pharmacological therapy, and ${ }^{3}$ biomedical research, regenerative medicine. 
hence dietary L-Pro is the only source of L-arginine (Tomlinson et al., 2011a,b). In motile human spermatozoa, L-Pro is the precursor of polyamines such as putrescine, spermidine and spermine (Figure 3; Wu et al., 2005, 2008), which are deregulated in hyper-proliferative cancer cells (Bachmann and Geerts, 2018), and thus a potential target for therapeutic anticancer intervention (Murray-Stewart et al., 2016). The three-step L-Pro to $\alpha-K G$ conversion is also activated to generate Krebs-derived metabolic intermediates. For instance, cells of mouse retinal pigment epithelium use L-Pro to synthesize and export citrate, which is consumed by the outer retina (Figure 3; Chao et al., 2017; Yam et al., 2019; Du et al., 2021).

\section{PROLINE IN ANTISTRESS RESPONSE}

Living cells are subjected to a fluctuating environment involving transient or continuous changes in physicochemical parameters such as temperature, humidity and UV radiation. For instance, humans renal and corneal cells are exposed to discontinuous but substantial variations in osmolality/salinity. To prevent the detrimental effects of such harmful environmental imbalances, cells utilize adaptive mechanisms, including accumulation of highly soluble non-toxic osmolytes and chemical chaperones (protein stabilizers) such as L-Pro. Of course, living cells can tolerate extensive accumulation of L-Pro (up to a 100-fold increase) without suffering of the ionic imbalances induced by

TABLE 2 | Diseases associated with defects in genes involved in the proline metabolism.

\begin{tabular}{|c|c|c|c|c|c|c|}
\hline Process & Gene & Syndrome & * & OMIM & Phenotype & References \\
\hline \multirow[t]{7}{*}{ Proline biosynthesis } & ALDH18A1 (P5CS) & Cutis laxa 3 & $A D$ & 616603 & $\begin{array}{l}\text { Wrinkled and thin skin, cataracts, joint } \\
\text { hyperlaxity }\end{array}$ & $\begin{array}{l}\text { Jukkola et al. (1998), Fischer-Zirnsak } \\
\text { et al. (2015), Bhola et al. (2017) }\end{array}$ \\
\hline & & Cutis laxa type IIIA & $\mathrm{AR}$ & 219150 & $\begin{array}{l}\text { Growth retardation, poor postnatal } \\
\text { growth, }\end{array}$ & $\begin{array}{l}\text { de Barsy et al. (1968), Baumgartner } \\
\text { et al. (2000), Bicknell et al. (2008), } \\
\text { Skidmore et al. (2011), Fischer et al. } \\
\text { (2014) }\end{array}$ \\
\hline & & $\begin{array}{l}\text { Spastic paraplegia } \\
\text { 9A }\end{array}$ & $A D$ & 601162 & $\begin{array}{c}\text { Short stature, skeletal abnormalities, } \\
\text { cataracts }\end{array}$ & $\begin{array}{c}\text { Slavotinek et al. (1996), Seri et al. } \\
\text { (1999), Coutelier et al. (2015), Panza } \\
\text { et al. (2016) }\end{array}$ \\
\hline & & $\begin{array}{l}\text { Spastic paraplegia } \\
\text { 9B }\end{array}$ & $\mathrm{AR}$ & 616586 & $\begin{array}{l}\text { Short stature, delayed psychomotor } \\
\text { development }\end{array}$ & $\begin{array}{l}\text { Coutelier et al. (2015), Magini et al. } \\
\text { (2019) }\end{array}$ \\
\hline & PYCR1 (P5CR1) & Cutis laxa, type IIB & $\mathrm{AR}$ & 612940 & $\begin{array}{c}\text { Aged appearance, joint } \\
\text { hyperextensibility, osteopenia }\end{array}$ & $\begin{array}{c}\text { Guernsey et al. (2009), Reversade et al. } \\
\text { (2009), Kretz et al. (2011) }\end{array}$ \\
\hline & & Cutis laxa type IIIB & $\mathrm{AR}$ & 614438 & $\begin{array}{l}\text { Growth retardation, cutis laxa, aged } \\
\text { appearance }\end{array}$ & Reversade et al. (2009), Lin et al. (2011) \\
\hline & PYCR2 (P5CR2) & $\begin{array}{l}\text { Leukodystrophy, } \\
\text { hypomyelinating, } \\
10\end{array}$ & $\mathrm{AR}$ & 616420 & $\begin{array}{l}\text { Poor overall growth, malformed ears, } \\
\text { cerebral atrophy }\end{array}$ & $\begin{array}{l}\text { Nakayama et al. (2015), Zaki et al. } \\
\text { (2016), Patel et al. (2021) }\end{array}$ \\
\hline \multirow[t]{3}{*}{ Proline degradation } & PRODH & $\begin{array}{l}\text { Hyperprolinemia, } \\
\text { type I }\end{array}$ & $\mathrm{AR}$ & 239500 & $\begin{array}{c}\text { Neurologic defects, mental retardation, } \\
\text { schizophrenia }\end{array}$ & $\begin{array}{l}\text { Campbell et al. (1997), Jacquet et al. } \\
\qquad(2002,2003,2005)\end{array}$ \\
\hline & & $\begin{array}{l}\text { Schizophrenia } \\
\text { susceptibility } 4\end{array}$ & $A D$ & 600850 & $\begin{array}{c}\text { Psychosis, hallucinations, delusions, } \\
\text { erratic behavior }\end{array}$ & $\begin{array}{l}\text { Karayiorgou et al. (1995), Yoon et al. } \\
\qquad(2016)\end{array}$ \\
\hline & P5CDH (ALDH4A1) & $\begin{array}{l}\text { Hyperprolinemia, } \\
\text { type ॥ }\end{array}$ & $\mathrm{AR}$ & 239510 & $\begin{array}{c}\text { Recurrent seizures, mental retardation, } \\
\text { epilepsy }\end{array}$ & $\begin{array}{l}\text { Valle et al. (1974, 1976), Geraghty et al. } \\
\text { (1998), Kaur et al. (2021) }\end{array}$ \\
\hline \multirow[t]{8}{*}{ Proline transport } & SLC6A20 & Hyperglycinuria & $A D$ & 138500 & Renal oxalate stones, renal colic & $\begin{array}{c}\text { Scriver (1968), Greene et al. (1973), } \\
\text { Broer et al. (2008) }\end{array}$ \\
\hline & & $\begin{array}{l}\text { Iminoglycinuria, } \\
\text { digenic }\end{array}$ & $\mathrm{AR}, \mathrm{DR}$ & 242600 & Hyperprolinuria, hyperhydroxyprolinuria & Tancredi et al. (1970) \\
\hline & SLC6A19 (B॰AT1) & Hartnup disorder & $\mathrm{AR}$ & 234500 & $\begin{array}{l}\text { Short stature, intermittent cerebellar } \\
\text { ataxia, psychosis }\end{array}$ & Kleta et al. (2004), Seow et al. (2004) \\
\hline & & Hyperglycinuria & $A D$ & 138500 & Renal oxalate stones, renal colic & $\begin{array}{l}\text { Scriver (1968), Greene et al. (1973), } \\
\text { Broer et al. (2008) }\end{array}$ \\
\hline & & $\begin{array}{l}\text { Iminoglycinuria, } \\
\text { digenic }\end{array}$ & $\mathrm{AR}, \mathrm{DR}$ & 242600 & Hyperprolinuria, hyperhydroxyprolinuria & Tancredi et al. (1970) \\
\hline & SLC36A2 (PAT2) & Hyperglycinuria & $A D$ & 138500 & Renal oxalate stones, renal colic & $\begin{array}{c}\text { Scriver (1968), Greene et al. (1973), } \\
\text { Broer et al. (2008) }\end{array}$ \\
\hline & & $\begin{array}{l}\text { Iminoglycinuria, } \\
\text { digenic }\end{array}$ & $\mathrm{AR}, \mathrm{DR}$ & 242600 & Hyperprolinuria, hyperhydroxyprolinuria & Tancredi et al. (1970) \\
\hline & SLC6A7 (PROT) & Unknown & & 606205 & Unknown & $\begin{array}{l}\text { Fremeau et al. (1992), Shafqat et al. } \\
\text { (1995), Velaz-Faircloth et al. (1995) }\end{array}$ \\
\hline
\end{tabular}

*Inheritance.

$A D$, autosomal dominant; $A R$, autosomal recessive; $D R$, digenic recessive. 
accumulation of inorganic osmolytes (e.g., $\mathrm{Na}^{+}, \mathrm{K}^{+}, \mathrm{Mg}^{+2}$ or $\mathrm{Ca}^{+2}$ salts).

\section{Osmoprotection}

Hypertonic shocks induce water outflow, which reduces the cell volume and lowers macromolecule stability (Burg et al., 2007; Hoffmann et al., 2009; Stadmiller et al., 2017). Cells respond by accumulating L-Pro, which generates an opposite force of water retention (Figure 4). In bacteria, L-Pro accumulation occurs by uptake of extracellular free L-Pro after the induction (up to 700-fold) of a low-affinity L-Pro transporter (Csonka and Hanson, 1991), through degradation of extracellular L-Pro-rich proteins (Zaprasis et al., 2013) and/or de novo L-Pro biosynthesis (Patel et al., 2018). The ability to accumulate L-Pro is vital to organisms inhabiting mutable (fresh/brackish water, intertidal) habitats, such as gastropod mollusks (Wiesenthal et al., 2019). Plants respond to drought, salinity and freezing temperatures by accumulating L-Pro (Yoshiba et al., 1997; Szabados and Savoure, 2010; Hnilickova et al., 2021; Papu et al., 2021), and in tomato cells concentrations can reach $60 \mathrm{mM}$ (500-fold higher than normal levels) (Handa et al., 1983). L-Pro accumulation protects human cells from hyperosmotic stress (Thiemicke and Neuert, 2021). Indeed, L-Pro uptake facilitates the recovery a viable cell volume after hypertonic stress (Law, 1991; Bevilacqua et al., 2005; Krokowski et al., 2017), and the PP1 phosphatase subunit protein
PPP1R15A/GADD34 promotes cis-to-trans Golgi trafficking, and the plasma membrane localization of SLC38A2 L-Pro transporter (Figure 4; Krokowski et al., 2017).

\section{Antifreeze Activity}

In yeast, L-Pro accumulation confers ethanol and freezing tolerance (Takagi, 2008). In overwintering insects, L-Pro contributes to water retention and freezing tolerance (Figure 4), and levels increase to $\sim 80 \%$ of the total pool of free amino acids (Kostal et al., 2011, 2016; Rozsypal et al., 2018; Stetina et al., 2018). Of note, hyperprolinemic larvae of the fly Chymomyza costata can survive immersion in liquid nitrogen $\left(-196^{\circ} \mathrm{C}\right)$ (Kostal et al., 2011). In Drosophila larvae, an L-Pro-rich diet increases the whole-body L-Pro concentration (up to $60 \mathrm{mM}$ ) and freezing tolerance (Kostal et al., 2012).

\section{Radical Scavenging}

L-Proline protects various human cells such as HEK293, HeLa, HepG2, Jurkat, BJAB, WM35, skin keratinocytes and fibroblasts against ROS-mediated oxidative stress (Figure 4; Wondrak et al., 2005; Krishnan et al., 2008; Natarajan et al., 2012). Of note, the five-membered ring of L-Pro molecule, known as pyrrolidine or tetrahydropyrrole, quenches hydroxyl radicals ( $\mathrm{OH}$ ) (Signorelli, 2016). In plants L-Pro accumulates in response to oxidative compounds (Yang et al., 2009; Ben Rejeb et al., 2015), and

TABLE 3 | Proline-rich antimicrobial peptides.

\begin{tabular}{|c|c|c|c|c|}
\hline Peptide & Isolated from & Susceptible organism & Molecular mechanism & References \\
\hline Apidaecins (18-20 aa) & Apis mellifera lymph fluid & $\begin{array}{l}\text { Antibacterial (Gram-) Human } \\
\text { and plant pathogens }\end{array}$ & $\begin{array}{l}\text { Protein translation inhibition } \\
\text {-Trapping RF1 and RF2 -Blocks } \\
\text { assembly of } 50 S\end{array}$ & $\begin{array}{l}\text { Casteels et al. (1989), Li et al. (2006), } \\
\text { Krizsan et al. (2015), Chen et al. (2017), } \\
\text { Florin et al. (2017), Matsumoto et al. } \\
\text { (2017), Graf et al. (2018) }\end{array}$ \\
\hline Astacidins & Procambarus clarkii & Broad spectrum antimicrobial & & Shi et al. (2014), Roncevic et al. (2020) \\
\hline Arasin 1 (37 aa) & Hyas araneus (spider crab) & Antibacterial & & Stensvag et al. (2008) \\
\hline Bactenicins (5-7 kD) & $\begin{array}{l}\text { Bovine neutrophils Sheep and } \\
\text { goat leukocytes }\end{array}$ & Broad spectrum antimicrobial & $\begin{array}{l}\text { Protein translation inhibition } \\
\text { Binds } 70 S \text { T. thermophilus and } \\
\text { E. coli }\end{array}$ & $\begin{array}{l}\text { Gennaro et al. (1989), Shamova et al. } \\
\text { (1999), Benincasa et al. (2010), } \\
\text { Mardirossian et al. (2014, 2018a), } \\
\text { Gagnon et al. (2016), Seefeldt et al. } \\
\text { (2016) }\end{array}$ \\
\hline BnPRP1 (35 aa-3.8 kD) & Brassica napus & $\begin{array}{l}\text { Antibacterial (Gram+, Gram-) } \\
\text { Broad spectrum antifungal }\end{array}$ & & Cao et al. (2015) \\
\hline Cg-Prp (37 aa) & Crassostrea gigas (oyster) & Antibacterial & & Gueguen et al. (2009) \\
\hline Dolphin Tur1 (32 aa) & Tursiops truncatus & & $\begin{array}{l}\text { Protein translation inhibition } \\
\text { Binds ribosome }\end{array}$ & Mardirossian et al. (2018b) \\
\hline Drosocins (19 aa) & Drosophila Oregon & Antibacterial & & Bulet et al. (1993) \\
\hline Formaecin (16 aa) & Myrmecia gulosa (red bull ant) & Antibacterial & & Mackintosh et al. (1998) \\
\hline Metchlnikowin (26 aa) & Drosophila Oregon & $\begin{array}{l}\text { Antibacterial (Gram+), } \\
\text { antifungal }\end{array}$ & & Levashina et al. (1995) \\
\hline Oncocins (19 aa) & Oncopeltus fasciatus & Antibacterial (Gram-) & $\begin{array}{l}\text { Protein translation inhibition } \\
\text { Binds exit tunnel of } 70 S E \text {. coli }\end{array}$ & $\begin{array}{l}\text { Knappe et al. (2010), Roy et al. (2015), } \\
\text { Seefeldt et al. (2015) }\end{array}$ \\
\hline P1 to P11 (3-9.5 kD) & Rapana venosa hemolymph & Antibacterial (Gram+, Gram-) & & Dolashka et al. (2011) \\
\hline $\operatorname{Pr}-39$ & Sus scrofa & Multidrug-resistant bacteria & & $\begin{array}{l}\text { Agerberth et al. (1991), Linde et al. } \\
\text { (2001), Gennaro et al. (2002) }\end{array}$ \\
\hline Pyrrhocoricins & Pyrrhocoris apterus & Antibacterial (Gram-) & $\begin{array}{l}\text { Protein translation Inhibition } \\
\text { E. coli }\end{array}$ & $\begin{array}{l}\text { Cociancich et al. (1994), Kragol et al. } \\
\text { (2002), Taniguchi et al. (2016) }\end{array}$ \\
\hline AmAMP14 & Antheraea mylita & Antibacterial, antifungal & $\begin{array}{l}\text { Cell membrane damage, cell } \\
\text { Iysis }\end{array}$ & Chowdhury et al. (2021) \\
\hline
\end{tabular}




\section{- Antimicrobial Peptides -}

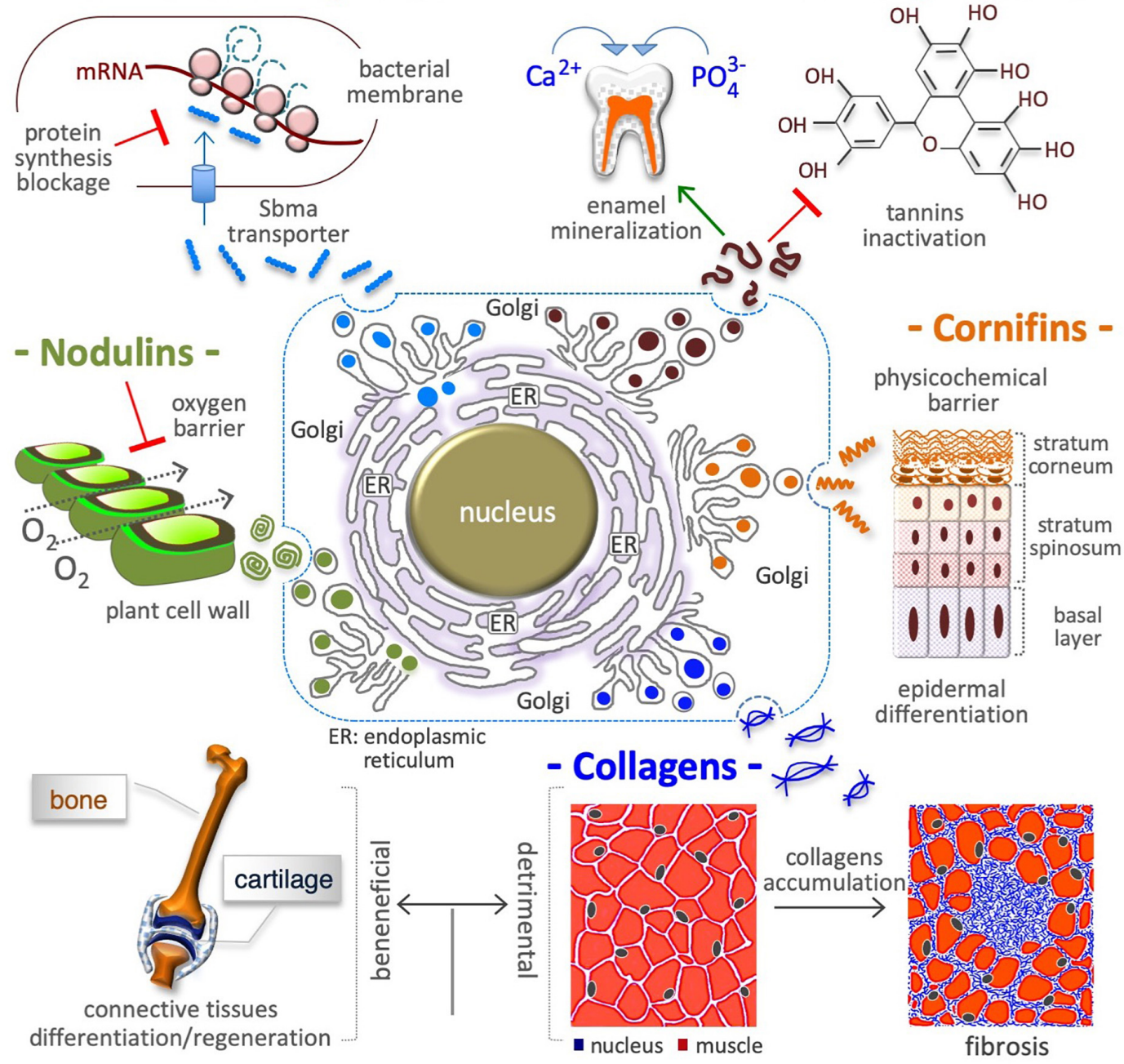

FIGURE 2 | Proline in extracellular matrix production. Proline is a crucial building block of antimicrobial peptides, salivary proteins, epidermal cornifins, interstitial collagens, and plant nodulins. These proteins are all rich in proline residues (with up to $50 \%$ of total amino acids) and are all secreted in the extracellular space. In addition to shape cell/tissue microenvironment/architecture (fibrillar collagens), proline-rich proteins contribute to innate immunity (antibiotic activity) by inhibiting bacterial protein synthesis (top left), to diet selection (astringency) by binding polyphenolic tannis (top right) and, to teeth health by inducing enamel mineralization and preventing bacterial attacks (top right), to selective permeation (barrier of water, $\mathrm{O}_{2}$ ) by nodulins in $\mathrm{N}_{2}$ fixing root nodules of leguminous plants (middle left), and by cornifins in skin (middle right), and to signaling mechanical forces (ECM stiffness). The accumulation of interstitial collagens leads to pathological fibrosis and occurs in different tumoral tissues (bottom right).

contributes to protect plants from photo-oxidative stress (i.e., light-dependent generation of ROS) (Liang et al., 2013). Recently, it emerged that salivary L-Pro-rich proteins can neutralize ROS, and specifically hydroxyl radicals (Komatsu et al., 2020).

\section{Heavy Metal Detoxification}

In plants, L-Pro is accumulated after exposure to heavy metals such as cadmium, chromium, and zinc (Sharma et al., 1998; Verbruggen and Hermans, 2008; Hayat et al., 2012; Dubey et al., 2018; Dong et al., 2021; Pejam et al., 2021; Zdunek-Zastocka et al., 2021), and this mitigates the detrimental effects of cadmium in young olive plants (Zouari et al., 2016) and cultured tobacco cells (Islam et al., 2009). Heavy metal toxicity is usually associated with ROS accumulation (Figure 4). Indeed, cadmium induces p53 (Aimola et al., 2012), a transcriptional inducer of PRODH expression (Polyak et al., 1997), which catalyzes L-Pro oxidation in mitochondria, leading to abnormal ROS production and apoptosis (Liu et al., 2006, 2008, 2009; Oscilowska et al., 2021). Thus, a $\mathrm{p} 53 \rightarrow \mathrm{PRODH} \rightarrow \mathrm{ROS} \rightarrow$ apoptosis axis may be activated as a response to toxic metals such as cadmium.

\section{ER Stress Relief}

At a molecular level, various stressful conditions (e.g., suboptimal temperature, high salinity and oxidative agents) can destabilize the structure and conformation of cellular proteins and other macromolecules. Thus, the accumulation of L-Pro (chemical 


\section{- Flying Insects -}

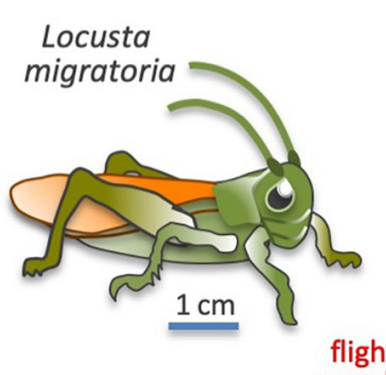

Glossina diptera (tsetse fly)

- Tumor Cells -
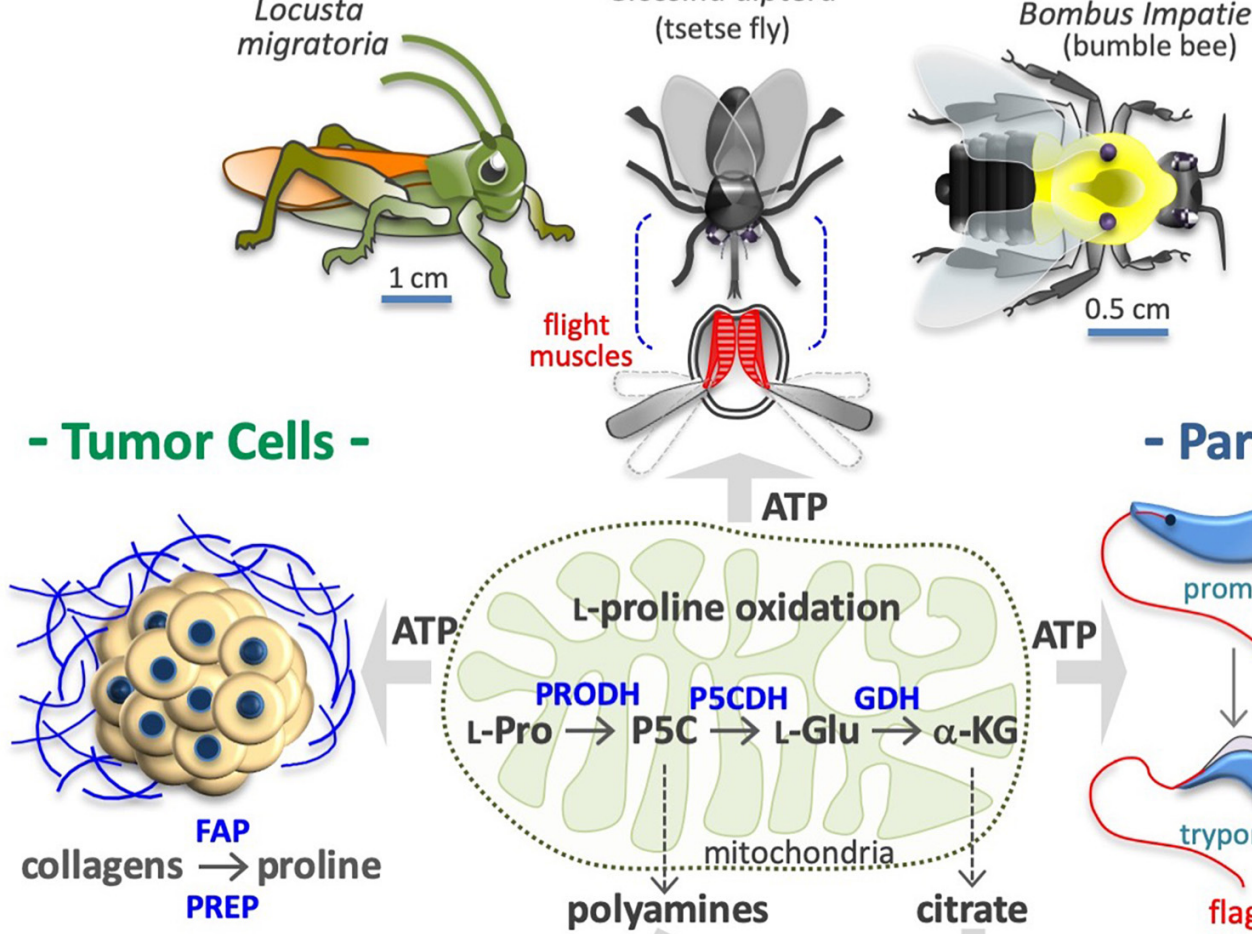

- Parasites -
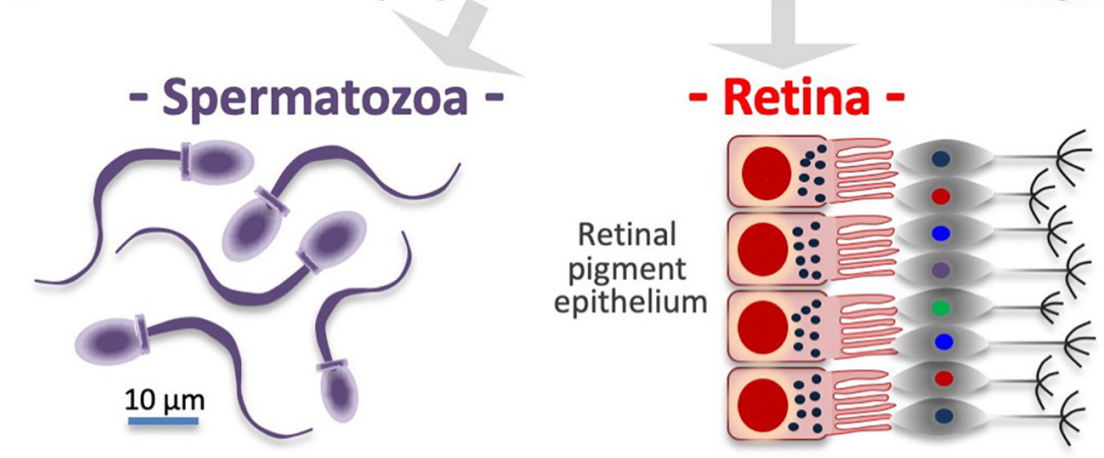

FIGURE 3 | Proline is a source of energy and metabolites. Many cell types obtain ATP/energy from mitochondrial oxidation of proline (center), including flight muscle cells of insects (top), protozoan parasites (middle right), and human cancer cells (middle left). Other cells, including motile spermatozoa (bottom left) use the carbon skeleton of proline to produce polyamines via conversion into pyrroline-5-carboxylic acid (P5C) and ornithine. Lastly, retinal epithelial cells (bottom right), produce citrate via conversion of L-proline into L-glutamate (L-Glu) and $\alpha$-ketoglutarate $(\alpha-K G)$. In the tumor microenvironment, collagens degradation enzymes such as fibroblast activation protein (FAP), and prolyl endopeptidase PREP) release proline-rich peptides and free proline, which after internalization can serves to produce ATP and/or new collagens. Intramitochondrial enzymes involved in L-proline (L-Pro) oxidation, namely proline dehydrogenase (PRODH) and the pyrroline-5-carboxylate dehydrogenase $(\mathrm{P} 5 \mathrm{CDH})$, and glutamate dehydrogenase $(\mathrm{GDH})$, are indicated.

chaperone) represents a convergent response of cells aimed at inhibiting the formation of unfolded/misfolded protein aggregates. In this context, induction of ATF4 expression (Figure 4), and subsequent enhancement of the transcription of genes involved in L-Pro uptake (SLC38A2) and biosynthesis (ALDH18A2, PYCR1) can contribute to intracellular L-Pro accumulation (D'Aniello et al., 2015). By stabilizing protein folding and/or promoting protein refolding, L-Pro can avoid and/or relieve ER stress.

\section{PROLINE IS A NEURAL METABOTOXIN}

Schafer et al. (1962) reported a link between hyperprolinemia (HP), characterized by high levels of plasmatic L-Pro, and neuronal dysfunction in human patients. It later emerged that different forms of hereditary human HP (type I or II) are associated with defects in L-Pro oxidation/degradation (Geraghty et al., 1998; Jacquet et al., 2002). Indeed, ectopic expression of PRODH in glioblastoma cells reduces the level of L-Pro 


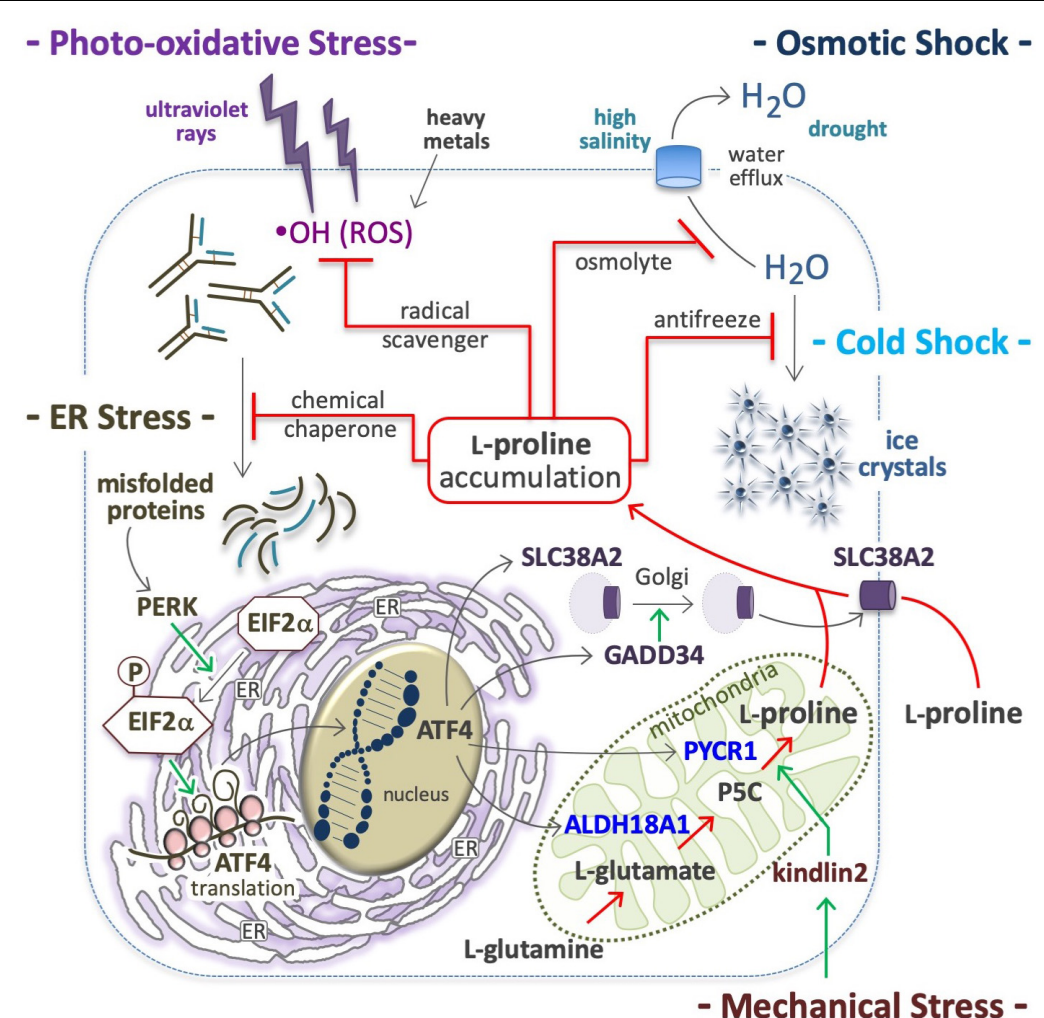

FIGURE 4 | Proline in anti-stress response. Proline accumulation is an evolutionary conserved cell defense mechanism against stressful environments; by quenching hydroxyl radicals $(\mathrm{OH})$, protects the cells from ROS oxidations (top left); as osmolyte avoids high salinity-mediated cell shrinkage (top right), as well as the formation of ice crystal, and thus protects many organisms (yeast, plants, overwinter insect) from cell disruption by freezing (middle right). As a chemical chaperone avoids protein denaturation and thus the accumulation of misfolded proteins (middle left), which are potent inducers of a molecular response that involves the protein kinase R-like endoplasmic reticulum kinase (PERK), phosphorylation of eukaryotic initiation factor 2 (EIF2), and eventually, the translation of activating transcription factor 4 (ATF4) (bottom left); ATF4 in turn, induces the expression of solute carrier family 38 member 2 (SLC38A2), growth arrest and DNA damage-inducible protein (GADD34), aldehyde dehydrogenase 18 family member a1 (ALDH18A1) and pyrroline-5-carboxylate reductase 1 (PYCR1) (bottom right). Intracellular proline accumulation through proline uptake and de novo proline biosynthesis (center) can contribute to stress alleviation.

(Cappelletti et al., 2018). Free L-Pro can interfere with excitatory presynaptic transmission, and therefore normal neuronal activity in the central nervous system (CNS) (Shafqat et al., 1995; VelazFaircloth et al., 1995; Wyse and Netto, 2011). Of note, the psychostimulant methamphetamine induces L-Pro synthesis in human neuroblastoma cells (Jones et al., 2021).

\section{Schizophrenia Induction and Neurotoxicity}

Hyperprolinemia is an etiopathogenetic factor of schizophrenia, a heterogeneous disorder that affects about 21 million people worldwide (Disease et al., 2017). HPI Drosophila models (PRODH mutants) exhibit a depressed 'sluggish' behavior (Hayward et al., 1993), while HPII models (defects in P5C to L-glutamate conversion due to a $P 5 C D H$ mutation) display larval and pupal lethality (He and DiMario, 2011). Conversely, PRODHoverexpressing flies exhibit an opposite 'aggressive' behavior (Zwarts et al., 2017). HPI mouse models also exhibit sluggish movements (Blake and Russell, 1972; Kanwar et al., 1975) and schizophrenia-related phenotypes (learning, memory and sensorimotor gating) (Gogos et al., 1999; Paterlini et al., 2005).
Human patients with genetic defects in PRODH (HPI, LPro levels up to 10 -fold higher than normal) or in $P 5 C D H$ (ALDH4A1; HPII, L-Pro levels up to 15-fold higher and P5C excretion) suffer schizoaffective disorders and schizophrenia (Table 2; Liu et al., 2002; Bender et al., 2005; Raux et al., 2007; Clelland et al., 2011; Nagaoka et al., 2020). At high levels, L-Pro can be oxidized/converted into the neurotransmitter Lglutamate, which is associated with schizophrenia (Figure 5). Excess L-glutamate disturbs synaptic transmission and can destroy neurons, a process known as excitotoxicity (Nadler et al., 1988; Cohen and Nadler, 1997). Moreover, acting as a GABA mimetic inhibitor of the GAD enzyme, L-Pro can reduce the synthesis the GABA neurotransmitter, thereby provoking synaptic dysfunction (Figure 5; Crabtree et al., 2016). Of note, L-Pro antagonizes GABA signaling in plants (Haudecoeur et al., 2009).

\section{Neural Transporters}

In neural tissues, two transporters of L-Pro are expressed; solute carrier family 6 member 7 (SLC6A7, PROT), a member of GABA family, and solute carrier family 6 member 19 (SLC6A19, B AT1) 


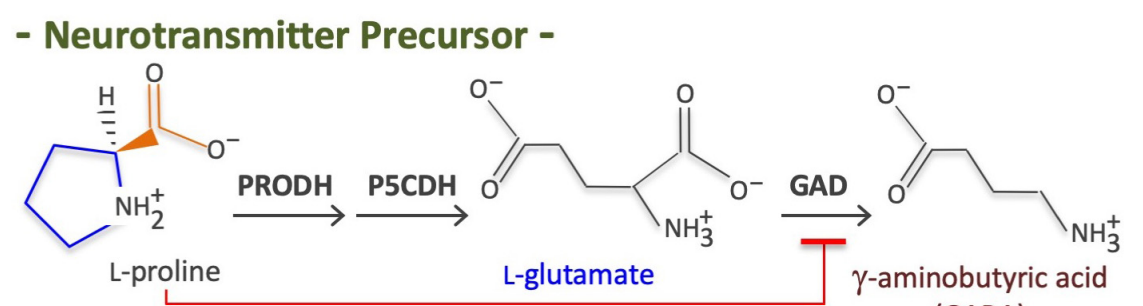

(GABA)

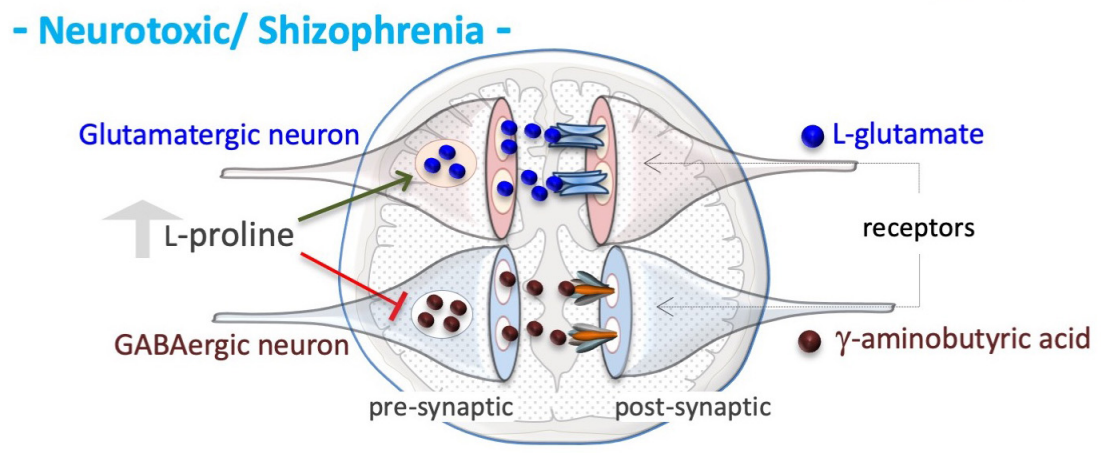

- Neural Transporters -

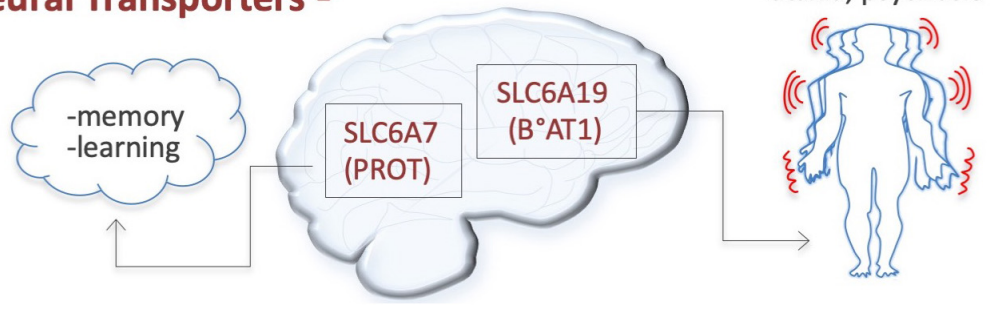

FIGURE 5 | Proline is a neural metabotoxin. Proline is a metabolic precursor of L-glutamate and gamma-aminobutyric acid (GABA), i.e., the two major neurotransmitters in mammalian brain (top). At high plasma concentrations (2-3 millimolar instead of 150-200 micromolar), as occurs in patient suffering of hyperprolinemia type II (HPII, Table 3), the neurons can channeled free proline into glutamate biosynthesis, thus increasing free glutamate level. At a high level free proline can inhibit glutamate decarboxylase (GAD) enzyme (GABA biosynthesis) thus reducing GABA level in pre synaptic neurons. Altered levels of both these crucial neurotransmitters, and thus alterations in neurotransmission (middle), can explain some of the symptoms of hyperprolinemic patients, including schizophrenia. Defects in neural proline transport, which is mediated by different transporters such as the solute carrier family 6 member 7 (SLC6A7), a high affinity proline transporter, also known as proline transporter 1 (PROT1), and by the solute carrier family 6 member 19 (SLC6A19), also known as system B(0) neutral amino acid transporter 1 (BOAT1), are associated with ataxia and psychosis.

(Figure 5; Roigaard-Petersen and Sheikh, 1984; Malandro and Kilberg, 1996; Thwaites and Anderson, 2007, 2011; Verrey et al., 2009). Genetic and/or pharmacological inhibition of SLC6A7 reduces locomotor activity and improves mouse learning and memory (Zipp et al., 2014; Schulz et al., 2018). SLC6A7 is induced in fibroblasts of patients suffering of Friedreich's ataxia, characterized by a lack of control in muscle activity/movements (Napierala et al., 2017). Mutations of SLC6A19 are associated with Hartnup disease, a complex syndrome involving cerebellar ataxia and psychosis (Seow et al., 2004). SLC6A20 (IMINO) is expressed in human neurons and regulates L-Pro and glycine homeostasis (Bae et al., 2021).

\section{Neural Bioactive Peptides}

Collagen-derived peptides such as Pro-Pro-OH induce the expression of crucial neural growth factors in the hippocampus of mice, increasing both dopamine concentration in the prefrontal cortex and proliferation of neural progenitor cells, and, eventually, reducing depression-like behavior (Mizushige et al., 2019; Nogimura et al., 2020). L-Pro-containing peptides (Gly-Pro-Glu and cyclo-Gly-Pro) inhibit inflammation and induce vascular remodeling, thereby protecting brain tissues from ischemic injury (Guan and Gluckman, 2009). Moreover, a phosphine analog of Pro-Gly-Pro tripeptide displays neuroprotective properties (Alexey et al., 2021).

\section{Leukodystrophy/Cerebral Hypomyelination}

Genetic defects in PYCR2, a PYCR1 paralog, are associated with leukodystrophy-hypomyelinating 10 (HLD10; Table 2), a syndrome characterized by microcephaly and psychomotor disability (Nakayama et al., 2015; Zaki et al., 2016). PYCR2deficient fibroblasts derived from HLD10 patients are highly susceptible to oxidative stress-induced apoptosis, and this may contribute to this complex phenotype (Reversade et al., 2009; Nakayama et al., 2015). 


\section{PROLINE MODULATES SIGNALING PATHWAYS}

The availability of some amino acids influences the activity of cell signaling pathways. For instance, the level of L-glutamine, L-leucine, and L-arginine impacts the mechanistic target of rapamycin (mTOR) pathway (Curi et al., 2007; Xie and Klionsky, 2007; Ryter et al., 2013; Bar-Peled and Sabatini, 2014; Lahiri et al., 2019). L-tyrosine and L-phenylalanine modulate the G protein-coupled receptor 142 (GPR142)-mediated pathway (Lin et al., 2016). It emerged that mESCs, isolated from mouse blastocysts, suffer from a finely regulated partial shortage of LPro, and that an increase in free L-Pro availability modulates the activity of the amino acid stress response (AAR), fibroblast growth factor/extracellular signal-related kinase (FGF/ERK), TGF $\beta$, wingless and int-1 (WNT), and redox signaling pathways. As expected, specific signaling modulators such as halofuginone (AAR inducer), SB431542 (TGFß inhibitor), CHIR99021 (WNT agonist) and PD0325901 (MEK/ERK inhibitor) fully counteract L-Pro supplementation effects (Comes et al., 2013; D’Aniello et al., 2015). Moreover, L-Pro impacts mTOR pathway in porcine trophectoderm cells (Liu et al., 2021).

\section{Amino Acid Starvation Response}

In cultured ESCs, exogenously available L-Pro, at a physiological concentration range $(50-250 \mu \mathrm{M})$, disables the AAR pathway by improving L-Pro-tRNA loading, inactivating (dephosphorylation) eukaryotic translation initiation factor alpha (EIF2 $\alpha$ ), and eventually, preventing translation of ATF4 mRNA (Figure 6; D'Aniello et al., 2015). In the absence of ATF4, the genes involved in L-Pro biosynthesis (ALDH18A1 and PYCR1), and L-Pro uptake (SLC38A2 and GADD34) are silenced (Gaccioli et al., 2006; D’Aniello et al., 2015). L-Pro-ATF4 interplay also impacts cardiac fibroblast metabolism (Qin et al., 2017). Human kidney and breast cancer cells suffer from a similar intrinsic and partial shortage of L-Pro (Loayza-Puch et al., 2016; Sahu et al., 2016).

\section{Extracellular Signal-Regulated Kinase}

In stem and cancer cells, a high L-Pro regimen induces phosphorylation of ERK1 and enhances the transcription of ERKrelated genes (Figure 6; Liu et al., 2006; D’Aniello et al., 2016). Supplemental L-Pro induces the expression of growth factors (FGF5, FGF8, and FGF13) and the synthesis of collagen, and this can contribute to the induction of the ILK/ERK superpathway, as revealed by transcriptome analysis (Comes et al., 2013; D'Aniello et al., 2016, 2019b). Indeed, collagen mimics consisting of repeated units (5 or 10) of the Pro-Pro-Gly tripeptide activate phosphoinositide 3-kinase (PI3K)-dependent p38 mitogen-activated protein kinase (MAPK) phosphorylation (Weinberger et al., 2005).

\section{Transforming Growth Factor}

In ESCs, supplemental L-Pro induces expression of leftright determination factors (LEFTY1 and LEFTY2) and phosphorylation (activation) of small mother against decapentaplegic (SMAD2), which are extracellular inhibitors and intracellular effector of TGF $\beta$-signaling, respectively (Figure 6; D'Aniello et al., 2015, 2016). In VSMCs of injured arteries (Majesky et al., 1991; Ensenat et al., 2001), and in meniscal fibrochondrocytes (Pangborn and Athanasiou, 2005), supplemental TGF $\beta$ induces L-Pro uptake and collagen deposition. A L-Pro $\rightarrow$ TGF $\beta \rightarrow$ L-Pro regulatory loop should allow the induction of collagen synthesis only when free L-Pro is sufficient to warrant timely tRNA loading, thus avoiding ribosome stalling (ER stress).

\section{Wingless and Int-1}

Pluripotent stem cells tend to proliferate as tightly packed cell aggregates, a trend that is inverted by a high L-Pro regimen (Comes et al., 2013). This phenotypic effect of LPro is fully counteracted by CHIR99021, a WNT signaling agonist. Moreover, L-Pro abundance delocalizes E-cadherin from the plasma membrane, where it is involved in cell-cell adherent junctions, to the Golgi. This subcellular redistribution of E-cadherin relies on the protein kinase domain containing, cytoplasmic (PKDCC), also known as vertebrate lonesome kinase (VLK) (Figure 6; Comes et al., 2013). L-Pro supplementation induces the expression of insulin-related genes such as IGF2, IGFR1, IGFBP3, IRS1 and IRS2 (D'Aniello et al., 2016), which are modulators of glycogen synthase kinase 3 (GSK3) activity (Desbois-Mouthon et al., 2001), and enhanced translation of collagen XVIII, which contains a frizzled-like domain (Heljasvaara et al., 2017), and can contribute to WNT modulation.

\section{Autophagy}

In mouse ESCs, L-Pro supplementation enhances L-Pro-tRNA loading and inhibits autophagy. Accordingly, halofuginone inhibits L-Pro-tRNA loading and activates autophagy (D'Aniello et al., 2015). In human and murine ECSLC, knockdown of Tap73 tumor protein reduces L-Pro biosynthesis and induces autophagy (Sharif et al., 2019). Protracted exposure to free L-Pro induces stem cell motility, invasiveness, and macro-autophagy (D'Aniello et al., 2015). In cancer cells overexpressing PRODH and exposed to a high exogenous L-Pro regimen, autophagy is induced (Liu et al., 2012b).

\section{Reactive Oxygen Species and Hypoxia-Inducible Factors}

Electrons released during mitochondrial L-Pro oxidation reduce flavin adenine dinucleotide (FAD) to generate FADH2 and/or $\mathrm{O}_{2}$ during the production of ROS (Figure 6; Donald et al., 2001). In Arabidopsis thaliana, PRODH-mediated production of sub-lethal levels of ROS induces disease resistance (Cecchini et al., 2011), and in Caenorhabditis elegans this prolongs the nematodes life span (Zarse et al., 2012). In C. elegans, defects in L-Pro catabolism results in premature reproductive senescence and male infertility (Yen and Curran, 2021). In cancer cells, the L-Pro-> PRODH-> ROS axis can activate either pro-tumorigenic (cell survival) or anti-tumorigenic (cell death) signaling (Moloney and Cotter, 2018; Oscilowska et al., 2021). 


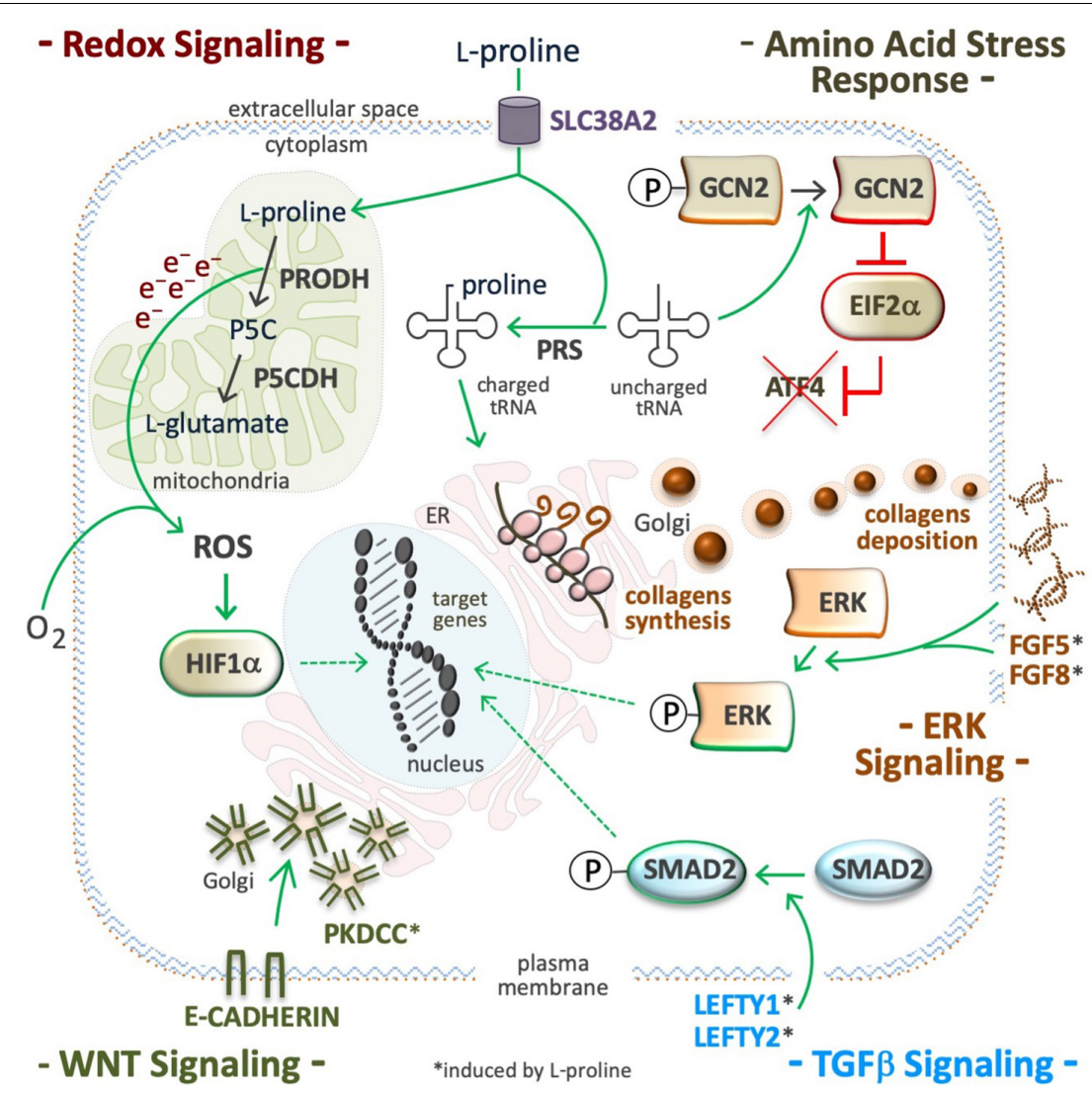

FIGURE 6 | Proline modulates signaling pathways. Supplemental proline, after being transported into the cell cytoplasm can be used and/or for mitochondrial oxidation (catabolism) and/or for the loading of uncharged tRNA (anabolism). ROS are byproducts of proline oxidation (top left) and their accumulation can stabilize the hypoxia inducible factors (HIF), and modulate redox signaling (middle left). Proline-tRNA loading induces dephosphorylation (inactivation) of the general control non-repressible 2 (GCN2) kinase, also known as eukaryotic translation initiation factor 2 alpha kinase 4 (EIF2AK4). The inactive form of GCN2 is unable to phosphorylate eukaryotic translation initiation Factor 2A (EIF2A), and to promote translation of activating transcription factor 4 (ATF4), so inactivating the amino acid stress response (AAR). Proline-tRNA loading also improves collagens expression, which are modulators of the integrin linked kinase/extracellular signal-regulated Kinase (ILK/ERK) super-pathway (middle right). Proline abundance induces left-right determination factors (LEFTY1, LEFTY2), the phosphorylation of mothers against decapentaplegic homolog 2 (SMAD2), and thus, the activation of the transforming growth factor beta signaling pathway (bottom right). Proline abundance also induces the expression of the protein kinase domain containing, cytoplasmic (PKDCC), and the delocalization the E-cadherin from plasma membrane to trans Golgi (bottom left).

In rats' blood cells, hyperprolinemia increases oxidative damage of proteins, lipids and DNA (Ferreira et al., 2014). The effect of L-Pro on intracellular redox balance can be amplified by an NADPH-consuming futile cycle of L-Pro/P5C inter-conversion (Phang, 2019). Besides ROS, oxidative deamination of LPro generates $\alpha-K G$, an essential substrate for hydroxylating dioxygenase enzymes, including PHD1-3 enzymes that catalyze the post-translational hydroxylation of specific proline residues of hypoxia-inducible factors (HIFs) resulting in destabilization of the protein. Indeed, the induction of PRODH activity in cancer cells destabilizes HIF $1 \alpha$ and down-regulates the transcription of HIF1 $\alpha$ target genes (Liu et al., 2009).

\section{PROLINE IS AN EPIGENETIC MODIFIER}

Several metabolites may influence, directly or indirectly, the activity of chromatin-modifying enzymes, and thus the epigenetic landscape of the cells (Reid et al., 2017; D'Aniello et al., 2019b; Surguchov et al., 2021). L-Pro is not a substrate, product, cofactor, or allosteric regulator of any epigenetic enzyme, but in ESCs its availability influences the activity of ten-eleven translocation (TET; DNA) and Jumonji (JMJ, histone) demethylase enzymes, which are strictly dependent on the availability of $\mathrm{O}_{2}, \alpha-\mathrm{KG}$, and ascorbic acid (vitamin $\mathrm{C}$, VitC) to be active (Figure 7; Comes et al., 2013; D’Aniello et al., 2016, 2019b).

\section{DNA Methylation}

L-Proline supplementation increases DNA 5-methylcytosine $(5 \mathrm{mC})$ and reduces 5-hydroxy-methylcytosine (5hmC) levels, inducing $\sim 1 \times 10^{3}$ DMRs distributed throughout all chromosomes of ESCs, with $\sim 50 \%$ of DMRs located in gene promoter regions (mostly $\mathrm{H}$ ) and $\sim 20 \%$ in gene enhancers (D'Aniello et al., 2016). Importantly, $\sim 95 \%$ of genome sites hypermethylated after L-Pro supplementation are hypomethylated following VitC (50-150 $\mu \mathrm{M})$ supplementation, 


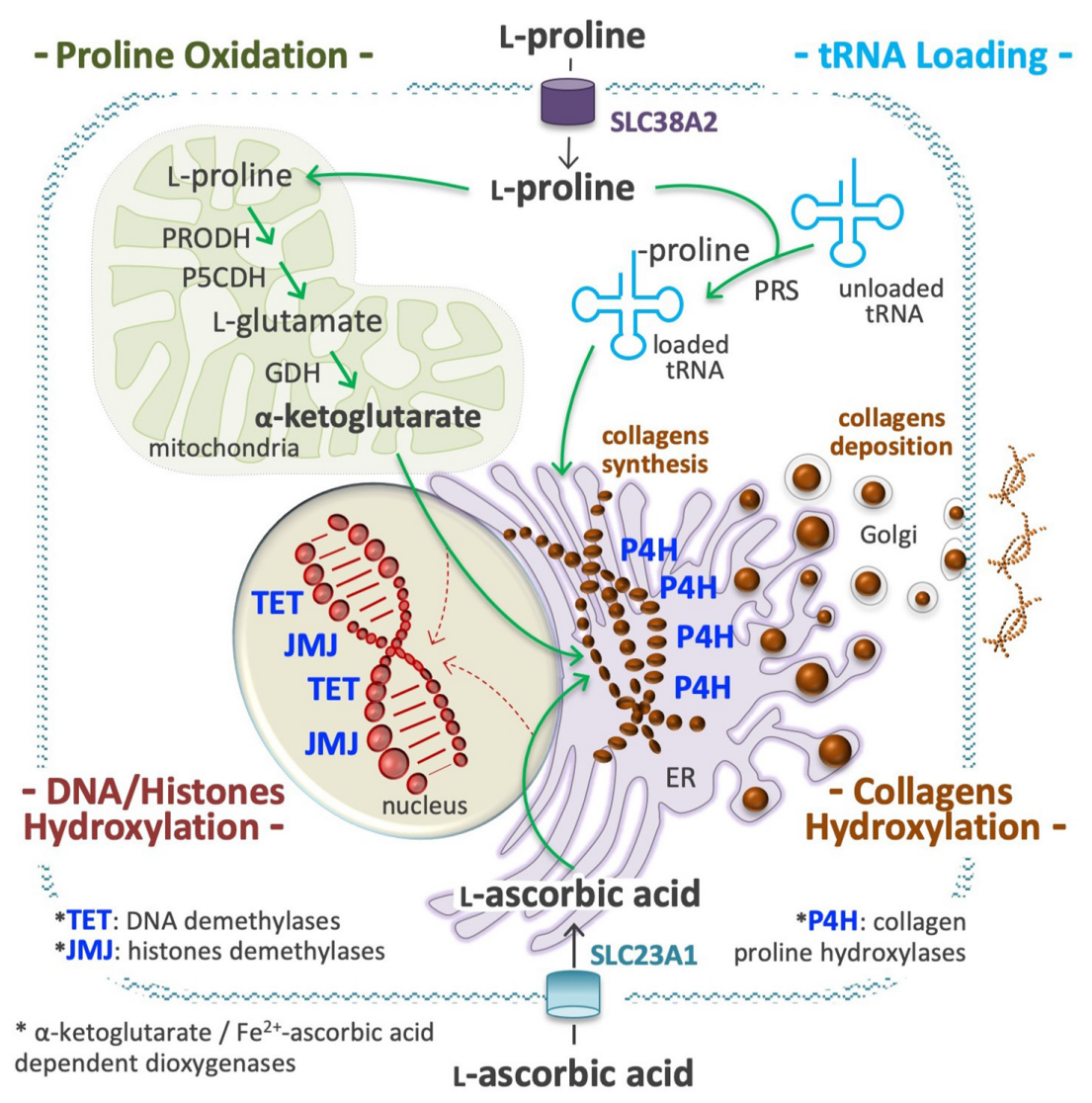

FIGURE 7 | Proline is an epigenetic modifier. At a high proline regimen, extracellular proline is channeled into the cell cytoplasm through a transport system, as the solute carrier family 38 member 2 (SLC38A2), also known as system $\mathrm{N}$ amino acid transporter 2 (SNAT2), and used to charge tRNA molecules (top right), in a reaction catalyzed by the prolyl-tRNA synthetase (PRS). A high level of charged Proline-tRNA is an essential requisite for collagens synthesis (middle). A high fraction of L-Pro residues of the nascent molecules of collagens are hydroxylated by prolyl 4-hydroxylases $(\mathrm{P} 4 \mathrm{H} 1,2,3)$ dioxygenases enzymes, a process that consume huge amounts of ascorbic acid (vitamin C, VitC) and $\alpha$-ketoglutarate ( $\alpha$-KG) (middle right). VitC is transported by members of the solute carrier family 23 (SLC23A1, 2; bottom), whereas $\alpha-K G$ is produced inside mitochondria using proline and/or glutamate as precursors (top left). A sudden and sizeable increment of $\mathrm{P} 4 \mathrm{H}$ activity in the endoplasmic reticulum (ER) can reduce the availability of VitC and $\alpha-K G$ for the activity of nuclear dioxygenases involved in DNA methylcytosine hydroxylation/demethylation (ten-eleven translocation, TET 1, 2, 3) and in histones lysine hydroxylation/demethylation (jumonji, JMJ) (bottom left). This compartmentalized metabolic perturbation, by increasing the DNA and histones methylation levels, can modify the epigenetic landscape of the cells.

indicating that L-Pro and VitC induce opposite epigenetic alterations in the same DNA regions. VitC is needed for the activity of TET demethylases (Blaschke et al., 2013), and $~ 90 \%$ of genomic regions hypermethylated in by a high L-Pro regimen are hypermethylated also in cells lacking TET-mediated DNA demethylase activity (Lu et al., 2014; D’Aniello et al., 2019a).

\section{Histone Methylation}

L-Proline supplementation also triggers a genome-wide reprogramming of $\mathrm{H} 3 \mathrm{~K} 9$ methylation status, altering more than $1.6 \times 10^{4}$ genome sites located mainly in non-coding intergenic regions (Comes et al., 2013). Demethylation is catalyzed by members of the JMJ dioxygenase enzyme family, and upon silencing of Jmjd1a (H3K9 demethylase), ESCs adopt a molecular (upregulation of Fgf5 and Brachyury genes) and phenotypic (irregular flat-shaped colonies, sensitivity to trypsin digestion) state of pluripotency, similar to that induced by a high
L-Pro regimen (Loh et al., 2007). Differences in the expression level and/or in the kinetic parameters (substrate affinity) of different JMJs can explain how L-Pro abundance alters the methylation level of some specific lysine residues (K9, K36) of histone $\mathrm{H} 3$.

\section{Metabolic Imbalance}

It recently emerged that a sudden and substantial increase in LPro stimulates collagen synthesis in the ER of ESCs (D'Aniello et al., 2019a), and that a significant fraction of L-Pro residues of nascent collagens are hydroxylated by prolyl 4-hydroxylase $(\mathrm{P} 4 \mathrm{H})$ dioxygenases, in particular by P4HA1 and P4HA2 enzymes, with depletion of $\alpha-K G$ and VitC. Under such conditions, nuclear dioxygenases such as TETs and JMJs lose activity, and consequently, DNA and histone methylation levels increase (Figure 7). Genetic and pharmacological evidence supports the idea that an abrupt induction of collagen synthesis leads to a 


\section{- Embryonic Stem Cells -}

\section{- Plant Stem Cells -}

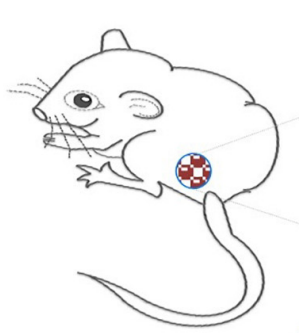

inner cell mass

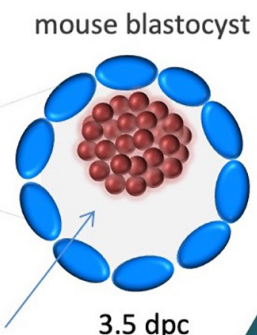

$3.5 \mathrm{dpc}$

.

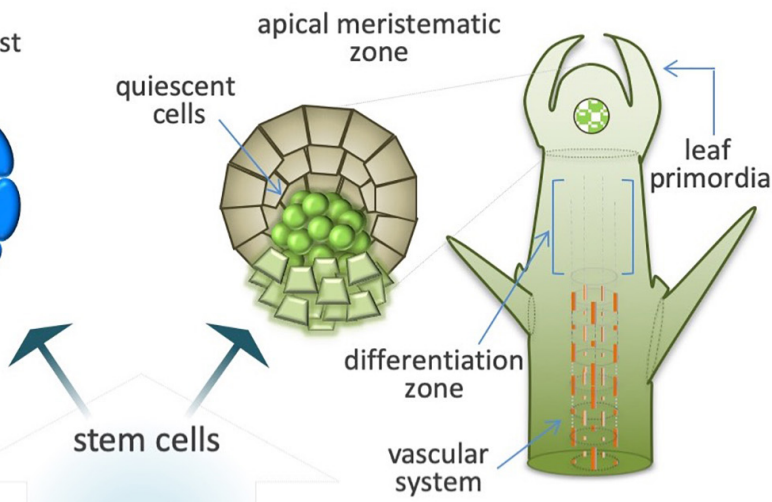

apical meristematic

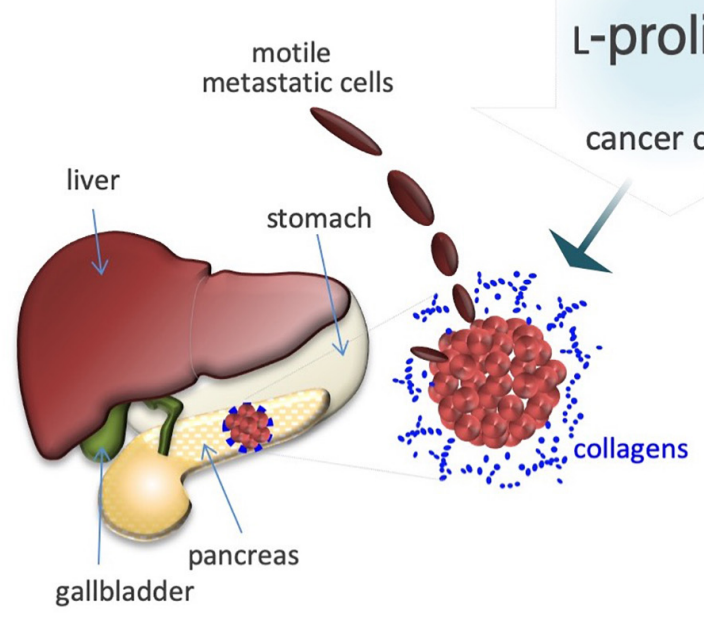

- Cancer Cells -

- Crown Galls -

FIGURE 8 | Proline induces proliferation of stem and cancer cells. Proline availability controls proliferation of pluripotent embryonic stem cells (ESCs), isolated from the inner cell mass of 3.5 days post coitum (dpc) mouse blastocysts (top left). Proline induces proliferation also of plant stem cells that shaped the shoot and root apical meristems and are responsible of post-embryonic organogenesis (top right). Proline improves proliferation and invasiveness of cancer cells primarily by increasing protein synthesis (bottom left). Deregulation of proline metabolism is involved in development and growth of plant tumors, such as the neoplastic hairy roots and are tumor-like structures known as crown galls. Usually, these tumors are formed in the roots or in the lower stem region (bottom right), and display a single and/or several centers of deregulated cell proliferation (hyperplasia), surrounded by hypertrophic tissues (bottom right).

similar metabolic imbalance and epigenome alterations also in cancer cells (D’Aniello et al., 2019a).

\section{PROLINE INDUCES PROLIFERATION OF STEM AND TUMOR CELLS}

Pluripotent stem cells shape the ICM in blastocysts of mammals and the apical meristems of plant organs (shoots and roots), and can self-renew and undergo differentiation into various somatic lineages. Cancer cells often display a stem cell-like growth behavior. Of note, L-Pro is a growth limiting metabolite (intrinsic starvation) for embryonic stem cells (D'Aniello et al., 2015), and for many different human cancer cells (D'Aniello et al., 2020). Similarly, L-Pro metabolism also influences the proliferation of meristematic and plant tumor cells (Trovato et al., 2001; Biancucci et al., 2015).

\section{Stem Cells}

Supplemental L-Pro (50-250 $\mu \mathrm{M})$ improves proliferation of ESCs (Figure 8; Washington et al., 2010; Casalino et al., 2011), development of pre-implantation embryos (Morris et al., 2020) and fetus survival (Liu et al., 2019). L-Pro is internalized into stem cell cytoplasm through the SLC38A2 (SNAT2) transporter (Tan et al., 2011), and halofuginone (prolyl-tRNA synthetase inhibitor) fully counteracts L-Pro induction of cell proliferation (D’Aniello et al., 2015). Moreover, halofuginone and L-Pro modify the ESC transcriptome in opposite directions (D'Aniello et al., 2015), showing that mouse ESCs are partially starved of L-Pro, even after incubation in complete rich medium. 


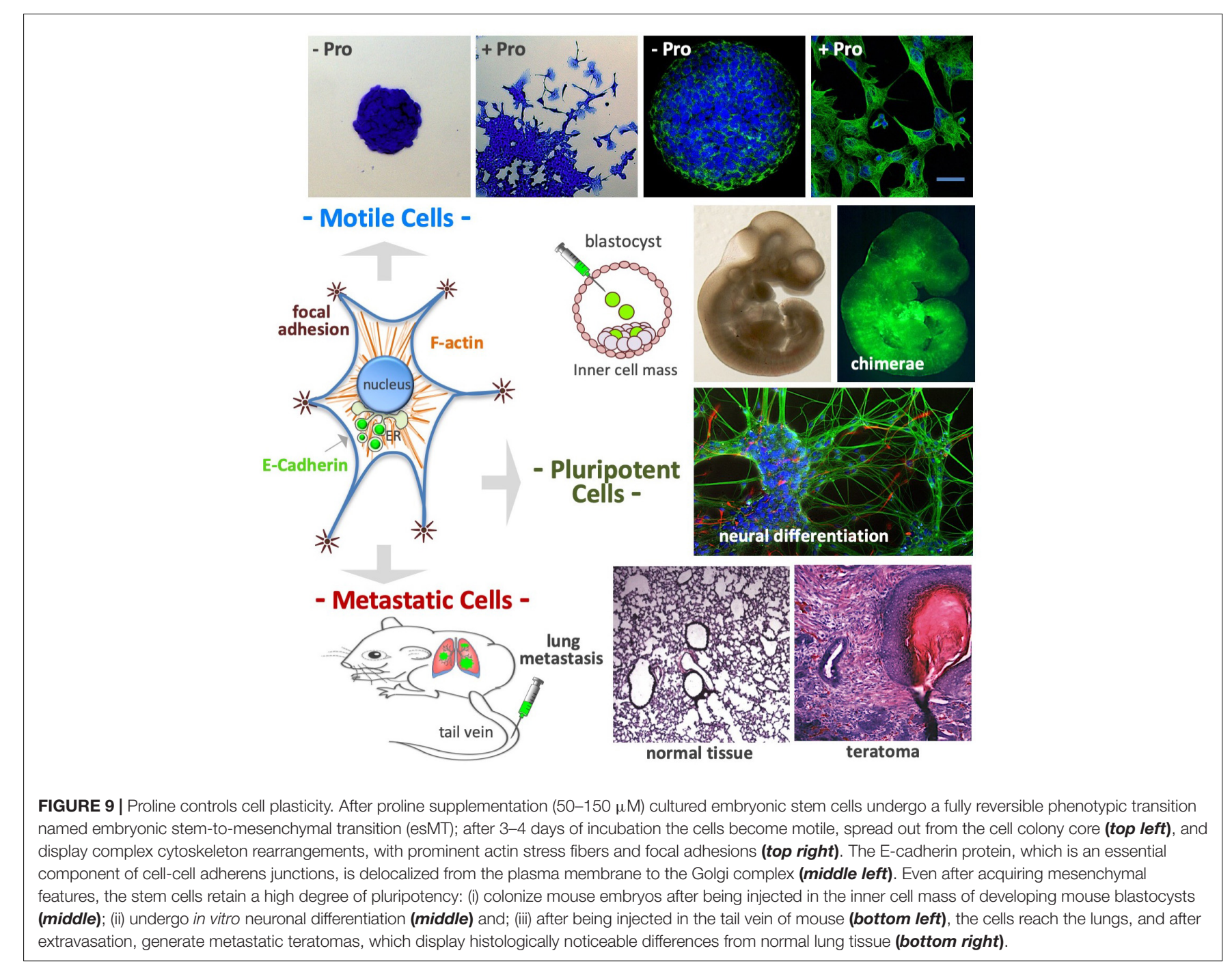

Of note, during in vitro fertilization of mouse oocytes, L-Pro supplementation improves stem cells (ICM) proliferation and embryo development (Treleaven et al., 2021).

\section{Cancer Cells}

L-Proline shortage is a major cause of partial ribosome stalling (diricore analysis) suffered by kidney and breast cancer cells (Loayza-Puch et al., 2016). Likewise, up-regulation of L-Pro biosynthesis genes (ALDH18A1 and PYCR1) also reveals L-Pro starvation in tumor cells (D'Aniello et al., 2020). Moreover, ALDH18A1 knock-down activates AAR stress signaling, and reduces melanoma tumor growth both in vitro and in vivo (Kardos et al., 2015), whereas PYCR1 induction improves proliferation and invasiveness of breast, esophagus, lung, melanoma, pancreas, and prostate cancer cells (Nilsson et al., 2014; Ding et al., 2017; Zeng et al., 2017; Cai et al., 2018; Ye et al., 2018; Kardos et al., 2020; Forlani et al., 2021). Of note, kindlerin 2 (KINDLING-2) protein stabilizes the mitochondrial PYCR1 enzyme, increasing L-Pro synthesis and lung adenocarcinoma cell proliferation (Guo et al., 2019).
Importantly, translocation of KINDLING-2 into mitochondria is regulated by ECM stiffness (Guo et al., 2019) and PINCH1 (particularly interesting new Cys-His protein 1) protein (Guo et al., 2020; Ding et al., 2021), and PYCR1 activity is modulated by the mitochondrial deacetylase sirtuin (SIRT3) (Chen et al., 2019). PYCR1 stabilization by KINDLING-2 induces L-Pro synthesis in human lung fibroblasts and contributes to pulmonary fibrosis progression (Zhang et al., 2021a).

\section{Meristematic Cells}

Post-embryonic organogenesis in adult plants relies on apical meristems, and a fine-tuned balance between self-renewal and differentiation fates adapts organ morphogenesis to a fluctuating environment (Figure 8; Mattioli et al., 2009; Lehmann et al., 2010; Szabados and Savoure, 2010). In Arabidopsis, L-Pro availability controls root meristem activity (Biancucci et al., 2015) by modifying the expression of L-Pro-rich proteins, and regulating a compartmentalized (mitochondria/cytoplasm) cycle of L-Pro synthesis and degradation that modifies the $\mathrm{NADP}^{+} / \mathrm{NADPH}$ ratio (Verslues and Sharma, 2010). Therefore, it is tempting to 


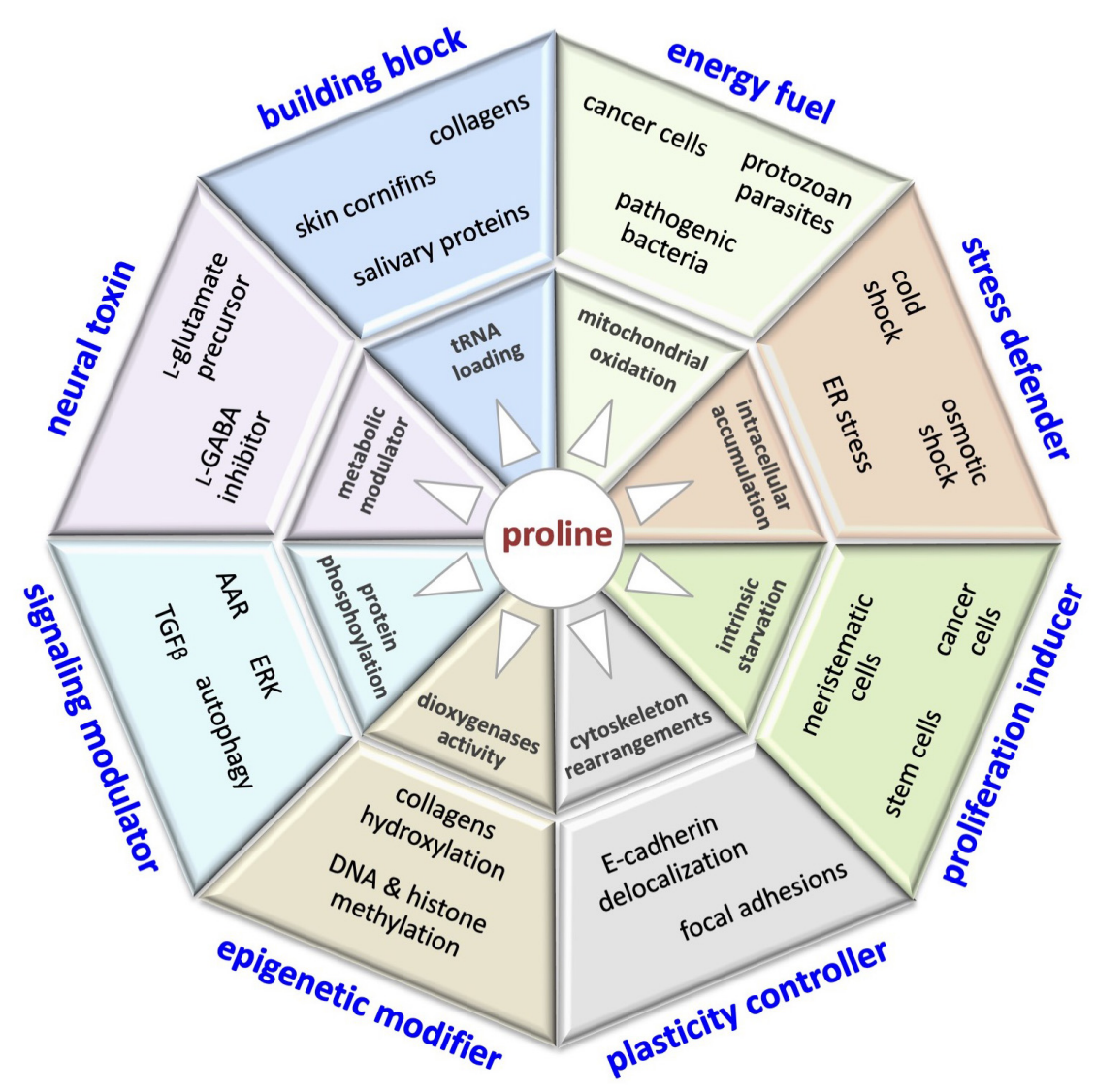

FIGURE 10 | This illustration encompasses the multifaceted roles of proline in cell biology, including: building block of proteins (collagens, cornifins, salivary proteins); energy fuel (bacteria, parasites, cancer cells); stress defender (cold shock, drought/salinity, ER stress); proliferation inducer (stem, meristematic, cancer cells); plasticity controller (cell shape, motility); epigenetic modifier (DNA/histone methylation); modulator of cell signaling pathways (AAR, autophagy, ERK, TGF $\beta$ ) and neural toxin associated (schizophrenia).

hypothesize that the induction of L-Pro accumulation during osmotic shock (see Figure 4), by altering the behavior/fate of stem cells, can contribute to couple a harmful environment (soil wetness) with the induction of organogenesis (root elongation).

\section{Neoplastic Hairy Roots}

L-Proline metabolism and plant tumor development are linked by the rolD gene of Agrobacterium rhizogenes, which encodes OCD that catalyzes L-Orn to L-Pro conversion, and is essential for the induction of neoplastic hairy roots (Figure 8; White et al., 1985; Costantino et al., 1994; Trovato et al., 2001). L-Pro accumulates in root tumor-like galls induced by the nematode Meloidogyne javanica or by Agrobacterium tumefaciens (Wachter et al., 2003; Trovato et al., 2018). Importantly, bacteria-induced tumorigenesis is attenuated in transgenic plants with low L-Pro levels (Haudecoeur et al., 2009).

\section{PROLINE CONTROLS CELL PLASTICITY}

Some metabolites modulate relevant phenotypic transformations such as stem cell differentiation, somatic cell reprogramming, and EMT. For instance, butyric acid drives the differentiation of MSCs into adipocytes (Tugnoli et al., 2019), and, conversely, enhances the reprogramming efficiency of fetal fibroblasts into pluripotent cells (Liang et al., 2010; Mali et al., 2010). Likewise, VitC improves cell differentiation (Cao et al., 2012) and reprogramming (Esteban et al., 2010). Similarly, L-Pro governs the morphology, migratory behavior and pluripotency state of stem cells (Washington et al., 2010; Casalino et al., 2011).

\section{Cytoskeletal Rearrangements}

Embryonic stem cells seeded at a low density $\left(50-250\right.$ cells $\left./ \mathrm{cm}^{2}\right)$ in a high L-Pro regimen develop flat-shaped cell colonies formed by a core of adherent cells surrounded by a crown of detached cells showing mesenchymal features such as long actin stress fibers and mature focal adhesion complexes (Figure 9; Casalino et al., 2011; Comes et al., 2013). These L-Pro-induced cells are in a 'metastable' equilibrium, spread out from the colony core and rapidly moving back to re-establish adherent cell-cell contacts, a fully reversible phenotypic transition known as embryonic stem cell-to-mesenchymal transition (esMT) (Comes et al., 2013). Of note, in detached cells, E-cadherin is delocalized from the plasma membrane to the Golgi (see Figure 6) and unlike canonical 
EMT, during esMT the CDH1 gene is not down-regulated (Comes et al., 2013).

\section{Invasion/Metastasis}

After exposure to a high L-Pro regimen, ESCs acquire the ability to migrate through matrigel-coated porous membranes in response to serum gradients, or toward chemo-attractants such as EGF and stromal cell-derived factor 1 (Comes et al., 2013). These cells are able to reach the lung tissues after intravenous injection, and to generate tumors with a histological complexity of teratomas (Comes et al., 2013). Thus, a high L-Pro regimen converts adherent stem cells into spindle-shaped, motile and metastatic stem cells (Figure 9).

\section{Metabolic Reprogramming}

The morphological changes induced by L-Pro supplementation are associated with a metabolic switch from a bivalent to a more glycolytic metabolism. Indeed, metabolome profile analysis revealed higher lactate levels and increased susceptibility to 2DG, a specific inhibitor of the glycolytic pathway (D'Aniello et al., 2016). Moreover, a high L-Pro regimen reduces the mitochondrial membrane potential, which relies on oxidative phosphorylation rates (D’Aniello et al., 2017), thus supporting glycolytic energy metabolism.

\section{Pluripotency}

L-Proline supplementation remodels the transcriptome of naïve ESCs by altering the expression of $\sim 1.5 \times 10^{3}$ protein-coding genes mainly related to cell adhesion, cell junction, and cell motility functions (Comes et al., 2013; D'Aniello et al., 2017). Cells treated with L-Pro are leukemia inhibitory factor (LIF)dependent, express pluripotency markers as Nanog homeobox, can differentiate into cardiomyocytes and neurons in vitro, and are able to colonize mouse blastocysts (chimeric embryos; Figure 9; Casalino et al., 2011). Recently, Cermola et al. (2021) reported that L-Pro-treated ESCs can differentiate into primordial germ cell like cells (PGCLCs), and are competent to develop elongated gastruloids, suggesting that L-Pro abundance drives ESCs into an early primed state of pluripotency.

\section{Proline Antagonists}

L-Proline-induced esMT is inhibited by well-known chemical modulators of key signaling pathways such as CHIR99021 (WNT agonist) and PD0325901 (TGF $\beta$ antagonist) (D'Aniello et al., 2016). Moreover, D'Aniello et al. (2019a) made use of the cell colony morphology to develop a high-throughput screening method, and identified 14 FDA-approved drugs (from 1200 assayed) able to inhibit esMT without preventing L-Proinduced cell proliferation. Spiramycin (macrolide), Propafenone (flavonoid) and Budesonide (steroid) inhibit esMT and have very different chemical structures, implying molecular complexity in L-Pro-mediated control of stem cell plasticity. Importantly, VitC, but not other antioxidants such as NAC, is a full inhibitor of esMT (D’Aniello et al., 2016).

\section{CONCLUSION AND PERSPECTIVES}

The control of L-Pro metabolism in human cells is relatively poorly understood, even though it might have a great impact on human health (Figure 10). For instance, PrAMPs displaying potent antimicrobial activity and low toxicity for human cells could be efficient tools to fight multidrug-resistant pathogens, a serious public health concern (Charon et al., 2019). Salivary proline-rich peptides able to neutralize microbe attacks could contribute to avoiding the development of dental caries, an infectious disease that affects billions of people (Werneck et al., 2010; Stromberg et al., 2017). Moreover, salivary proteins could contribute to food choices, and so to nutrition status and health (Melis et al., 2021). Translational suppression of proline-rich proteins by pharmacological targeting of the PRS is emerging as an attractive therapeutic approach for the treatment of different diseases. Of note, halofuginone, a specific inhibitor of the PRS, is already in clinical trials for the treatment of fibrotic diseases (Pines and Spector, 2015), and has been recently shown to inhibit SARS-CoV-2 infection, suppressing the translation of proline-rich host attachment factors (Sandoval et al., 2021).

Exploitation of L-Pro as a source of carbon and/or energy appears to be an adaptive response of cells to high-L-Pro microenvironments, which can be generated by pathological tissue damage (bacterial invasion, cancer progression, trauma). Although never measured, it is possible to speculate that in an extremely confined extracellular space, free LPro can reach exceptionally high concentrations. L-Pro supports invasiveness of bacteria, parasites and cancer cells, all processes that engage tissue degradation/remodeling (Christgen and Becker, 2019; D'Aniello et al., 2020), and D-Pro-derived peptidomimetic inhibitors of human gelatinases/metalloproteinases involved in tissue remodeling are potential anti-metastatic agents (Lenci et al., 2021). Moreover, enzymes involved in L-Pro metabolism are potential targets of antiparasitic drugs (Saye et al., 2017; Ugwu et al., 2018).

Various stressful conditions, including suboptimal temperature, high salinity and oxidative agents, can alter the conformations of proteins and other macromolecules. Since L-Pro is a potent and non-toxic chemical chaperone, its intracellular accumulation could be an evolutionarily conserved response aimed at inhibiting the formation of unfolded/misfolded protein aggregates. Indeed, hemocompatible gold nanoparticles coated with L-Pro inhibit both collagen fibril formation (Anand et al., 2017) and insulin aggregation (Prajapati et al., 2021), and could provide a basis for creating antifibrotic and antiamyloid formulations.

Numerous studies conclude that at high levels, free LPro is a neurotoxin. Lactic acid inhibits PRODH activity, and lactic acidosis syndrome (blood lactic acid $>5 \mathrm{mM}$ ) is frequently associated with hyperprolinemia, supporting the idea that in adult humans L-Pro homeostasis is strictly dependent on L-Pro oxidation. Of note, L-Pro at high levels is harmful for brain/neural activity, but acting as a chemical chaperone it can prevent protein 
unfolding/misfolding (Liang et al., 2014). Thus, regulation of LPro metabolism is studied in the context of neurodegenerative diseases associated with the formation of protein aggregates, as exemplified by Huntington's, Parkinson's, and Alzheimer's (Powers et al., 2009; Khan et al., 2010).

Beyond some cancer cells, whether and which normal human cells oxidize L-Pro, and whether this contributes to maintain prolinemia, remains unknown. The concomitant activation of L-Pro oxidation (for ATP production in mitochondria) and tRNA loading (for collagen synthesis in the ER) remains uncharacterized at the single-cell level. By generating sublethal amounts of ROS, L-Pro oxidation can induce redox signaling, and eventually a compensatory stress response, through the induction of ROS consuming/neutralizing enzymes. Importantly, in bacteria (Zhang et al., 2015), fungi (Chen and Dickman, 2005) and nematodes (Zarse et al., 2012), L-Pro oxidation increases cell resilience to stressful conditions. However, the induction of stress tolerance by L-Pro oxidation in human cells remains an open question.

Aging is usually associated with a significant reduction (quantitative and qualitative) in CTs (tendon, bone, cartilage), for which L-Pro is essential. Of note, older people and patients suffering hereditary defects L-Pro biosynthesis share a similar aged appearance (e.g., osteopenia, cataracts, wrinkled skin, cutis laxa). Furthermore, sedentary life-induced sarcopenia is associated with hyperprolinemia, but its impact on neural disorders suffered by the elderly is unknown.

How L-Pro availability modulates stem and cancer cell proliferation is an interesting question that is getting increasingly attention. Free L-Pro can improve the translation of L-Prorich proteins (Sabi and Tuller, 2015; Chyzynska et al., 2021) or simple protein stretches, as demonstrated for HOXB4 involved in leukemia (Cusan et al., 2017). Recently, cell-based drug screening identified 137 drugs (out of 1200 assayed) able to inhibit stem cell proliferation, of which $80 \%$ also inhibited cancer cells (D'Aniello et al., 2019a), suggesting a similar chemosensitivity spectrum.

\section{REFERENCES}

Agami, C. P. N., Puchot, C., and Sevestre, H. (1987). The role of proline in the asymmetric step of the woodward synthesis of erythromycin. Tetrahedron 43:8.

Agerberth, B., Lee, J. Y., Bergman, T., Carlquist, M., Boman, H. G., Mutt, V., et al. (1991). Amino acid sequence of PR-39. Isolation from pig intestine of a new member of the family of proline-arginine-rich antibacterial peptides. Eur. J. Biochem. 202, 849-854. doi: 10.1111/j.1432-1033.1991.tb16442.x

Aimola, P., Carmignani, M., Volpe, A. R., Di Benedetto, A., Claudio, L., Waalkes, M. P., et al. (2012). Cadmium induces p53-dependent apoptosis in human prostate epithelial cells. PLoS One 7:e33647. doi: 10.1371/journal.pone.003 3647

Alderson, T. R., Lee, J. H., Charlier, C., Ying, J., and Bax, A. (2018). Propensity for cis-Proline formation in unfolded proteins. Chembiochem 19, 37-42. doi: 10.1002/cbic. 201700548

Alexey, V. V., Maxim, D. E., Lyudmila, A. A., Alexey, U. A., Valery, S. P., Kristina, S. N., et al. (2021). Phosphine modification of proline-glycine-proline tripeptide and study of its neuroprotective properties. Biochem. Biophys. Res. Commun. 539, 15-19. doi: 10.1016/j.bbrc.2020.12.087

Anand, B. G., Dubey, K., Shekhawat, D. S., Prajapati, K. P., and Kar, K. (2017). Strategically designed antifibrotic gold nanoparticles to prevent collagen fibril formation. Langmuir 33, 13252-13261. doi: 10.1021/acs.langmuir.7b01504
Thus, the development of therapeutic strategies to target LPro metabolism may provide new options to eradicate cancer cells. Importantly, L-Pro abundance induces invasiveness in stem cells, a peculiar trait of migrating cancer cells. Certainly, the ability of L-Pro to control morphogenesis is not limited to stem cells. For instance, L-Pro availability influences plant shoot and root development (see Biancucci et al., 2015, for a review), hyphal morphology in the pathogenic fungus Colletotrichum trifolii (Memmott et al., 2002), and filamentation (yeast-tohyphal transition) in the pathogenic yeast Candida albicans (Dabrowa et al., 1976; Silao et al., 2019).

\section{AUTHOR CONTRIBUTIONS}

EP and GM contributed to the conception and design of the review. FC, CD'A, AF, OG, and DD performed the literature search, and wrote the first draft of the manuscript. EP and FC prepared the figures. EP and GM critically revised the text and provided substantial scientific contribution. All authors approved the final version of the manuscript.

\section{FUNDING}

This work was supported by AIRC (IG 20736), POR Campania FESR 2014/2020 (Project SATIN), European Training Network RENOIR (https://renoir-itn.eu/), and Italian Ministry of Education-University-Research (CTN01_00177 Cluster ALISEI_IRMI and PRIN 2017XJ38A4).

\section{ACKNOWLEDGMENTS}

We are most grateful to Prof. Maurizio Iaccarino for critical comments.

Bachmann, A. S., and Geerts, D. (2018). Polyamine synthesis as a target of MYC oncogenes. J. Biol. Chem. 293, 18757-18769. doi: 10.1074/jbc.tm118.003336

Bae, M., Roh, J. D., Kim, Y., Kim, S. S., Han, H. M., Yang, E., et al. (2021). SLC6A20 transporter: a novel regulator of brain glycine homeostasis and NMDAR function. EMBO Mol. Med. 13:e12632.

Baliga, C., Brown, T. J., Florin, T., Colon, S., Shah, V., Skowron, K. J., et al. (2021). Charting the sequence-activity landscape of peptide inhibitors of translation termination. Proc. Natl. Acad. Sci. U S A. 118:e2026465118. doi: 10.1073/pnas. 2026465118

Barcus, C. E., O’leary, K. A., Brockman, J. L., Rugowski, D. E., Liu, Y., Garcia, N., et al. (2017). Elevated collagen-I augments tumor progressive signals, intravasation and metastasis of prolactin-induced estrogen receptor alpha positive mammary tumor cells. Breast Cancer Res. 19:9.

Barison, M. J., Rapado, L. N., Merino, E. F., Furusho Pral, E. M., Mantilla, B. S., Marchese, L., et al. (2017). Metabolomic profiling reveals a finely tuned, starvation-induced metabolic switch in Trypanosoma cruzi epimastigotes. J. Biol. Chem. 292, 8964-8977. doi: 10.1074/jbc.m117.778522

Bar-Peled, L., and Sabatini, D. M. (2014). Regulation of mTORC1 by amino acids. Trends Cell Biol. 24, 400-406.

Baumgartner, M. R., Hu, C. A., Almashanu, S., Steel, G., Obie, C., Aral, B., et al. (2000). Hyperammonemia with reduced ornithine, citrulline, arginine and proline: a new inborn error caused by a mutation in the gene encoding 
delta(1)-pyrroline-5-carboxylate synthase. Hum. Mol. Genet. 9, 2853-2858. doi: $10.1093 / \mathrm{hmg} / 9.19 .2853$

Ben Rejeb, K., Lefebvre-De Vos, D., Le Disquet, I., Leprince, A. S., Bordenave, M., Maldiney, R., et al. (2015). Hydrogen peroxide produced by NADPH oxidases increases proline accumulation during salt or mannitol stress in Arabidopsis thaliana. New Phytol. 208, 1138-1148. doi: 10.1111/nph.13550

Bender, H. U., Almashanu, S., Steel, G., Hu, C. A., Lin, W. W., Willis, A., et al. (2005). Functional consequences of PRODH missense mutations. Am. J. Hum. Genet. 76, 409-420. doi: 10.1086/428142

Benias, P. C., Wells, R. G., Sackey-Aboagye, B., Klavan, H., Reidy, J., Buonocore, D., et al. (2018). Structure and distribution of an unrecognized interstitium in human tissues. Sci. Rep. 8:4947.

Benincasa, M., Pelillo, C., Zorzet, S., Garrovo, C., Biffi, S., Gennaro, R., et al. (2010). The proline-rich peptide Bac7(1-35) reduces mortality from Salmonella typhimurium in a mouse model of infection. BMC Microbiol. 10:178. doi: 10. 1186/1471-2180-10-178

Bertolo, R. F., and Burrin, D. G. (2008). Comparative aspects of tissue glutamine and proline metabolism. J. Nutr. 138, 2032S-2039S.

Bevilacqua, E., Bussolati, O., Dall'asta, V., Gaccioli, F., Sala, R., Gazzola, G. C., et al. (2005). SNAT2 silencing prevents the osmotic induction of transport system A and hinders cell recovery from hypertonic stress. FEBS Lett. 579, 3376-3380. doi: 10.1016/j.febslet.2005.05.002

Bhola, P. T., Hartley, T., Bareke, E., Care4Rare Canada Consortium, Boycott, K. M., Nikkel, S. M., et al. (2017). Autosomal dominant cutis laxa with progeroid features due to a novel, de novo mutation in ALDH18A1. J. Hum. Genet. 62, 661-663. doi: 10.1038/jhg.2017.18

Biancucci, M., Mattioli, R., Moubayidin, L., Sabatini, S., Costantino, P., and Trovato, M. (2015). Proline affects the size of the root meristematic zone in Arabidopsis. BMC Plant Biol. 15:263. doi: 10.1186/s12870-015-0637-8

Bicknell, L. S., Pitt, J., Aftimos, S., Ramadas, R., Maw, M. A., and Robertson, S. P. (2008). A missense mutation in ALDH18A1, encoding Delta1-pyrroline5-carboxylate synthase (P5CS), causes an autosomal recessive neurocutaneous syndrome. Eur. J. Hum. Genet. 16, 1176-1186. doi: 10.1038/ejhg.2008.91

Blake, R. L., and Russell, E. S. (1972). Hyperprolinemia and prolinuria in a new inbred strain of mice. PRO-Re. Science 176, 809-811. doi: 10.1126/science.176. 4036.809

Blaschke, K., Ebata, K. T., Karimi, M. M., Zepeda-Martinez, J. A., Goyal, P., Mahapatra, S., et al. (2013). Vitamin C induces Tet-dependent DNA demethylation and a blastocyst-like state in ES cells. Nature 500, 222-226. doi: $10.1038 /$ nature 12362

Bringaud, F., Barrett, M. P., and Zilberstein, D. (2012). Multiple roles of proline transport and metabolism in trypanosomatids. Front. Biosci. (Landmark Ed) 17:349-374. doi: 10.2741/3931

Broer, S., Bailey, C. G., Kowalczuk, S., Ng, C., Vanslambrouck, J. M., Rodgers, H., et al. (2008). Iminoglycinuria and hyperglycinuria are discrete human phenotypes resulting from complex mutations in proline and glycine transporters. J. Clin. Invest. 118, 3881-3892. doi: 10.1172/jci36625

Bulet, P., Dimarcq, J. L., Hetru, C., Lagueux, M., Charlet, M., Hegy, G., et al. (1993). A novel inducible antibacterial peptide of Drosophila carries an O-glycosylated substitution. J. Biol. Chem. 268, 14893-14897. doi: 10.1016/s0021-9258(18) 82417-6

Burg, M. B., Ferraris, J. D., and Dmitrieva, N. I. (2007). Cellular response to hyperosmotic stresses. Physiol. Rev. 87, 1441-1474. doi: 10.1152/physrev. 00056.2006

Bursell, E. (1975). Substrates of oxidative metabolism in dipteran flight muscle. Comp. Biochem. Physiol. B 52, 235-238. doi: 10.1016/0305-0491(75)90057-7

Cai, F., Miao, Y., Liu, C., Wu, T., Shen, S., Su, X., et al. (2018). Pyrroline5-carboxylate reductase 1 promotes proliferation and inhibits apoptosis in non-small cell lung cancer. Oncol. Lett. 15, 731-740.

Campbell, H. D., Webb, G. C., and Young, I. G. (1997). A human homologue of the Drosophila melanogaster sluggish-A (proline oxidase) gene maps to 22q11.2, and is a candidate gene for type-I hyperprolinaemia. Hum. Genet. 101, 69-74. doi: $10.1007 /$ s004390050589

Candy, D. J., Becker, A., and Wegener, G. (1997). Coordination and integration of metabolism in insect flight. Comp. Biochem. Physiol. Part B: Biochem. Mol. Biol. 117:15.

Canon, F., Belloir, C., Bourillot, E., Brignot, H., Briand, L., Feron, G., et al. (2021). Perspectives on astringency sensation: an alternative hypothesis on the molecular origin of astringency. J. Agric. Food Chem. 69, 3822-3826. doi: 10.1021/acs.jafc.0c07474

Cao, H., Ke, T., Liu, R., Yu, J., Dong, C., Cheng, M., et al. (2015). Identification of a novel proline-rich antimicrobial peptide from Brassica napus. PLoS One 10:e0137414. doi: 10.1371/journal.pone.0137414

Cao, N., Liu, Z., Chen, Z., Wang, J., Chen, T., Zhao, X., et al. (2012). Ascorbic acid enhances the cardiac differentiation of induced pluripotent stem cells through promoting the proliferation of cardiac progenitor cells. Cell Res. 22, 219-236. doi: 10.1038/cr.2011.195

Cappelletti, P., Tallarita, E., Rabattoni, V., Campomenosi, P., Sacchi, S., and Pollegioni, L. (2018). Proline oxidase controls proline, glutamate, and glutamine cellular concentrations in a U87 glioblastoma cell line. PLoS One 13:e0196283. doi: 10.1371/journal.pone.0196283

Casalino, L., Comes, S., Lambazzi, G., De Stefano, B., Filosa, S., De Falco, S., et al. (2011). Control of embryonic stem cell metastability by L-proline catabolism. J. Mol. Cell Biol. 3, 108-122. doi: 10.1093/jmcb/mjr001

Casteels, P., Ampe, C., Jacobs, F., Vaeck, M., and Tempst, P. (1989). Apidaecins: antibacterial peptides from honeybees. $E M B O ~ J .8,2387-2391$. doi: 10.1002/j. 1460-2075.1989.tb08368.x

Cecchini, N. M., Monteoliva, M. I., and Alvarez, M. E. (2011). Proline dehydrogenase contributes to pathogen defense in Arabidopsis. Plant Physiol. 155, 1947-1959. doi: 10.1104/pp.110.167163

Cermola, F., D'aniello, C., Tate, R., De Cesare, D., Martinez-Arias, A., Minchiotti, G., et al. (2021). Gastruloid development competence discriminates different states of pluripotency. Stem Cell Rep. 16, 354-369. doi: 10.1016/j.stemcr.2020. 12.013

Chao, J. R., Knight, K., Engel, A. L., Jankowski, C., Wang, Y., Manson, M. A., et al. (2017). Human retinal pigment epithelial cells prefer proline as a nutrient and transport metabolic intermediates to the retinal side. J. Biol. Chem. 292, 12895-12905. doi: 10.1074/jbc.m117.788422

Charon, J., Manteca, A., and Innis, C. A. (2019). Using the bacterial ribosome as a discovery platform for peptide-based antibiotics. Biochemistry 58, 75-84. doi: 10.1021/acs.biochem.8b00927

Chen, C., and Dickman, M. B. (2005). Proline suppresses apoptosis in the fungal pathogen Colletotrichum trifolii. Proc. Natl. Acad. Sci. U S A. 102, 3459-3464. doi: 10.1073/pnas.0407960102

Chen, S., Yang, X., Yu, M., Wang, Z., Liu, B., Liu, M., et al. (2019). SIRT3 regulates cancer cell proliferation through deacetylation of PYCR1 in proline metabolism. Neoplasia 21, 665-675. doi: 10.1016/j.neo.2019.04.008

Chen, X., Li, J., Sun, H., Li, S., Chen, T., Liu, G., et al. (2017). High-level heterologous production and functional secretion by recombinant Pichia pastoris of the shortest proline-rich antibacterial honeybee peptide Apidaecin. Sci. Rep. 7:14543.

Choudhary, S., Kishore, N., and Hosur, R. V. (2015). Inhibition of insulin fibrillation by osmolytes: mechanistic insights. Sci. Rep. 5:17599.

Choudhary, S., Save, S. N., Kishore, N., and Hosur, R. V. (2016). Synergistic inhibition of protein fibrillation by proline and sorbitol: biophysical investigations. PLoS One 11:e166487. doi: 10.1371/journal.pone.0166487

Chowdhury, T., Mandal, S. M., Dutta, S., and Ghosh, A. K. (2021). Identification of a novel proline-rich antimicrobial protein from the hemolymph of Antheraea mylitta. Arch. Insect. Biochem. Physiol. 106:e21771.

Christgen, S. L., and Becker, D. F. (2019). Role of proline in pathogen and host interactions. Antioxid. Redox. Signal. 30, 683-709. doi: 10.1089/ars.2017.7335

Chyzynska, K., Labun, K., Jones, C., Grellscheid, S. N., and Valen, E. (2021). Deep conservation of ribosome stall sites across RNA processing genes. NAR Genom Bioinform. 3:lqab038.

Clelland, C. L., Read, L. L., Baraldi, A. N., Bart, C. P., Pappas, C. A., Panek, L. J., et al. (2011). Evidence for association of hyperprolinemia with schizophrenia and a measure of clinical outcome. Schizophr. Res. 131, 139-145. doi: 10.1016/ j.schres.2011.05.006

Cociancich, S., Dupont, A., Hegy, G., Lanot, R., Holder, F., Hetru, C., et al. (1994). Novel inducible antibacterial peptides from a hemipteran insect, the sap-sucking bug Pyrrhocoris apterus. Biochem. J. 300(Pt 2), 567-575. doi: 10. 1042/bj3000567

Cohen, S. M., and Nadler, J. V. (1997). Proline-induced potentiation of glutamate transmission. Brain Res. 761, 271-282. doi: 10.1016/s0006-8993(97)00352-1

Comes, S., Gagliardi, M., Laprano, N., Fico, A., Cimmino, A., Palamidessi, A., et al. (2013). L-Proline induces a mesenchymal-like invasive program in embryonic 
stem cells by remodeling H3K9 and H3K36 methylation. Stem Cell Rep. 1, 307-321. doi: 10.1016/j.stemcr.2013.09.001

Costantino, P., Capone, I., Cardarelli, M., De Paolis, A., Mauro, M. L., and Trovato, M. (1994). Bacterial plant oncogenes: the rol genes' saga. Genetica 94, 203-211. doi: $10.1007 / \mathrm{bf} 01443434$

Coulthard, G., Erb, W., and Aggarwal, V. K. (2012). Stereocontrolled organocatalytic synthesis of prostaglandin PGF2alpha in seven steps. Nature 489, 278-281. doi: 10.1038/nature11411

Coutelier, M., Goizet, C., Durr, A., Habarou, F., Morais, S., Dionne-Laporte, A., et al. (2015). Alteration of ornithine metabolism leads to dominant and recessive hereditary spastic paraplegia. Brain 138, 2191-2205.

Crabtree, G. W., Park, A. J., Gordon, J. A., and Gogos, J. A. (2016). Cytosolic accumulation of L-Proline disrupts GABA-Ergic transmission through GAD blockade. Cell Rep. 17, 570-582. doi: 10.1016/j.celrep.2016.09.029

Csonka, L. N., and Hanson, A. D. (1991). Prokaryotic osmoregulation: genetics and physiology. Annu. Rev. Microbiol. 45, 569-606. doi: 10.1146/annurev.mi. 45.100191 .003033

Curi, R., Newsholme, P., Procopio, J., Lagranha, C., Gorjao, R., and Pithon-Curi, T. C. (2007). Glutamine, gene expression, and cell function. Front. Biosci. 12:344-357. doi: $10.2741 / 2068$

Cusan, M., Vegi, N. M., Mulaw, M. A., Bamezai, S., Kaiser, L. M., Deshpande, A. J., et al. (2017). Controlled stem cell amplification by HOXB4 depends on its unique proline-rich region near the $\mathrm{N}$ terminus. Blood 129, 319-323. doi: 10.1182/blood-2016-04-706978

Dabrowa, N., Taxer, S. S., and Howard, D. H. (1976). Germination of Candida albicans induced by proline. Infect. Immun. 13, 830-835. doi: 10.1128/iai.13. $3.830-835.1976$

D'Aniello, C., Cermola, F., Palamidessi, A., Wanderlingh, L. G., Gagliardi, M., Migliaccio, A., et al. (2019a). Collagen Prolyl hydroxylation-dependent metabolic perturbation governs epigenetic remodeling and mesenchymal transition in pluripotent and Cancer cells. Cancer Res. 79, 3235-3250. doi: 10.1158/0008-5472.can-18-2070

D’Aniello, C., Cermola, F., Patriarca, E. J., and Minchiotti, G. (2019b). MetabolicEpigenetic axis in pluripotent state transitions. Epigenomes 3:13. doi: 10.3390/ epigenomes 3030013

D'Aniello, C., Cermola, F., Patriarca, E. J., and Minchiotti, G. (2017). Vitamin C in stem cell biology: impact on extracellular matrix homeostasis and epigenetics. Stem Cells Int. 2017:8936156.

D’Aniello, C., Fico, A., Casalino, L., Guardiola, O., Di Napoli, G., Cermola, F., et al. (2015). A novel autoregulatory loop between the Gcn2-Atf4 pathway and (L)Proline [corrected] metabolism controls stem cell identity. Cell Death Differ. 22, 1094-1105. doi: 10.1038/cdd.2015.24

D’Aniello, C., Habibi, E., Cermola, F., Paris, D., Russo, F., Fiorenzano, A., et al. (2016). Vitamin C and 1-Proline antagonistic effects capture alternative states in the pluripotency continuum. Stem Cell Rep. 8, 1-10. doi: 10.1016/j.stemcr. 2016.11.011

D'Aniello, C., Patriarca, E. J., Phang, J. M., and Minchiotti, G. (2020). Proline metabolism in tumor growth and metastatic progression. Front. Oncol. 10:776. doi: $10.3389 /$ fonc. 2020.00776

de Barsy, A. M., Moens, E., and Dierckx, L. (1968). Dwarfism, oligophrenia and degeneration of the elastic tissue in skin and cornea. a new syndrome?. Helv. Paediatr. Acta 23, 305-313.

Deng, Y., Zheng, X., Zhang, Y., Xu, M., Ye, C., Lin, M., et al. (2020). High SPRR1A expression is associated with poor survival in patients with colon cancer. Oncol. Lett. 19, 3417-3424.

Desbois-Mouthon, C., Cadoret, A., Blivet-Van Eggelpoel, M. J., Bertrand, F., Cherqui, G., Perret, C., et al. (2001). Insulin and IGF-1 stimulate the beta-catenin pathway through two signalling cascades involving GSK-3beta inhibition and Ras activation. Oncogene 20, 252-259. doi: 10.1038/sj.onc. 1204064

Ding, J., Kuo, M. L., Su, L., Xue, L., Luh, F., Zhang, H., et al. (2017). Human mitochondrial pyrroline-5-carboxylate reductase 1 promotes invasiveness and impacts survival in breast cancers. Carcinogenesis 38, 519-531. doi: 10.1093/ carcin/bgx022

Ding, Z., Ericksen, R. E., Lee, Q. Y., and Han, W. (2021). Reprogramming of mitochondrial proline metabolism promotes liver tumorigenesis. Amino Acids. Online ahead of print.
Disease, G. B. D., Injury, I., and Prevalence, C. (2017). Global, regional, and national incidence, prevalence, and years lived with disability for 328 diseases and injuries for 195 countries, 1990-2016: a systematic analysis for the Global Burden of Disease Study 2016. Lancet 390, 1211-1259.

Doerfel, L. K., Wohlgemuth, I., Kothe, C., Peske, F., Urlaub, H., and Rodnina, M. V. (2013). EF-P is essential for rapid synthesis of proteins containing consecutive proline residues. Science 339, 85-88. doi: 10.1126/science.1229017

Dolashka, P., Moshtanska, V., Borisova, V., Dolashki, A., Stevanovic, S., Dimanov, T., et al. (2011). Antimicrobial proline-rich peptides from the hemolymph of marine snail Rapana venosa. Peptides 32, 1477-1483. doi: 10.1016/j.peptides. 2011.05.001

Dolezelova, E., Kunzova, M., Dejung, M., Levin, M., Panicucci, B., Regnault, C., et al. (2020). Cell-based and multi-omics profiling reveals dynamic metabolic repurposing of mitochondria to drive developmental progression of Trypanosoma brucei. PLoS Biol. 18:e3000741. doi: 10.1371/journal.pbio. 3000741

Donald, S. P., Sun, X. Y., Hu, C. A., Yu, J., Mei, J. M., Valle, D., et al. (2001). Proline oxidase, encoded by p53-induced gene-6, catalyzes the generation of proline-dependent reactive oxygen species. Cancer Res. 61, 1810-1815.

Dong, X., Chang, Y., Zheng, R., Wang, X., Yan, X., and Ma, X. F. (2021). Phytoremediation of cadmium contaminated soil: impacts on morphological traits. proline content and stomata parameters of sweet sorghum seedlings. Bull. Environ. Contam. Toxicol. 106, 528-535. doi: 10.1007/s00128-021-03125-7

Du, J., Zhu, S., Lim, R. R., and Chao, J. R. (2021). Proline metabolism and transport in retinal health and disease. Amino Acids. Online ahead of print.

Dubey, S., Gupta, A., Khare, A., Jain, G., Bose, S., and Rani, V. (2018). Longand short-term protective responses of rice seedling to combat $\mathrm{Cr}(\mathrm{VI})$ toxicity. Environ. Sci. Pollut. Res. Int. 25, 36163-36172. doi: 10.1007/s11356-018-3422-z

Dufourc, E. J. (2021). Wine tannins, saliva proteins and membrane lipids. Biochim. Biophys. Acta Biomembr. 1863:183670. doi: 10.1016/j.bbamem.2021.183670

Elia, I., Broekaert, D., Christen, S., Boon, R., Radaelli, E., Orth, M. F., et al. (2017). Proline metabolism supports metastasis formation and could be inhibited to selectively target metastasizing cancer cells. Nat. Commun. 8:15267.

Elnagdi, N. M., and Al-Hokbany, N. S. (2012). Organocatalysis in synthesis: L-proline as an enantioselective catalyst in the synthesis of pyrans and thiopyrans. Molecules 17, 4300-4312. doi: 10.3390/molecules 17044300

Ensenat, D., Hassan, S., Reyna, S. V., Schafer, A. I., and Durante, W. (2001). Transforming growth factor-beta 1 stimulates vascular smooth muscle cell L-proline transport by inducing system a amino acid transporter 2 (SAT2) gene expression. Biochem. J. 360, 507-512. doi: 10.1042/bj3600507

Esteban, M. A., Wang, T., Qin, B., Yang, J., Qin, D., Cai, J., et al. (2010). Vitamin C enhances the generation of mouse and human induced pluripotent stem cells. Cell Stem Cell 6, 71-79.

Fabro, G., Kovacs, I., Pavet, V., Szabados, L., and Alvarez, M. E. (2004). Proline accumulation and AtP5CS2 gene activation are induced by plant-pathogen incompatible interactions in Arabidopsis. Mol. Plant Microbe Interact. 17, 343-350. doi: 10.1094/mpmi.2004.17.4.343

Faundes, V., Jennings, M. D., Crilly, S., Legraie, S., Withers, S. E., Cuvertino, S., et al. (2021). Impaired eIF5A function causes a mendelian disorder that is partially rescued in model systems by spermidine. Nat. Commun. 12:833.

Ferreira, A. G., Scherer, E. B., Da Cunha, A. A., Manfredini, V., Biancini, G. B., Vanzin, C. S., et al. (2014). Hyperprolinemia induces DNA, protein and lipid damage in blood of rats: antioxidant protection. Int. J. Biochem. Cell Biol. 54, 20-25. doi: 10.1016/j.biocel.2014.05.027

Fischer, B., Callewaert, B., Schroter, P., Coucke, P. J., Schlack, C., Ott, C. E., et al. (2014). Severe congenital cutis laxa with cardiovascular manifestations due to homozygous deletions in ALDH18A1. Mol. Genet. Metab. 112, 310-316. doi: 10.1016/j.ymgme.2014.05.003

Fischer-Zirnsak, B., Escande-Beillard, N., Ganesh, J., Tan, Y. X., Al Bughaili, M., Lin, A. E., et al. (2015). Recurrent de novo mutations affecting residue Arg138 of Pyrroline-5-Carboxylate synthase cause a progeroid form of autosomaldominant cutis laxa. Am. J. Hum. Genet. 97, 483-492. doi: 10.1016/j.ajhg.2015. 08.001

Florin, T., Maracci, C., Graf, M., Karki, P., Klepacki, D., Berninghausen, O., et al. (2017). An antimicrobial peptide that inhibits translation by trapping release factors on the ribosome. Nat. Struct. Mol. Biol. 24, 752-757. doi: 10.1038/nsmb. 3439 
Forlani, G., Sabbioni, G., Ragno, D., Petrollino, D., and Borgatti, M. (2021). Phenylsubstituted aminomethylene-bisphosphonates inhibit human $\mathrm{P} 5 \mathrm{C}$ reductase and show antiproliferative activity against proline-hyperproducing tumour cells. J. Enzyme. Inhib. Med. Chem. 36, 1248-1257. doi: 10.1080/14756366.2021. 1919890

Francisco, S. M., and Tierney, M. L. (1990). Isolation and characterization of a proline-rich cell wall protein from soybean seedlings. Plant Physiol. 94, 1897-1902. doi: 10.1104/pp.94.4.1897

Freimark, D., Sehl, C., Weber, C., Hudel, K., Czermak, P., Hofmann, N., et al. (2011). Systematic parameter optimization of a Me(2)SO- and serum-free cryopreservation protocol for human mesenchymal stem cells. Cryobiology 63, 67-75. doi: 10.1016/j.cryobiol.2011.05.002

Fremeau, R. T. Jr., Caron, M. G., and Blakely, R. D. (1992). Molecular cloning and expression of a high affinity L-proline transporter expressed in putative glutamatergic pathways of rat brain. Neuron 8, 915-926. doi: 10.1016/08966273(92)90206-s

Gaccioli, F., Huang, C. C., Wang, C., Bevilacqua, E., Franchi-Gazzola, R., Gazzola, G. C., et al. (2006). Amino acid starvation induces the SNAT2 neutral amino acid transporter by a mechanism that involves eukaryotic initiation factor 2alpha phosphorylation and cap-independent translation. J. Biol. Chem. 281, 17929-17940. doi: 10.1074/jbc.m600341200

Gagnon, M. G., Roy, R. N., Lomakin, I. B., Florin, T., Mankin, A. S., and Steitz, T. A. (2016). Structures of proline-rich peptides bound to the ribosome reveal a common mechanism of protein synthesis inhibition. Nucleic Acids Res. 44, 2439-2450. doi: 10.1093/nar/gkw018

Gennaro, R., Skerlavaj, B., and Romeo, D. (1989). Purification, composition, and activity of two bactenecins, antibacterial peptides of bovine neutrophils. Infect. Immun. 57, 3142-3146. doi: 10.1128/iai.57.10.3142-3146.1989

Gennaro, R., Zanetti, M., Benincasa, M., Podda, E., and Miani, M. (2002). Pro-rich antimicrobial peptides from animals: structure, biological functions and mechanism of action. Curr. Pharm. Des. 8, 763-778. doi: 10.2174/ 1381612023395394

Geraghty, M. T., Vaughn, D., Nicholson, A. J., Lin, W. W., Jimenez-Sanchez, G., Obie, C., et al. (1998). Mutations in the Delta1-pyrroline 5-carboxylate dehydrogenase gene cause type II hyperprolinemia. Hum. Mol. Genet. 7, 14111415. doi: $10.1093 / \mathrm{hmg} / 7.9 .1411$

Gogos, J. A., Santha, M., Takacs, Z., Beck, K. D., Luine, V., Lucas, L. R., et al. (1999). The gene encoding proline dehydrogenase modulates sensorimotor gating in mice. Nat. Genet. 21, 434-439. doi: 10.1038/7777

Goldstrohm, D. A., Pennington, J. E., and Wells, M. A. (2003). The role of hemolymph proline as a nitrogen sink during blood meal digestion by the mosquito Aedes aegypti. J. Insect Physiol. 49, 115-121. doi: 10.1016/s00221910(02)00267-6

Gonen, N., Meller, A., Sabath, N., and Shalgi, R. (2019). Amino acid biosynthesis regulation during endoplasmic reticulum stress is coupled to protein expression demands. iScience 19, 204-213. doi: 10.1016/j.isci.2019.07.022

Graf, M., Huter, P., Maracci, C., Peterek, M., Rodnina, M. V., and Wilson, D. N. (2018). Visualization of translation termination intermediates trapped by the Apidaecin 137 peptide during RF3-mediated recycling of RF1. Nat. Commun. 9:3053.

Graf, M., Mardirossian, M., Nguyen, F., Seefeldt, A. C., Guichard, G., Scocchi, M., et al. (2017). Proline-rich antimicrobial peptides targeting protein synthesis. Nat. Prod. Rep. 34, 702-711. doi: 10.1039/c7np00020k

Graf, M., and Wilson, D. N. (2019). Intracellular antimicrobial peptides targeting the protein synthesis machinery. Adv. Exp. Med. Biol. 1117, 73-89. doi: 10. 1007/978-981-13-3588-4_6

Greene, M. L., Lietman, P. S., Rosenberg, L. E., and Seegmiller, J. E. (1973). Familial hyperglycinuria. New defect in renal tubular transport of glycine and imino acids. Am. J. Med. 54, 265-271.

Guan, J., and Gluckman, P. D. (2009). IGF-1 derived small neuropeptides and analogues: a novel strategy for the development of pharmaceuticals for neurological conditions. Br. J. Pharmacol. 157, 881-891. doi: 10.1111/j.14765381.2009.00256.x

Gueguen, Y., Bernard, R., Julie, F., Paulina, S., Delphine, D. G., Franck, V., et al. (2009). Oyster hemocytes express a proline-rich peptide displaying synergistic antimicrobial activity with a defensin. Mol. Immunol. 46, 516-522. doi: 10.1016/ j.molimm.2008.07.021
Guernsey, D. L., Jiang, H., Evans, S. C., Ferguson, M., Matsuoka, M., Nightingale, M., et al. (2009). Mutation in pyrroline-5-carboxylate reductase 1 gene in families with cutis laxa type 2. Am. J. Hum. Genet. 85, 120-129. doi: 10.1016/ j.ajhg.2009.06.008

Guo, L., Cui, C., Wang, J., Yuan, J., Yang, Q., Zhang, P., et al. (2020). PINCH1 regulates mitochondrial dynamics to promote proline synthesis and tumor growth. Nat. Commun. 11:4913.

Guo, L., Cui, C., Zhang, K., Wang, J., Wang, Y., Lu, Y., et al. (2019). Kindlin-2 links mechano-environment to proline synthesis and tumor growth. Nat. Commun. 10:845.

Gutierrez, E., Shin, B. S., Woolstenhulme, C. J., Kim, J. R., Saini, P., Buskirk, A. R., et al. (2013). eIF5A promotes translation of polyproline motifs. Mol. Cell 51, 35-45. doi: 10.1016/j.molcel.2013.04.021

Haindrich, A. C., Ernst, V., Naguleswaran, A., Oliveres, Q. F., Roditi, I., and Rentsch, D. (2021). Nutrient availability regulates proline/alanine transporters in Trypanosoma brucei. J. Biol. Chem. 296:100566. doi: 10.1016/j.jbc.2021. 100566

Han, J., Back, S. H., Hur, J., Lin, Y. H., Gildersleeve, R., Shan, J., et al. (2013). ERstress-induced transcriptional regulation increases protein synthesis leading to cell death. Nat. Cell Biol. 15, 481-490. doi: 10.1038/ncb2738

Handa, S., Bressan, R. A., Handa, A. K., Carpita, N. C., and Hasegawa, P. M. (1983). Solutes contributing to osmotic adjustment in cultured plant cells adapted to water stress. Plant Physiol. 73, 834-843. doi: 10.1104/pp.73.3.834

Haudecoeur, E., Planamente, S., Cirou, A., Tannieres, M., Shelp, B. J., Morera, S., et al. (2009). Proline antagonizes GABA-induced quenching of quorum-sensing in Agrobacterium tumefaciens. Proc. Natl. Acad. Sci. U S A. 106, 14587-14592. doi: 10.1073/pnas.0808005106

Hayat, S., Hayat, Q., Alyemeni, M. N., Wani, A. S., Pichtel, J., and Ahmad, A. (2012). Role of proline under changing environments: a review. Plant Signal. Behav. 7, 1456-1466. doi: 10.4161/psb.21949

Hayward, D. C., Delaney, S. J., Campbell, H. D., Ghysen, A., Benzer, S., Kasprzak, A. B., et al. (1993). The sluggish-A gene of Drosophila melanogaster is expressed in the nervous system and encodes proline oxidase, a mitochondrial enzyme involved in glutamate biosynthesis. Proc. Natl. Acad. Sci. U S A. 90, 2979-2983. doi: 10.1073/pnas.90.7.2979

He, F., and DiMario, P. J. (2011). Drosophila delta-1-pyrroline-5-carboxylate dehydrogenase $(\mathrm{P} 5 \mathrm{CDh})$ is required for proline breakdown and mitochondrial integrity-Establishing a fly model for human type II hyperprolinemia. Mitochondrion 11, 397-404. doi: 10.1016/j.mito.2010.12.001

He, W., Li, P., and Wu, G. (2021). Amino acid nutrition and metabolism in chickens. Adv. Exp. Med. Biol. 1285, 109-131. doi: 10.1007/978-3-030-544 62-1_7

Heljasvaara, R., Aikio, M., Ruotsalainen, H., and Pihlajaniemi, T. (2017). Collagen XVIII in tissue homeostasis and dysregulation - lessons learned from model organisms and human patients. Matrix Biol. 57-58, 55-75. doi: 10.1016/j. matbio.2016.10.002

Hewitt, S. N., Dranow, D. M., Horst, B. G., Abendroth, J. A., Forte, B., Hallyburton, I., et al. (2017). Biochemical and structural characterization of selective allosteric inhibitors of the plasmodium falciparum drug target, Prolyl-tRNAsynthetase. ACS Infect. Dis. 3, 34-44.

Hnilickova, H., Kraus, K., Vachova, P., and Hnilicka, F. (2021). Salinity stress affects photosynthesis, malondialdehyde formation, and proline content in Portulaca oleracea L. Plants (Basel) 10:845. doi: 10.3390/plants10050845

Hoffmann, E. K., Lambert, I. H., and Pedersen, S. F. (2009). Physiology of cell volume regulation in vertebrates. Physiol. Rev. 89, 193-277. doi: 10.1152/ physrev.00037.2007

Hung, J. J., Dear, B. J., Dinin, A. K., Borwankar, A. U., Mehta, S. K., Truskett, T. T., et al. (2018). Improving viscosity and stability of a highly concentrated monoclonal antibody solution with concentrated proline. Pharm. Res. 35:133.

Ignatova, Z., and Gierasch, L. M. (2006). Inhibition of protein aggregation in vitro and in vivo by a natural osmoprotectant. Proc. Natl. Acad. Sci. U S A. 103, 13357-13361. doi: 10.1073/pnas.0603772103

Islam, M. M., Hoque, M. A., Okuma, E., Banu, M. N., Shimoishi, Y., Nakamura, Y., et al. (2009). Exogenous proline and glycinebetaine increase antioxidant enzyme activities and confer tolerance to cadmium stress in cultured tobacco cells. J. Plant Physiol. 166, 1587-1597. doi: 10.1016/j.jplph.2009. 04.002 
Jacquet, H., Berthelot, J., Bonnemains, C., Simard, G., Saugier-Veber, P., Raux, G., et al. (2003). The severe form of type I hyperprolinaemia results from homozygous inactivation of the PRODH gene. J. Med. Genet. 40:e7.

Jacquet, H., Demily, C., Houy, E., Hecketsweiler, B., Bou, J., Raux, G., et al. (2005). Hyperprolinemia is a risk factor for schizoaffective disorder. Mol. Psychiatry 10, 479-485. doi: 10.1038/sj.mp.4001597

Jacquet, H., Raux, G., Thibaut, F., Hecketsweiler, B., Houy, E., Demilly, C., et al. (2002). PRODH mutations and hyperprolinemia in a subset of schizophrenic patients. Hum. Mol. Genet. 11, 2243-2249. doi: 10.1093/hmg/11.19.2243

Jaksic, T., Wagner, D. A., and Young, V. R. (1990). Plasma proline kinetics and concentrations in young men in response to dietary proline deprivation. Am. J. Clin. Nutr. 52, 307-312. doi: 10.1093/ajcn/52.2.307

Jones, B., Balasubramaniam, M., Lebowitz, J. J., Taylor, A., Villalta, F., Khoshbouei, H., et al. (2021). Activation of proline biosynthesis is critical to maintain glutamate homeostasis during acute methamphetamine exposure. Sci. Rep. 11:1422.

Jukkola, A., Kauppila, S., Risteli, L., Vuopala, K., Risteli, J., Leisti, J., et al. (1998). New lethal disease involving type I and III collagen defect resembling geroderma osteodysplastica, De Barsy syndrome, and Ehlers-Danlos syndrome IV. J. Med. Genet. 35, 513-518. doi: 10.1136/jmg.35.6.513

Kanwar, Y. S., Krakower, C. A., Manaligod, J. R., Justice, P., and Wong, P. W. (1975). Biochemical, morphological and hybrid studies in hyperprolinemic mice. Biomedicine 22, 209-216.

Karayiorgou, M., Morris, M. A., Morrow, B., Shprintzen, R. J., Goldberg, R., Borrow, J., et al. (1995). Schizophrenia susceptibility associated with interstitial deletions of chromosome 22q11. Proc. Natl. Acad. Sci. U S A. 92, 7612-7616. doi: $10.1073 /$ pnas.92.17.7612

Kardos, G. R., Gowda, R., Dinavahi, S. S., Kimball, S., and Robertson, G. P. (2020). Salubrinal in combination with 4E1RCat synergistically impairs melanoma development by disrupting the protein synthetic machinery. Front. Oncol. 10:834. doi: 10.3389/fonc. 2020.00834

Kardos, G. R., Wastyk, H. C., and Robertson, G. P. (2015). Disruption of proline synthesis in melanoma inhibits protein production mediated by the GCN2 pathway. Mol. Cancer Res. 13, 1408-1420. doi: 10.1158/1541-7786.mcr-150048

Kaur, R., Paria, P., Saini, A. G., Suthar, R., Bhatia, V., and Attri, S. V. (2021). Metabolic epilepsy in hyperprolinemia type II due to a novel nonsense ALDH4A1 gene variant. Metab. Brain Dis. 36, 1413-1417. doi: 10.1007/s11011021-00757-W

Khan, S. H., Ahmad, N., Ahmad, F., and Kumar, R. (2010). Naturally occurring organic osmolytes: from cell physiology to disease prevention. IUBMB Life 62, 891-895. doi: 10.1002/iub.406

Kieliszewski, M. J., and Lamport, D. T. (1994). Extensin: repetitive motifs, functional sites, post-translational codes, and phylogeny. Plant J. 5, 157-172. doi: 10.1046/j.1365-313x.1994.05020157.x

Killiny, N., Hijaz, F., El-Shesheny, I., Alfaress, S., Jones, S. E., and Rogers, M. E. (2017). Metabolomic analyses of the haemolymph of the Asian citrus psyllid Diaphorina citri, the vector of huanglongbing. Physiol. Entomol. 42, 134-145. doi: $10.1111 /$ phen. 12183

Kleta, R., Romeo, E., Ristic, Z., Ohura, T., Stuart, C., Arcos-Burgos, M., et al. (2004). Mutations in SLC6A19, encoding B0AT1, cause Hartnup disorder. Nat. Genet. 36, 999-1002. doi: 10.1038/ng1405

Knappe, D., Piantavigna, S., Hansen, A., Mechler, A., Binas, A., Nolte, O., et al. (2010). Oncocin (VDKPPYLPRPRPPRRIYNR-NH2): a novel antibacterial peptide optimized against gram-negative human pathogens. J. Med. Chem. 53, 5240-5247. doi: 10.1021/jm100378b

Komatsu, T., Kobayashi, K., Morimoto, Y., Helmerhorst, E., Oppenheim, F., and Chang-Il Lee, M. (2020). Direct evaluation of the antioxidant properties of salivary proline-rich proteins. J. Clin. Biochem. Nutr. 67, 131-136. doi: 10.3164/ jcbn.19-75

Kostal, V., Korbelova, J., Poupardin, R., Moos, M., and Simek, P. (2016). Arginine and proline applied as food additives stimulate high freeze tolerance in larvae of Drosophila melanogaster. J. Exp. Biol. 219, 2358-2367. doi: 10.1242/jeb.1 42158

Kostal, V., Simek, P., Zahradnickova, H., Cimlova, J., and Stetina, T. (2012). Conversion of the chill susceptible fruit fly larva (Drosophila melanogaster) to a freeze tolerant organism. Proc. Natl. Acad. Sci. U S A. 109, 3270-3274. doi: $10.1073 /$ pnas.1119986109
Kostal, V., Zahradnickova, H., and Simek, P. (2011). Hyperprolinemic larvae of the drosophilid fly, Chymomyza costata, survive cryopreservation in liquid nitrogen. Proc. Natl. Acad. Sci. U S A. 108, 13041-13046. doi: 10.1073/pnas. 1107060108

Kragol, G., Hoffmann, R., Chattergoon, M. A., Lovas, S., Cudic, M., Bulet, P., et al. (2002). Identification of crucial residues for the antibacterial activity of the proline-rich peptide, pyrrhocoricin. Eur. J. Biochem. 269, 4226-4237. doi: 10.1046/j.1432-1033.2002.03119.x

Kretz, R., Bozorgmehr, B., Kariminejad, M. H., Rohrbach, M., Hausser, I., Baumer, A., et al. (2011). Defect in proline synthesis: pyrroline-5-carboxylate reductase 1 deficiency leads to a complex clinical phenotype with collagen and elastin abnormalities. J. Inherit. Metab. Dis. 34, 731-739. doi: 10.1007/s10545-0119319-3

Krishnan, N., Dickman, M. B., and Becker, D. F. (2008). Proline modulates the intracellular redox environment and protects mammalian cells against oxidative stress. Free Radic. Biol. Med. 44, 671-681. doi: 10.1016/j. freeradbiomed.2007.10.054

Krizsan, A., Prahl, C., Goldbach, T., Knappe, D., and Hoffmann, R. (2015). Short Proline-Rich antimicrobial peptides inhibit either the bacterial $70 \mathrm{~S}$ ribosome or the assembly of its large 50 S subunit. Chembiochem 16, 2304-2308. doi: 10.1002/cbic. 201500375

Krokowski, D., Guan, B. J., Wu, J., Zheng, Y., Pattabiraman, P. P., Jobava, R., et al. (2017). GADD34 function in protein trafficking promotes adaptation to hyperosmotic stress in human corneal cells. Cell Rep. 21, 2895-2910. doi: 10.1016/j.celrep.2017.11.027

Lahiri, V., Hawkins, W. D., and Klionsky, D. J. (2019). Watch what you (Self-) eat: autophagic mechanisms that modulate metabolism. Cell Metab. 29, 803-826. doi: 10.1016/j.cmet.2019.03.003

Lamport, D. T., Kieliszewski, M. J., Chen, Y., and Cannon, M. C. (2011). Role of the extensin superfamily in primary cell wall architecture. Plant Physiol. 156, 11-19. doi: 10.1104/pp.110.169011

Law, R. O. (1991). Amino acids as volume-regulatory osmolytes in mammalian cells. Comp. Biochem. Physiol. A Comp. Physiol. 99, 263-277. doi: 10.1016/03009629(91)90001-s

Lehmann, S., Funck, D., Szabados, L., and Rentsch, D. (2010). Proline metabolism and transport in plant development. Amino Acids 39, 949-962. doi: 10.1007/ s00726-010-0525-3

Lenci, E., Angeli, A., Calugi, L., Innocenti, R., Carta, F., Supuran, C. T., et al. (2021). Multitargeting application of proline-derived peptidomimetics addressing cancer-related human matrix metalloproteinase 9 and carbonic anhydrase II. Eur. J. Med. Chem. 214:113260. doi: 10.1016/j.ejmech.2021.113260

Levashina, E. A., Ohresser, S., Bulet, P., Reichhart, J. M., Hetru, C., and Hoffmann, J. A. (1995). Metchnikowin, a novel immune-inducible proline-rich peptide from Drosophila with antibacterial and antifungal properties. Eur. J. Biochem. 233, 694-700. doi: 10.1111/j.1432-1033.1995.694_2.x

Levine, M. (1959). A new method for isolation of hydroxy-L-proline and L-proline from gelatin. J. Biol. Chem. 234, 1731-1732. doi: 10.1016/s0021-9258(18) 69916-8

Li, N., Yu, J., Yang, F., Shao, Y., Wu, S., Liu, B., et al. (2021). L-Proline: an effective agent for frozen and post-thawed donkey semen storage. J. Equine Vet. Sci. 101:103393. doi: 10.1016/j.jevs.2021.103393

Li, P., and Wu, G. (2018). Roles of dietary glycine, proline, and hydroxyproline in collagen synthesis and animal growth. Amino Acids 50, 29-38. doi: 10.1007/ s00726-017-2490-6

Li, W. F., Ma, G. X., and Zhou, X. X. (2006). Apidaecin-type peptides: biodiversity, structure-function relationships and mode of action. Peptides 27, 2350-2359. doi: 10.1016/j.peptides.2006.03.016

Liang, G., Taranova, O., Xia, K., and Zhang, Y. (2010). Butyrate promotes induced pluripotent stem cell generation. J. Biol. Chem. 285, 25516-25521. doi: 10.1074/ jbc.m110.142059

Liang, X., Dickman, M. B., and Becker, D. F. (2014). Proline biosynthesis is required for endoplasmic reticulum stress tolerance in Saccharomyces cerevisiae. J. Biol. Chem. 289, 27794-27806. doi: 10.1074/jbc.m114.562827

Liang, X., Zhang, L., Natarajan, S. K., and Becker, D. F. (2013). Proline mechanisms of stress survival. Antioxid. Redox. Signal. 19, 998-1011. doi: 10.1089/ars.2012. 5074

Lin, D. S., Chang, J. H., Liu, H. L., Wei, C. H., Yeung, C. Y., Ho, C. S., et al. (2011). Compound heterozygous mutations in PYCR1 further expand the phenotypic 
spectrum of De Barsy syndrome. Am. J. Med. Genet. A 155A, 3095-3099. doi: 10.1002/ajmg.a.34326

Lin, H. V., Efanov, A. M., Fang, X., Beavers, L. S., Wang, X., Wang, J., et al. (2016). GPR142 controls tryptophan-induced insulin and incretin hormone secretion to improve glucose metabolism. PLoS One 11:e0157298. doi: 10.1371/journal. pone. 0157298

Linde, C. M., Hoffner, S. E., Refai, E., and Andersson, M. (2001). . In vitro activity of PR-39, a proline-arginine-rich peptide, against susceptible and multi-drugresistant Mycobacterium tuberculosis. J. Antimicrob. Chemother 47, 575-580. doi: $10.1093 / \mathrm{jac} / 47.5 .575$

Linder, S., Castanos-Velez, E., Von Rosen, A., and Biberfeld, P. (2001). Immunohistochemical expression of extracellular matrix proteins and adhesion molecules in pancreatic carcinoma. Hepatogastroenterology 48, 1321-1327.

List, B., and Castello, C. (2001). A novel proline-catalyzed three-component reaction of ketones, aldehydes, and Meldrum's acid. Synlett 1687-1689. doi: 10.1055/s-2001- 18095

List, B., Hoang, L., and Martin, H. J. (2004). New mechanistic studies on the proline-catalyzed aldol reaction. Proc. Natl. Acad. Sci. U S A. 101, 5839-5842. doi: $10.1073 /$ pnas.0307979101

Liu, H., Heath, S. C., Sobin, C., Roos, J. L., Galke, B. L., Blundell, M. L., et al. (2002). Genetic variation at the 22q11 PRODH2/DGCR6 locus presents an unusual pattern and increases susceptibility to schizophrenia. Proc. Natl. Acad. Sci. U S A. 99, 3717-3722. doi: 10.1073/pnas.042700699

Liu, N., Dai, Z., Zhang, Y., Chen, J., Yang, Y., Wu, G., et al. (2019). Maternal L-proline supplementation enhances fetal survival, placental development, and nutrient transport in micedagger. Biol. Reprod. 100, 1073-1081. doi: 10.1093/ biolre/ioy 240

Liu, N., Yang, Y., Si, X., Jia, H., Zhang, Y., Jiang, D., et al. (2021). L-Proline activates mammalian target of rapamycin complex 1 and modulates redox environment in porcine trophectoderm cells. Biomolecules 11:742. doi: 10.3390/ biom 11050742

Liu, W., Glunde, K., Bhujwalla, Z. M., Raman, V., Sharma, A., and Phang, J. M. (2012a). Proline oxidase promotes tumor cell survival in hypoxic tumor microenvironments. Cancer Res. 72, 3677-3686. doi: 10.1158/0008-5472.can12-0080

Liu, W., Le, A., Hancock, C., Lane, A. N., Dang, C. V., Fan, T. W., et al. (2012b). Reprogramming of proline and glutamine metabolism contributes to the proliferative and metabolic responses regulated by oncogenic transcription factor c-MYC. Proc. Natl. Acad. Sci. U S A. 109, 8983-8988. doi: 10.1073/pnas. 1203244109

Liu, Y., Borchert, G. L., Donald, S. P., Diwan, B. A., Anver, M., and Phang, J. M. (2009). Proline oxidase functions as a mitochondrial tumor suppressor in human cancers. Cancer Res. 69, 6414-6422. doi: 10.1158/0008-5472.can-091223

Liu, Y., Borchert, G. L., Surazynski, A., Hu, C. A., and Phang, J. M. (2006). Proline oxidase activates both intrinsic and extrinsic pathways for apoptosis: the role of ROS/superoxides, NFAT and MEK/ERK signaling. Oncogene 25, 5640-5647. doi: 10.1038/sj.onc. 1209564

Liu, Y., Borchert, G. L., Surazynski, A., and Phang, J. M. (2008). Proline oxidase, a p53-induced gene, targets COX-2/PGE2 signaling to induce apoptosis and inhibit tumor growth in colorectal cancers. Oncogene 27, 6729-6737. doi: 10.1038/onc. 2008.322

Loayza-Puch, F., Rooijers, K., Buil, L. C., Zijlstra, J., Oude Vrielink, J. F., Lopes, R., et al. (2016). Tumour-specific proline vulnerability uncovered by differential ribosome codon reading. Nature 530, 490-494. doi: 10.1038/nature16982

Loh, Y. H., Zhang, W., Chen, X., George, J., and Ng, H. H. (2007). Jmjd1a and Jmjd2c histone H3 Lys 9 demethylases regulate self-renewal in embryonic stem cells. Genes Dev. 21, 2545-2557. doi: 10.1101/gad.1588207

Lorenzo-Pouso, A. I., Perez-Sayans, M., Bravo, S. B., Lopez-Jornet, P., GarciaVence, M., Alonso-Sampedro, M., et al. (2018). Protein-Based salivary profiles as novel biomarkers for oral diseases. Dis. Markers 2018:6141845.

Lu, F., Liu, Y., Jiang, L., Yamaguchi, S., and Zhang, Y. (2014). Role of tet proteins in enhancer activity and telomere elongation. Genes Dev. 28, 2103-2119. doi: 10.1101/gad.248005.114

Luo, Y., Luo, Y., Chang, J., Xiao, Z., and Zhou, B. (2020). Identification of candidate biomarkers and pathways associated with psoriasis using bioinformatics analysis. Hereditas 157:30.
Mackintosh, J. A., Veal, D. A., Beattie, A. J., and Gooley, A. A. (1998). Isolation from an ant Myrmecia gulosa of two inducible O-glycosylated proline-rich antibacterial peptides. J. Biol. Chem. 273, 6139-6143. doi: 10.1074/jbc.273.11. 6139

Magini, P., Marco-Marin, C., Escamilla-Honrubia, J. M., Martinelli, D., DionisiVici, C., Faravelli, F., et al. (2019). P5CS expression study in a new family with ALDH18A1-associated hereditary spastic paraplegia SPG9. Ann. Clin. Transl. Neurol. 6, 1533-1540.

Majesky, M. W., Lindner, V., Twardzik, D. R., Schwartz, S. M., and Reidy, M. A. (1991). Production of transforming growth factor beta 1 during repair of arterial injury. J. Clin. Invest. 88, 904-910. doi: 10.1172/jci115393

Malandro, M. S., and Kilberg, M. S. (1996). Molecular biology of mammalian amino acid transporters. Annu. Rev. Biochem. 65, 305-336. doi: 10.1146/ annurev.bi.65.070196.001513

Mali, P., Chou, B. K., Yen, J., Ye, Z., Zou, J., Dowey, S., et al. (2010). Butyrate greatly enhances derivation of human induced pluripotent stem cells by promoting epigenetic remodeling and the expression of pluripotency-associated genes. Stem Cells 28, 713-720. doi: 10.1002/stem.402

Mandal, A., Mandal, S., and Park, M. H. (2014). Genome-wide analyses and functional classification of proline repeat-rich proteins: potential role of eIF5A in eukaryotic evolution. PLoS One 9:e111800. doi: 10.1371/journal.pone. 0111800

Mantilla, B. S., Marchese, L., Casas-Sanchez, A., Dyer, N. A., Ejeh, N., Biran, M., et al. (2017). Proline metabolism is essential for trypanosoma Brucei brucei survival in the tsetse vector. PLoS Pathog 13:e1006158. doi: 10.1371/journal. ppat. 1006158

Mantilla, B. S., Paes, L. S., Pral, E. M., Martil, D. E., Thiemann, O. H., FernandezSilva, P., et al. (2015). Role of Delta1-pyrroline-5-carboxylate dehydrogenase supports mitochondrial metabolism and host-cell invasion of Trypanosoma cruzi. J. Biol. Chem. 290, 7767-7790. doi: 10.1074/jbc.m114.574525

Mardirossian, M., Barriere, Q., Timchenko, T., Muller, C., Pacor, S., Mergaert, P., et al. (2018a). Fragments of the non-lytic proline-rich antimicrobial peptide Bac5 kill E. coli cells by inhibiting protein synthesis. Antimicrob Agents Chemother. 62:e00534-18.

Mardirossian, M., Perebaskine, N., Benincasa, M., Gambato, S., Hofmann, S., Huter, P., et al. (2018b). The dolphin proline-rich antimicrobial peptide Tur1A inhibits protein synthesis by targeting the bacterial ribosome. Cell Chem. Biol. 25, 530-539.e7.

Mardirossian, M., Grzela, R., Giglione, C., Meinnel, T., Gennaro, R., Mergaert, P., et al. (2014). The host antimicrobial peptide Bac71-35 binds to bacterial ribosomal proteins and inhibits protein synthesis. Chem. Biol. 21, 1639-1647. doi: 10.1016/j.chembiol.2014.10.009

Martins, R. M., Covarrubias, C., Rojas, R. G., Silber, A. M., and Yoshida, N. (2009). Use of L-proline and ATP production by Trypanosoma cruzi metacyclic forms as requirements for host cell invasion. Infect. Immun. 77, 3023-3032. doi: 10.1128/iai.00138-09

Marvin, K. W., George, M. D., Fujimoto, W., Saunders, N. A., Bernacki, S. H., and Jetten, A. M. (1992). Cornifin, a cross-linked envelope precursor in keratinocytes that is down-regulated by retinoids. Proc. Natl. Acad. Sci. U S A. 89, 11026-11030. doi: 10.1073/pnas.89.22.11026

Mateos, B., Conrad-Billroth, C., Schiavina, M., Beier, A., Kontaxis, G., Konrat, R., et al. (2020). The ambivalent role of proline residues in an intrinsically disordered protein: from disorder promoters to compaction facilitators. J. Mol. Biol. 432, 3093-3111. doi: 10.1016/j.jmb.2019.11.015

Matsumoto, K., Yamazaki, K., Kawakami, S., Miyoshi, D., Ooi, T., Hashimoto, S., et al. (2017). In vivo target exploration of apidaecin based on acquired resistance induced by gene overexpression (ARGO assay). Sci. Rep. 7:12136.

Mattioli, R., Costantino, P., and Trovato, M. (2009). Proline accumulation in plants: not only stress. Plant Signal. Behav. 4, 1016-1018. doi: 10.4161/psb.4. 11.9797

Mattiuzzo, M., Bandiera, A., Gennaro, R., Benincasa, M., Pacor, S., Antcheva, N., et al. (2007). Role of the Escherichia coli SbmA in the antimicrobial activity of proline-rich peptides. Mol. Microbiol. 66, 151-163. doi: 10.1111/j.1365-2958. 2007.05903.x

Mazzalupo, S., Isoe, J., Belloni, V., and Scaraffia, P. Y. (2016). Effective disposal of nitrogen waste in blood-fed Aedes aegypti mosquitoes requires alanine aminotransferase. FASEB J. 30, 111-120. doi: 10.1096/fj.15-277087 
Melis, M., Mastinu, M., Pintus, S., Cabras, T., Crnjar, R., and Tomassini Barbarossa, I. (2021). Differences in salivary proteins as a function of PROP taster status and gender in normal weight and obese subjects. Molecules 26:2244. doi: 10.3390/molecules26082244

Memmott, S. D., Ha, Y. S., and Dickman, M. B. (2002). Proline reverses the abnormal phenotypes of Colletotrichum trifolii associated with expression of endogenous constitutively active Ras. Appl. Environ. Microbiol. 68, 1647-1651. doi: 10.1128/aem.68.4.1647-1651.2002

Messana, I., Cabras, T., Iavarone, F., Manconi, B., Huang, L., Martelli, C., et al. (2015). Chrono-proteomics of human saliva: variations of the salivary proteome during human development. J. Proteome Res. 14, 1666-1677. doi: 10.1021/ pr501270x

Michalkova, V., Benoit, J. B., Weiss, B. L., Attardo, G. M., and Aksoy, S. (2014). Vitamin B6 generated by obligate symbionts is critical for maintaining proline homeostasis and fecundity in tsetse flies. Appl. Environ. Microbiol. 80, 58445853. doi: 10.1128/aem.01150-14

Mishra, A. K., Choi, J., Moon, E., and Baek, K. H. (2018). Tryptophan-Rich and proline-rich antimicrobial peptides. Molecules 23:815. doi: 10.3390/ molecules23040815

Mizushige, T., Nogimura, D., Nagai, A., Mitsuhashi, H., Taga, Y., Kusubata, M., et al. (2019). Ginger-Degraded Collagen hydrolysate exhibits antidepressant activity in mice. J. Nutr. Sci. Vitaminol. (Tokyo) 65, 251-257. doi: 10.3177/jnsv. 65.251

Moloney, J. N., and Cotter, T. G. (2018). ROS signalling in the biology of cancer. Semin. Cell Dev. Biol. 80, 50-64. doi: 10.1016/j.semcdb.2017.05.023

Morgan, A. A., and Rubenstein, E. (2013). Proline: the distribution, frequency, positioning, and common functional roles of proline and polyproline sequences in the human proteome. PLoS One 8:e53785. doi: 10.1371/journal.pone. 0053785

Morris, M. B., Ozsoy, S., Zada, M., Zada, M., Zamfirescu, R. C., Todorova, M. G., et al. (2020). Selected amino acids promote mouse pre-implantation embryo development in a growth factor-like manner. Front. Physiol. 11:140. doi: 10. 3389/fphys.2020.00140

Murray-Stewart, T. R., Woster, P. M., Casero, R. A., and Jr. (2016). Targeting polyamine metabolism for cancer therapy and prevention. Biochem. J. 473, 2937-2953. doi: 10.1042/bcj20160383

Nadler, J. V., Wang, A., and Hakim, A. (1988). Toxicity of L-proline toward rat hippocampal neurons. Brain Res. 456, 168-172. doi: 10.1016/0006-8993(88) 90358-7

Nagaoka, A., Kunii, Y., Hino, M., Izumi, R., Nagashima, C., Takeshima, A., et al. (2020). ALDH4A1 expression levels are elevated in postmortem brains of patients with schizophrenia and are associated with genetic variants in enzymes related to proline metabolism. J. Psychiatr. Res. 123, 119-127. doi: 10.1016/j. jpsychires.2020.02.001

Nagesh, P. K. B., Hatami, E., Chowdhury, P., Kashyap, V. K., Khan, S., Hafeez, B. B., et al. (2018). Tannic acid induces endoplasmic reticulum stressmediated apoptosis in Prostate cancer. Cancers (Basel) 10:68. doi: 10.3390/ cancers 10030068

Nakayama, T., Al-Maawali, A., El-Quessny, M., Rajab, A., Khalil, S., Stoler, J. M., et al. (2015). Mutations in PYCR2, encoding Pyrroline-5-Carboxylate reductase 2, cause microcephaly and hypomyelination. Am. J. Hum. Genet. 96, 709-719. doi: 10.1016/j.ajhg.2015.03.003

Nam, S. Y., Yoou, M. S., Kim, H. M., and Jeong, H. J. (2016). Efficacy of proline in the treatment of menopause. Exp. Biol. Med. (Maywood) 241, 611-619. doi: $10.1177 / 1535370216629011$

Napierala, J. S., Li, Y., Lu, Y., Lin, K., Hauser, L. A., Lynch, D. R., et al. (2017). Comprehensive analysis of gene expression patterns in Friedreich's ataxia fibroblasts by RNA sequencing reveals altered levels of protein synthesis factors and solute carriers. Dis. Model Mech. 10, 1353-1369. doi: 10.1242/dmm.030536

Natarajan, S. K., Zhu, W., Liang, X., Zhang, L., Demers, A. J., Zimmerman, M. C., et al. (2012). Proline dehydrogenase is essential for proline protection against hydrogen peroxide-induced cell death. Free Radic. Biol. Med. 53, 1181-1191. doi: 10.1016/j.freeradbiomed.2012.07.002

Nilsson, R., Jain, M., Madhusudhan, N., Sheppard, N. G., Strittmatter, L., Kampf, C., et al. (2014). Metabolic enzyme expression highlights a key role for MTHFD2 and the mitochondrial folate pathway in cancer. Nat. Commun. $5: 3128$.
Nishida, I., Watanabe, D., and Takagi, H. (2016). Putative mitochondrial alphaketoglutarate-dependent dioxygenase Fmp12 controls utilization of proline as an energy source in Saccharomyces cerevisiae. Microb Cell 3, 522-528. doi: $10.15698 / \mathrm{mic} 2016.10 .535$

Nogimura, D., Mizushige, T., Taga, Y., Nagai, A., Shoji, S., Azuma, N., et al. (2020). Prolyl-hydroxyproline, a collagen-derived dipeptide, enhances hippocampal cell proliferation, which leads to antidepressant-like effects in mice. FASEB J. 34, 5715-5723. doi: 10.1096/fj.201902871r

Ogawa-Ohnishi, M., Matsushita, W., and Matsubayashi, Y. (2013). Identification of three hydroxyproline O-arabinosyltransferases in Arabidopsis thaliana. Nat. Chem. Biol. 9, 726-730. doi: 10.1038/nchembio.1351

Olivares, O., Mayers, J. R., Gouirand, V., Torrence, M. E., Gicquel, T., Borge, L., et al. (2017). Collagen-derived proline promotes pancreatic ductal adenocarcinoma cell survival under nutrient limited conditions. Nat. Commun. 8:16031.

Oscilowska, I., Huynh, T. Y. L., Baszanowska, W., Prokop, I., Surazynski, A., Galli, M., et al. (2021). Proline oxidase silencing inhibits p53-dependent apoptosis in MCF-7 breast cancer cells. Amino Acids. Online ahead of print.

Pangborn, C. A., and Athanasiou, K. A. (2005). Effects of growth factors on meniscal fibrochondrocytes. Tissue Eng. 11, 1141-1148. doi: 10.1089/ten.2005. 11.1141

Panza, E., Escamilla-Honrubia, J. M., Marco-Marin, C., Gougeard, N., De Michele, G., and Morra, V. B. (2016). ALDH18A1 gene mutations cause dominant spastic paraplegia SPG9: loss of function effect and plausibility of a dominant negative mechanism. Brain 139:e3. doi: 10.1093/brain/awv247

Papu, S., Berli, F., Piccoli, P., Paton, D., Ortega Rodriguez, D. R., and Roig, F. A. (2021). Physiological, biochemical, and anatomical responses of Araucaria araucana seedlings to controlled water restriction. Plant Physiol. Biochem. 165, 47-56. doi: 10.1016/j.plaphy.2021.05.005

Patel, S. M., Seravalli, J., Liang, X., Tanner, J. J., and Becker, D. F. (2021). Disease variants of human Delta(1)-pyrroline-5-carboxylate reductase 2 (PYCR2). Arch. Biochem. Biophys. 703:108852. doi: 10.1016/j.abb.2021.108852

Patel, V. K., Srivastava, R., Sharma, A., Srivastava, A. K., Singh, S., Srivastava, A. K., et al. (2018). Halotolerant Exiguobacterium profundum PHM11 tolerate salinity by accumulating L-Proline and fine-tuning gene expression profiles of related metabolic pathways. Front. Microbiol. 9:423. doi: 10.3389/fmicb.2018.0 0423

Paterlini, M., Zakharenko, S. S., Lai, W. S., Qin, J., Zhang, H., Mukai, J., et al. (2005). Transcriptional and behavioral interaction between 22q11.2 orthologs modulates schizophrenia-related phenotypes in mice. Nat. Neurosci. 8, 15861594. doi: $10.1038 / \mathrm{nn} 1562$

Pejam, F., Ardebili, Z. O., Ladan-Moghadam, A., and Danaee, E. (2021). Zinc oxide nanoparticles mediated substantial physiological and molecular changes in tomato. PLoS One 16:e248778. doi: 10.1371/journal.pone.0248778

Pelss, A., Gandhamsetty, N., Smith, J. R., Mailhol, D., Silvi, M., Watson, A., et al. (2018). Re-optimization of the organocatalyzed double aldol domino process to a key enal intermediate and its application to the total synthesis of Delta(1)(2)Prostaglandin J(3). Chemistry 24, 9542-9545. doi: 10.1002/chem.201802498

Pemberton, T. A., Still, B. R., Christensen, E. M., Singh, H., Srivastava, D., and Tanner, J. J. (2012). Proline: mother Nature's cryoprotectant applied to protein crystallography. Acta Crystallogr. D. Biol. Crystallogr. 68, 1010-1018. doi: 10. 1107/s0907444912019580

Phang, J. M. (2019). Proline metabolism in cell regulation and cancer biology: recent advances and hypotheses. Antioxid. Redox. Signal. 30, 635-649. doi: 10.1089/ars.2017.7350

Pines, M., and Spector, I. (2015). Halofuginone - the multifaceted molecule. Molecules 20, 573-594. doi: 10.3390/molecules20010573

Polyak, K., Xia, Y., Zweier, J. L., Kinzler, K. W., and Vogelstein, B. (1997). A model for p53-induced apoptosis. Nature 389, 300-305.

Powers, E. T., Morimoto, R. I., Dillin, A., Kelly, J. W., and Balch, W. E. (2009). Biological and chemical approaches to diseases of proteostasis deficiency. Annu. Rev. Biochem. 78, 959-991. doi: 10.1146/annurev.biochem.052308.11 4844

Prajapati, K. P., Panigrahi, A., Purohit, S., Ansari, M., Dubey, K., Behera, R. K., et al. (2021). Osmoprotectant coated thermostable gold nanoparticles efficiently restrict temperature-induced amyloid aggregation of insulin. J. Phys. Chem. Lett. 12, 1803-1813. doi: 10.1021/acs.jpclett.0c03492 
Psychogios, N., Hau, D. D., Peng, J., Guo, A. C., Mandal, R., Bouatra, S., et al. (2011). The human serum metabolome. PLoS One 6:e16957. doi: 10.1371/ journal.pone.0016957

Pure, E., and Blomberg, R. (2018). Pro-tumorigenic roles of fibroblast activation protein in cancer: back to the basics. Oncogene 37, 4343-4357. doi: 10.1038/ s41388-018-0275-3

Qiao, Y., Cai, H. L., Yang, X., Zang, Y. Y., and Chen, Z. G. (2018). Effects of natural deep eutectic solvents on lactic acid bacteria viability during cryopreservation. Appl. Microbiol. Biotechnol. 102, 5695-5705. doi: 10.1007/s00253-018-8 996-3

Qin, P., Arabacilar, P., Bernard, R. E., Bao, W., Olzinski, A. R., Guo, Y., et al. (2017). Activation of the amino acid response pathway blunts the effects of cardiac stress. J. Am. Heart Assoc. 6:e004453.

Qin, Q., Zhao, L., Liu, Z., Liu, T., Qu, J., Zhang, X., et al. (2020). Bioinspired 1-Proline oligomers for the cryopreservation of oocytes via controlling ice growth. ACS Appl. Mater. Interfaces 12, 18352-18362. doi: 10.1021/acsami. 0c02719

Rance, G. A., and Khlobystov, A. N. (2014). The effects of interactions between proline and carbon nanostructures on organocatalysis in the HajosParrish-Eder-Sauer-Wiechert reaction. Nanoscale 6, 11141-11146. doi: 10.1039/ c4nr04009k

Raux, G., Bumsel, E., Hecketsweiler, B., Van Amelsvoort, T., Zinkstok, J., Manouvrier-Hanu, S., et al. (2007). Involvement of hyperprolinemia in cognitive and psychiatric features of the 22q11 deletion syndrome. Hum. Mol. Genet. 16, 83-91. doi: 10.1093/hmg/ddl443

Reid, M. A., Dai, Z., and Locasale, J. W. (2017). The impact of cellular metabolism on chromatin dynamics and epigenetics. Nat. Cell Biol. 19, 1298-1306. doi: $10.1038 /$ ncb3629

Reversade, B., Escande-Beillard, N., Dimopoulou, A., Fischer, B., Chng, S. C., Li, Y., et al. (2009). Mutations in PYCR1 cause cutis laxa with progeroid features. Nat. Genet. 41, 1016-1021.

Roigaard-Petersen, H., and Sheikh, M. I. (1984). Renal transport of neutral amino acids. Demonstration of $\mathrm{Na}$-independent and $\mathrm{Na}+$-dependent electrogenic uptake of L-proline, hydroxy-L-proline and 5-oxo-L-proline by luminal-membrane vesicles. Biochem. J. 220, 25-33. doi: 10.1042/bj22 00025

Roncevic, T., Cikes-Culic, V., Maravic, A., Capanni, F., Gerdol, M., Pacor, S., et al. (2020). Identification and functional characterization of the astacidin family of proline-rich host defence peptides (PcAst) from the red swamp crayfish (Procambarus clarkii, Girard 1852). Dev. Comp. Immunol. 105:103574. doi: 10.1016/j.dci.2019.103574

Roy, R. N., Lomakin, I. B., Gagnon, M. G., and Steitz, T. A. (2015). The mechanism of inhibition of protein synthesis by the proline-rich peptide oncocin. Nat. Struct. Mol. Biol. 22, 466-469. doi: 10.1038/nsmb.3031

Rozsypal, J., Moos, M., Simek, P., and Kostal, V. (2018). Thermal analysis of ice and glass transitions in insects that do and do not survive freezing. J. Exp. Biol. 221:jeb170464.

Rudolph, A. S., and Crowe, J. H. (1985). Membrane stabilization during freezing: the role of two natural cryoprotectants, trehalose and proline. Cryobiology 22, 367-377. doi: 10.1016/0011-2240(85)90 184-1

Runti, G., Lopez Ruiz, Mdel, C., Stoilova, T., Hussain, R., Jennions, M., et al. (2013). Functional characterization of SbmA, a bacterial inner membrane transporter required for importing the antimicrobial peptide Bac7(1-35). J. Bacteriol. 195, 5343-5351. doi: 10.1128/jb.00818-13

Ryter, S. W., Cloonan, S. M., and Choi, A. M. (2013). Autophagy: a critical regulator of cellular metabolism and homeostasis. Mol. Cells 36, 7-16. doi: 10.1007/ s10059-013-0140-8

Sabi, R., and Tuller, T. (2015). A comparative genomics study on the effect of individual amino acids on ribosome stalling. BMC Genomics 16(Suppl. 10):S5. doi: 10.1186/1471-2164-16-S10-S5

Sahu, N., Dela Cruz, D., Gao, M., Sandoval, W., Haverty, P. M., Liu, J., et al. (2016). Proline starvation induces unresolved ER stress and hinders mTORC1Dependent tumorigenesis. Cell Metab. 24, 753-761. doi: 10.1016/j.cmet.2016. 08.008

Samuel, D., Kumar, T. K., Ganesh, G., Jayaraman, G., Yang, P. W., Chang, M. M., et al. (2000). Proline inhibits aggregation during protein refolding. Protein Sci. 9, 344-352. doi: 10.1110/ps.9.2.344
Samuel, D., Kumar, T. K., Jayaraman, G., Yang, P. W., and Yu, C. (1997). Proline is a protein solubilizing solute. Biochem. Mol. Biol. Int. 41, 235-242. doi: 10.1080/ 15216549700201241

Sanchez-Partida, L. G., Setchell, B. P., and Maxwell, W. M. (1998). Effect of compatible solutes and diluent composition on the post-thaw motility of ram sperm. Reprod. Fertil. Dev. 10, 347-357. doi: 10.1071/r9 8053

Sandoval, D. R., Clausen, T. M., Nora, C., Cribbs, A. P., Denardo, A., Clark, A. E., et al. (2021). The Prolyl-tRNA synthetase inhibitor halofuginone inhibits SARS-CoV-2 infection. bioRxiv [preprint] doi: 10.1101/2021.03.22.43 6522

Sasahira, T., Kurihara-Shimomura, M., Shimomura, H., Bosserhoff, A. K., and Kirita, T. (2021). Identification of oral squamous cell carcinoma markers MUC2 and SPRR1B downstream of TANGO. J. Cancer Res. Clin. Oncol. 147, 1659-1672. doi: 10.1007/s00432-021-03568-9

Saye, M., Fargnoli, L., Reigada, C., Labadie, G. R., and Pereira, C. A. (2017). Evaluation of proline analogs as trypanocidal agents through the inhibition of a proline transporter. Biochim. Biophys. Acta 1861, 2913-2921. doi: 10.1016/j. bbagen.2017.08.015

Scaraffia, P. Y., and Wells, M. A. (2003). Proline can be utilized as an energy substrate during flight of Aedes aegypti females. J. Insect Physiol. 49, 591-601. doi: 10.1016/s0022-1910(03)00031-3

Schafer, I. A., Scriver, C. R., and Efron, M. L. (1962). Familial hyperprolinemia, cerebral dysfunction and renal anomalies occurring in a family with hereditary nephropathy and deafness. N. Engl. J. Med. 267, 51-60. doi: 10.1056/ nejm 196207122670201

Scheres, B., Van De Wiel, C., Zalensky, A., Horvath, B., Spaink, H., Van Eck, H., et al. (1990). The ENOD12 gene product is involved in the infection process during the pea-Rhizobium interaction. Cell 60, 281-294. doi: 10.1016/00928674(90)90743-x

Schulz, D., Morschel, J., Schuster, S., Eulenburg, V., and Gomeza, J. (2018). Inactivation of the mouse L-Proline transporter PROT alters glutamatergic synapse biochemistry and perturbs behaviors required to respond to environmental changes. Front. Mol. Neurosci. 11:279. doi: 10.3389/fnmol.2018. 00279

Scriver, C. R. (1968). Renal tubular transport of proline, hydroxyproline, and glycine. 3. genetic basis for more than one mode of transport in human kidney. J. Clin. Invest. 47, 823-835. doi: 10.1172/jci105776

Seefeldt, A. C., Graf, M., Perebaskine, N., Nguyen, F., Arenz, S., Mardirossian, M., et al. (2016). Structure of the mammalian antimicrobial peptide Bac7(116) bound within the exit tunnel of a bacterial ribosome. Nucleic Acids Res. 44 2429-2438. doi: 10.1093/nar/gkv1545

Seefeldt, A. C., Nguyen, F., Antunes, S., Perebaskine, N., Graf, M., Arenz, S., et al. (2015). The proline-rich antimicrobial peptide Onc112 inhibits translation by blocking and destabilizing the initiation complex. Nat. Struct. Mol. Biol. 22, 470-475. doi: 10.1038/nsmb.3034

Seow, H. F., Broer, S., Broer, A., Bailey, C. G., Potter, S. J., Cavanaugh, J. A., et al. (2004). Hartnup disorder is caused by mutations in the gene encoding the neutral amino acid transporter SLC6A19. Nat. Genet. 36, 1003-1007. doi: $10.1038 / \mathrm{ng} 1406$

Seri, M., Cusano, R., Forabosco, P., Cinti, R., Caroli, F., Picco, P., et al. (1999). Genetic mapping to $10 \mathrm{q} 23.3-\mathrm{q} 24.2$, in a large Italian pedigree, of a new syndrome showing bilateral cataracts, gastroesophageal reflux, and spastic paraparesis with amyotrophy. Am. J. Hum. Genet. 64, 586-593. doi: 10.1086/ 302241

Servet, C., Ghelis, T., Richard, L., Zilberstein, A., and Savoure, A. (2012). Proline dehydrogenase: a key enzyme in controlling cellular homeostasis. Front. Biosci. (Landmark Ed) 17:607-620. doi: 10.2741/3947

Shafqat, S., Velaz-Faircloth, M., Henzi, V. A., Whitney, K. D., Yang-Feng, T. L., and Seldin, M. F. (1995). Human brain-specific L-proline transporter: molecular cloning, functional expression, and chromosomal localization of the gene in human and mouse genomes. Mol. Pharmacol. 48, 219-229.

Shamova, O., Brogden, K. A., Zhao, C., Nguyen, T., Kokryakov, V. N., and Lehrer, R. I. (1999). Purification and properties of proline-rich antimicrobial peptides from sheep and goat leukocytes. Infect. Immun. 67, 4106-4111. doi: 10.1128/iai. 67.8.4106-4111.1999

Sharif, T., Dai, C., Martell, E., Ghassemi-Rad, M. S., Hanes, M. R., Murphy, P. J., et al. (2019). TAp73 modifies metabolism and positively regulates growth 
of cancer stem-like cells in a redox-sensitive manner. Clin. Cancer Res. 25, 2001-2017. doi: 10.1158/1078-0432.ccr-17-3177

Sharma, S. S., Schat, H., and Vooijs, R. (1998). In vitro alleviation of heavy metalinduced enzyme inhibition by proline. Phytochemistry 49, 1531-1535. doi: 10.1016/s0031-9422(98)00282-9

Sherrier, D. J., Taylor, G. S., Silverstein, K. A., Gonzales, M. B., and Vandenbosch, K. A. (2005). Accumulation of extracellular proteins bearing unique proline-rich motifs in intercellular spaces of the legume nodule parenchyma. Protoplasma 225, 43-55. doi: 10.1007/s00709-0050090-x

Shi, X. Z., Zhao, X. F., and Wang, J. X. (2014). A new type antimicrobial peptide astacidin functions in antibacterial immune response in red swamp crayfish Procambarus clarkii. Dev. Comp. Immunol. 43, 121-128. doi: 10.1016/j.dci.2013. 11.003

Showalter, A. M. (1993). Structure and function of plant cell wall proteins. Plant Cell 5, 9-23. doi: $10.2307 / 3869424$

Signorelli, S. (2016). The fermentation analogy: a point of view for understanding the intriguing role of proline accumulation in stressed plants. Front. Plant Sci. 7:1339. doi: $10.3389 /$ fpls.2016.01339

Silao, F. G. S., Ward, M., Ryman, K., Wallstrom, A., Brindefalk, B., Udekwu, K., et al. (2019). Mitochondrial proline catabolism activates Ras1/cAMP/PKAinduced filamentation in Candida albicans. PLoS Genet. 15:e1007976. doi: 10. 1371/journal.pgen.1007976

Skidmore, D. L., Chitayat, D., Morgan, T., Hinek, A., Fischer, B., Dimopoulou, A., et al. (2011). Further expansion of the phenotypic spectrum associated with mutations in ALDH18A1, encoding Delta(1)-pyrroline-5-carboxylate synthase (P5CS). Am. J. Med. Genet. A 155A, 1848-1856. doi: 10.1002/ajmg.a. 34057

Slavotinek, A. M., Pike, M., Mills, K., and Hurst, J. A. (1996). Cataracts, motor system disorder, short stature, learning difficulties, and skeletal abnormalities: a new syndrome? Am. J. Med. Genet. 62, 42-47. doi: 10.1002/(sici)10968628(19960301)62:1<42::aid-ajmg9>3.0.co;2-y

Smith, K., and Rennie, M. J. (2007). New approaches and recent results concerning human-tissue collagen synthesis. Curr. Opin. Clin. Nutr. Metab. Care 10, 582-590. doi: 10.1097/mco.0b013e328285d858

Smith, T. K., Bringaud, F., Nolan, D. P., and Figueiredo, L. M. (2017). Metabolic reprogramming during the Trypanosoma brucei life cycle. F1000Res 6:F1000FacultyRev-683.

Stadmiller, S. S., Gorensek-Benitez, A. H., Guseman, A. J., and Pielak, G. J. (2017). Osmotic shock induced protein destabilization in living cells and its reversal by glycine betaine. J. Mol. Biol. 429, 1155-1161. doi: 10.1016/j.jmb.2017.03.001

Steinert, P. M., Candi, E., Kartasova, T., and Marekov, L. (1998a). Small prolinerich proteins are cross-bridging proteins in the cornified cell envelopes of stratified squamous epithelia. J. Struct. Biol. 122, 76-85. doi: 10.1006/jsbi.1998. 3957

Steinert, P. M., Kartasova, T., and Marekov, L. N. (1998b). Biochemical evidence that small proline-rich proteins and trichohyalin function in epithelia by modulation of the biomechanical properties of their cornified cell envelopes. J. Biol. Chem. 273, 11758-11769. doi: 10.1074/jbc.273.19.11758

Stensvag, K., Haug, T., Sperstad, S. V., Rekdal, O., Indrevoll, B., and Styrvold, O. B. (2008). Arasin 1, a proline-arginine-rich antimicrobial peptide isolated from the spider crab, Hyas araneus. Dev. Comp. Immunol. 32, 275-285. doi: 10.1016/j.dci.2007.06.002

Stetina, T., Hula, P., Moos, M., Simek, P., Smilauer, P., and Kostal, V. (2018). Recovery from supercooling, freezing, and cryopreservation stress in larvae of the drosophilid fly. Chymomyza costata. Sci. Rep. 8:4414.

Stromberg, N., Esberg, A., Sheng, N., Marell, L., Lofgren-Burstrom, A., Danielsson, K., et al. (2017). Genetic- and lifestyle-dependent dental caries defined by the acidic proline-rich protein genes PRH1 and PRH2. EBioMedicine 26, 38-46. doi: 10.1016/j.ebiom.2017.11.019

Sun, C., Li, T., Song, X., Huang, L., Zang, Q., Xu, J., et al. (2019). Spatially resolved metabolomics to discover tumor-associated metabolic alterations. Proc. Natl. Acad. Sci. U S A. 116, 52-57. doi: 10.1073/pnas.1808950116

Sun, H., Glasmacher, B., and Hofmann, N. (2012). Compatible solutes improve cryopreservation of human endothelial cells. Cryo. Lett. 33, 485-493.

Surguchov, A., Bernal, L., and Surguchev, A. A. (2021). Phytochemicals as regulators of genes involved in synucleinopathies. Biomolecules 11:624. doi: 10.3390/biom11050624
Szabados, L., and Savoure, A. (2010). Proline: a multifunctional amino acid. Trends Plant Sci. 15, 89-97. doi: 10.1016/j.tplants.2009.11.009

Takagi, H. (2008). Proline as a stress protectant in yeast: physiological functions, metabolic regulations, and biotechnological applications. Appl. Microbiol. Biotechnol. 81, 211-223. doi: 10.1007/s00253-008-1698-5

Tan, B. S., Lonic, A., Morris, M. B., Rathjen, P. D., and Rathjen, J. (2011). The amino acid transporter SNAT2 mediates L-proline-induced differentiation of ES cells. Am. J. Physiol. Cell Physiol. 300, C1270-C1279.

Tancredi, F., Guazzi, G., and Auricchio, S. (1970). Renal iminoglycinuria without intestinal malabsorption of glycine and imino acids. J. Pediatr. 76, 386-392. doi: 10.1016/s0022-3476(70)80477-2

Taniguchi, M., Ochiai, A., Kondo, H., Fukuda, S., Ishiyama, Y., Saitoh, E., et al. (2016). Pyrrhocoricin, a proline-rich antimicrobial peptide derived from insect, inhibits the translation process in the cell-free Escherichia coli protein synthesis system. J. Biosci. Bioeng. 121, 591-598. doi: 10.1016/j.jbiosc.2015. 09.002

Tanner, J. J., Fendt, S. M., and Becker, D. F. (2018). The proline cycle as a potential cancer therapy target. Biochemistry 57, 3433-3444. doi: 10.1021/acs.biochem. $8 \mathrm{~b} 00215$

Teulier, L., Weber, J. M., Crevier, J., and Darveau, C. A. (2016). Proline as a fuel for insect flight: enhancing carbohydrate oxidation in hymenopterans. Proc. Biol. Sci. 283:20160333. doi: 10.1098/rspb.2016.0333

Theillet, F. X., Kalmar, L., Tompa, P., Han, K. H., Selenko, P., Dunker, A. K., et al. (2013). The alphabet of intrinsic disorder: I. act like a Pro: on the abundance and roles of proline residues in intrinsically disordered proteins. Intrinsically Disord Proteins 1:e24360. doi: 10.4161/idp.24360

Thiemicke, A., and Neuert, G. (2021). Kinetics of osmotic stress regulate a cell fate switch of cell survival. Sci. Adv. 7:eabe1122. doi: 10.1126/sciadv.abe 1122

Thwaites, D. T., and Anderson, C. M. (2007). Deciphering the mechanisms of intestinal imino (and amino) acid transport: the redemption of SLC36A1. Biochim. Biophys. Acta 1768, 179-197. doi: 10.1016/j.bbamem.2006. 10.001

Thwaites, D. T., and Anderson, C. M. (2011). The SLC36 family of protoncoupled amino acid transporters and their potential role in drug transport. $\mathrm{Br}$. J. Pharmacol. 164, 1802-1816. doi: 10.1111/j.1476-5381.2011.01438.x

Tomlinson, C., Rafii, M., Ball, R. O., and Pencharz, P. B. (2011a). Arginine can be synthesized from enteral proline in healthy adult humans. J. Nutr. 141, 1432-1436. doi: 10.3945/jn.110.137224

Tomlinson, C., Rafii, M., Sgro, M., Ball, R. O., and Pencharz, P. (2011b). Arginine is synthesized from proline, not glutamate, in enterally fed human preterm neonates. Pediatr. Res. 69, 46-50. doi: 10.1203/pdr.0b013e3181fc6ab7

Town, B. W. (1928). The isolation of pure l-proline. Biochem. J. 22, 1083-1086. doi: $10.1042 / \mathrm{bj} 0221083$

Tran, D. H., Kesavan, R., Rion, H., Soflaee, M. H., Solmonson, A., Bezwada, D., et al. (2021). Mitochondrial NADP(+) is essential for proline biosynthesis during cell growth. Nat. Metab. 3, 571-585. doi: 10.1038/s42255-021-00 $374-y$

Treleaven, T., Hardy, M. L. M., Guttman-Jones, M., Morris, M. B., and Day, M. L. (2021). In vitro fertilisation of mouse oocytes in L-Proline and L-Pipecolic acid improves subsequent development. Cells 10:1352. doi: 10.3390/cells10061352

Trovato, M., Maras, B., Linhares, F., and Costantino, P. (2001). The plant oncogene rolD encodes a functional ornithine cyclodeaminase. Proc. Natl. Acad. Sci. U S A. 98, 13449-13453. doi: 10.1073/pnas.231320398

Trovato, M., Mattioli, R., and Costantino, P. (2018). From A. rhizogenes RolD to plant P5CS: exploiting proline to control plant development. Plants (Basel) 7:108. doi: 10.3390/plants7040108

Tugnoli, B., Bernardini, C., Forni, M., Piva, A., Stahl, C. H., and Grilli, E. (2019). Butyric acid induces spontaneous adipocytic differentiation of porcine bone marrow-derived mesenchymal stem cells. Vitro Cell Dev. Biol. Anim. 55, 17-24. doi: 10.1007/s11626-018-0307-x

Ugwu, D. I., Okoro, U. C., and Mishra, N. K. (2018). Synthesis of proline derived benzenesulfonamides: a potent anti-Trypanosoma brucei gambiense agent. Eur. J. Med. Chem. 154, 110-116. doi: 10.1016/j.ejmech.2018.05.017

Valle, D., Goodman, S. I., Applegarth, D. A., Shih, V. E., and Phang, J. M. (1976). Type II hyperprolinemia. Delta1-pyrroline-5-carboxylic acid dehydrogenase deficiency in cultured skin fibroblasts and circulating lymphocytes. J. Clin. Invest. 58, 598-603. doi: $10.1172 /$ jci108506 
Valle, D. L., Phang, J. M., and Goodman, S. I. (1974). Type 2 hyperprolinemia: absence of delta1-pyrroline-5-carboxylic acid dehydrogenase activity. Science 185, 1053-1054. doi: 10.1126/science.185.4156.1053

Velasquez, S. M., Ricardi, M. M., Dorosz, J. G., Fernandez, P. V., Nadra, A. D., Pol-Fachin, L., et al. (2011). O-glycosylated cell wall proteins are essential in root hair growth. Science 332, 1401-1403. doi: 10.1126/science.12 06657

Velaz-Faircloth, M., Guadano-Ferraz, A., Henzi, V. A., Fremeau, R. T., and Jr. (1995). Mammalian brain-specific L-proline transporter. neuronal localization of mRNA and enrichment of transporter protein in synaptic plasma membranes. J. Biol. Chem. 270, 15755-15761. doi: 10.1074/jbc.270.26.15755

Verbruggen, N., and Hermans, C. (2008). Proline accumulation in plants: a review. Amino Acids 35, 753-759. doi: 10.1007/s00726-008-0 061-6

Verrey, F., Singer, D., Ramadan, T., Vuille-Dit-Bille, R. N., Mariotta, L., and Camargo, S. M. (2009). Kidney amino acid transport. Pflugers. Arch. 458, 53-60.

Verslues, P. E., and Sharma, S. (2010). Proline metabolism and its implications for plant-environment interaction. Arabidopsis Book 8:e0140. doi: 10.1199/tab. 0140

Villafraz, O., Biran, M., Pineda, E., Plazolles, N., Cahoreau, E., Ornitz Oliveira, et al. (2021). Procyclic trypanosomes recycle glucose catabolites and TCA cycle intermediates to stimulate growth in the presence of physiological amounts of proline. PLoS Pathog 17:e1009204. doi: 10.1371/journal.ppat.10 09204

Wachter, R., Langhans, M., Aloni, R., Gotz, S., Weilmunster, A., Koops, A., et al. (2003). Vascularization, high-volume solution flow, and localized roles for enzymes of sucrose metabolism during tumorigenesis by Agrobacterium tumefaciens. Plant Physiol. 133, 1024-1037. doi: 10.1104/pp.103.02 8142

Wang, A., and Bolen, D. W. (1996). Effect of proline on lactate dehydrogenase activity: testing the generality and scope of the compatibility paradigm. Biophys. J. 71, 2117-2122. doi: 10.1016/s0006-3495(96)7 9410-9

Washington, J. M., Rathjen, J., Felquer, F., Lonic, A., Bettess, M. D., Hamra, N., et al. (2010). L-Proline induces differentiation of ES cells: a novel role for an amino acid in the regulation of pluripotent cells in culture. Am. J. Physiol. Cell Physiol. 298, C982-C992.

Weinberger, B., Hanna, N., Laskin, J. D., Heck, D. E., Gardner, C. R., Gerecke, D. R., et al. (2005). Mechanisms mediating the biologic activity of synthetic proline, glycine, and hydroxyproline polypeptides in human neutrophils. Mediators Inflamm. 2005, 31-38. doi: 10.1155/mi.2005.31

Werneck, R. I., Mira, M. T., and Trevilatto, P. C. (2010). A critical review: an overview of genetic influence on dental caries. Oral. Dis. 16, 613-623. doi: 10.1111/j.1601-0825.2010.01675.x

White, F. F., Taylor, B. H., Huffman, G. A., Gordon, M. P., and Nester, E. W. (1985). Molecular and genetic analysis of the transferred DNA regions of the root-inducing plasmid of Agrobacterium rhizogenes. J. Bacteriol. 164, 33-44. doi: $10.1128 /$ jb.164.1.33-44.1985

Wiesenthal, A. A., Muller, C., Harder, K., and Hildebrandt, J. P. (2019). Alanine, proline and urea are major organic osmolytes in the snail Theodoxus fluviatilis under hyperosmotic stress. J. Exp. Biol. 222(Pt 3):jeb193557.

Wondrak, G. T., Jacobson, M. K., and Jacobson, E. L. (2005). Identification of quenchers of photoexcited States as novel agents for skin photoprotection. J. Pharmacol. Exp. Ther. 312, 482-491. doi: 10.1124/jpet.104.07 5101

Wu, G., Bazer, F. W., Datta, S., Johnson, G. A., Li, P., Satterfield, M. C., et al. (2008). Proline metabolism in the conceptus: implications for fetal growth and development. Amino Acids 35, 691-702. doi: 10.1007/s00726-008-0 052-7

Wu, G., Bazer, F. W., Hu, J., Johnson, G. A., and Spencer, T. E. (2005). Polyamine synthesis from proline in the developing porcine placenta. Biol. Reprod. 72, 842-850. doi: 10.1095/biolreprod.104.036293

Wu, H., De Graaf, B., Mariani, C., and Cheung, A. Y. (2001). Hydroxyprolinerich glycoproteins in plant reproductive tissues: structure, functions and regulation. Cell Mol. Life. Sci. 58, 1418-1429. doi: 10.1007/pl0000 0785
Wu, J., Subbaiah, K. C. V., Xie, L. H., Jiang, F., Khor, E. S., Mickelsen, D., et al. (2020). Glutamyl-Prolyl-tRNA synthetase regulates proline-rich pro-fibrotic protein synthesis during cardiac fibrosis. Circ. Res. 127, 827-846. doi: 10.1161/ circresaha.119.315999

Wyse, A. T., and Netto, C. A. (2011). Behavioral and neurochemical effects of proline. Metab. Brain Dis. 26, 159-172. doi: 10.1007/s11011-011-9 246-x

Xie, Z., and Klionsky, D. J. (2007). Autophagosome formation: core machinery and adaptations. Nat. Cell Biol. 9, 1102-1109. doi: 10.1038/ncb10071102

Yam, M., Engel, A. L., Wang, Y., Zhu, S., Hauer, A., Zhang, R., et al. (2019). Proline mediates metabolic communication between retinal pigment epithelial cells and the retina. J. Biol. Chem. 294, 10278-10289. doi: 10.1074/jbc.ra119.007983

Yamaguchi, M., Shiraishi, T., and Hirama, M. (1996). Asymmetric michael addition of malonate anions to prochiral acceptors catalyzed by L-proline rubidium salt. J. Org. Chem. 61, 3520-3530. doi: 10.1021/jo960216c

Yang, S. L., Lan, S. S., and Gong, M. (2009). Hydrogen peroxideinduced proline and metabolic pathway of its accumulation in maize seedlings. J. Plant Physiol. 166, 1694-1699. doi: 10.1016/j.jplph.2009. 04.006

Ye, Y., Wu, Y., and Wang, J. (2018). Pyrroline-5-carboxylate reductase 1 promotes cell proliferation via inhibiting apoptosis in human malignant melanoma. Cancer Manag. Res. 10, 6399-6407. doi: 10.2147/cmar.s16 6711

Yen, C. A., and Curran, S. P. (2021). Incomplete proline catabolism drives premature sperm aging. Aging Cell 20:e13308.

Yoon, S. C., Jang, Y. L., Kim, J. W., Cho, E. Y., Park, D. Y., Hong, K. S., et al. (2016). Linkage and association analyses of schizophrenia with genetic variations on chromosome 22q11 in Koreans. Psychiatry Investig. 13, 630-636. doi: 10.4306/ pi.2016.13.6.630

Yoshiba, Y., Kiyosue, T., Nakashima, K., Yamaguchi-Shinozaki, K., and Shinozaki, K. (1997). Regulation of levels of proline as an osmolyte in plants under water stress. Plant Cell Physiol. 38, 1095-1102. doi: 10.1093/oxfordjournals.pcp. a029093

Zaki, M. S., Bhat, G., Sultan, T., Issa, M., Jung, H. J., Dikoglu, E., et al. (2016). PYCR2 mutations cause a lethal syndrome of microcephaly and failure to thrive. Ann. Neurol. 80, 59-70. doi: 10.1002/ana. 24678

Zaprasis, A., Brill, J., Thuring, M., Wunsche, G., Heun, M., Barzantny, H., et al. (2013). Osmoprotection of Bacillus subtilis through import and proteolysis of proline-containing peptides. Appl. Environ. Microbiol. 79, 576-587. doi: 10.1128/aem.01934-12

Zarse, K., Schmeisser, S., Groth, M., Priebe, S., Beuster, G., Kuhlow, D., et al. (2012). Impaired insulin/IGF1 signaling extends life span by promoting mitochondrial L-proline catabolism to induce a transient ROS signal. Cell Metab. 15, 451-465. doi: 10.1016/j.cmet.2012.02.013

Zdunek-Zastocka, E., Grabowska, A., Michniewska, B., and Orzechowski, S. (2021). Proline concentration and its metabolism are regulated in a leaf age dependent manner but not by abscisic acid in pea plants exposed to cadmium stress. Cells 10:946. doi: 10.3390/cells10040946

Zeng, T., Zhu, L., Liao, M., Zhuo, W., Yang, S., Wu, W., et al. (2017). Knockdown of PYCR1 inhibits cell proliferation and colony formation via cell cycle arrest and apoptosis in prostate cancer. Med. Oncol. 34:27.

Zhang, L., Alfano, J. R., and Becker, D. F. (2015). Proline metabolism increases katG expression and oxidative stress resistance in Escherichia coli. J. Bacteriol. 197, 431-440. doi: 10.1128/jb.02282-14

Zhang, L., Xue, X., Yan, J., Yan, L. Y., Jin, X. H., Zhu, X. H., et al. (2016a). Cryobiological characteristics of L-proline in mammalian oocyte cryopreservation. Chin. Med. J. (Engl) 129, 1963-1968. doi: 10.4103/0366-6999. 187846

Zhang, L., Xue, X., Yan, J., Yan, L. Y., Jin, X. H., Zhu, X. H., et al. (2016b). Lproline: a highly effective cryoprotectant for mouse oocyte vitrification. Sci. Rep. 6:26326.

Zhang, P., Wang, J., Luo, W., Yuan, J., Cui, C., Guo, L., et al. (2021a). Kindlin2 acts as a key mediator of lung fibroblast activation and pulmonary fibrosis progression. Am. J. Respir. Cell Mol. Biol. 65, 54-69. doi: 10.1165/rcmb.20200320 oc 
Zhang, X., Gong, X., Li, D., Yue, H., Qin, Y., Liu, Z., et al. (2021b). GenomeWide identification of PRP genes in apple genome and the role of MdPRP6 in response to heat stress. Int. J. Mol. Sci. 22:5942. doi: 10.3390/ijms2211 5942

Zhu, J., Schworer, S., Berisa, M., Kyung, Y. J., Ryu, K. W., Yi, J., et al. (2021). Mitochondrial $\operatorname{NADP}(\mathrm{H})$ generation is essential for proline biosynthesis. Science 372, 968-972. doi: 10.1126/science.abd 5491

Zipp, G. G., Barbosa, J., Green, M. A., Terranova, K. M., Fink, C., Yu, X. C., et al. (2014). Novel inhibitors of the high-affinity L-proline transporter as potential therapeutic agents for the treatment of cognitive disorders. Bioorg. Med. Chem. Lett. 24, 3886-3890. doi: 10.1016/j.bmcl.2014. 06.049

Zouari, M., Ben Ahmed, C., Elloumi, N., Bellassoued, K., Delmail, D., Labrousse, P., et al. (2016). Impact of proline application on cadmium accumulation, mineral nutrition and enzymatic antioxidant defense system of Olea europaea L. cv Chemlali exposed to cadmium stress. Ecotoxicol. Environ. Saf. 128, 195-205. doi: 10.1016/j.ecoenv.2016.02.024

Zwarts, L., Vulsteke, V., Buhl, E., Hodge, J. J. L., and Callaerts, P. (2017). SlgA, encoded by the homolog of the human schizophrenia-associated gene PRODH, acts in clock neurons to regulate Drosophila aggression. Dis. Model. Mech. 10, 705-716.

Conflict of Interest: The authors declare that the research was conducted in the absence of any commercial or financial relationships that could be construed as a potential conflict of interest.

Publisher's Note: All claims expressed in this article are solely those of the authors and do not necessarily represent those of their affiliated organizations, or those of the publisher, the editors and the reviewers. Any product that may be evaluated in this article, or claim that may be made by its manufacturer, is not guaranteed or endorsed by the publisher.

Copyright (C) 2021 Patriarca, Cermola, D'Aniello, Fico, Guardiola, De Cesare and Minchiotti. This is an open-access article distributed under the terms of the Creative Commons Attribution License (CC BY). The use, distribution or reproduction in other forums is permitted, provided the original author(s) and the copyright owner(s) are credited and that the original publication in this journal is cited, in accordance with accepted academic practice. No use, distribution or reproduction is permitted which does not comply with these terms. 